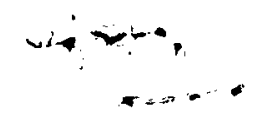

\title{
HIGH PRESSURE PHOTOPHYSICS \\ OF ORGANIC MOLECULES
}

\section{MASTER

BY

\section{LARRY ALDEN BREY}

B.S., University of Kansas, 1972

M.S., University of Illinois, 1976

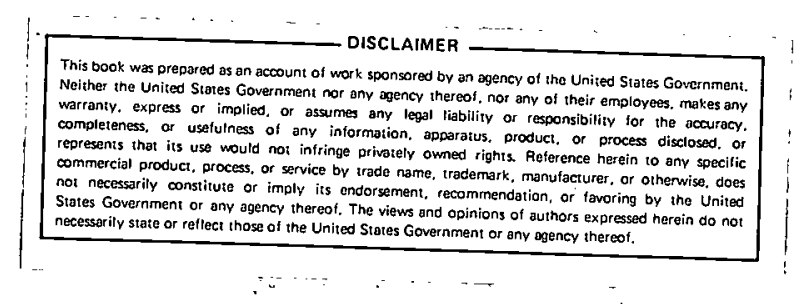

THES IS

Submitted in partial fulfillment of the requirements

for the degree of Doctor of Philosophy in Chemistry

in the Graduate College of the

Universfty of Illinois at Urbana-Champaign, 1979

Urbana, Illinois

DISTRLEUTION O. 


\section{DISCLAIMER}

This report was prepared as an account of work sponsored by an agency of the United States Government. Neither the United States Government nor any agency Thereof, nor any of their employees, makes any warranty, express or implied, or assumes any legal liability or responsibility for the accuracy, completeness, or usefulness of any information, apparatus, product, or process disclosed, or represents that its use would not infringe privately owned rights. Reference herein to any specific commercial product, process, or service by trade name, trademark, manufacturer, or otherwise does not necessarily constitute or imply its endorsement, recommendation, or favoring by the United States Government or any agency thereof. The views and opinions of authors expressed herein do not necessarily state or reflect those of the United States Government or any agency thereof. 


\section{DISCLAIMER}

Portions of this document may be illegible in electronic image products. Images are produced from the best available original document. 


\section{THIS PAGE}

WAS INTENTIONALLY

LEFT BLANK 


\section{ACKNOWLEDGMENTS}

It has been the author's privilege over the past four years to work rish Professor H. G. Drickamer. His advice and contagious enthusiasm for nseatific research have been invaluable assistance in the present work. 2tscussions with Professor G. B. Schuster have also been essential to this Livestigation.

Appreciation is also expressed to Bob Fults and Ron Harrison for salr highly skilied work in the construction and maintenance of the high gressure equipment. Their assistance has greatly facilitated this work. The advice of the author's fellow graduate students has been of rreat value. The equipment and techniques developed by Dr. W. D. Drotning, X. C. E. Tyner, Dr. D. I. Klick, Dr. J. Hook, and Dr. D. J. Mitchell have Len particularly useful. Friendships with Yorgos Chryssomallis, Martin Ilaston, Lon Rollinson, and Grant Webster have been extremely rewarding. Deaks are due to Professors $G$. Weber and $K$. Kaufmann for the use of cestain equipment and to their students Pete Torgerson and Kevin Smith for Holstance in 1ts use.

The author is deeply grateful to his parents Mr. and Mrs. Alden R. lem. to his brother and sister, and to his grandmother Mrs. R. W. May for their love and support.

Finally, the work described here has been supported by the U.S. Impartment of Energy under Contract EY-76-C-02-1198. 
TMODUCTION.

OLIL BACKGROUND AND THEORY

8. Bistorical Review and Background.................... 3

1.1 High Pressure Research....................... 3

1.2 Optical Spectroscopy......................... 4

2. Luminescence of Organic Molecules................... 5

2.1 Photophysical Processes and Parameters............. 5

2.2 The Fluorescence Rate Parameter.................. 6

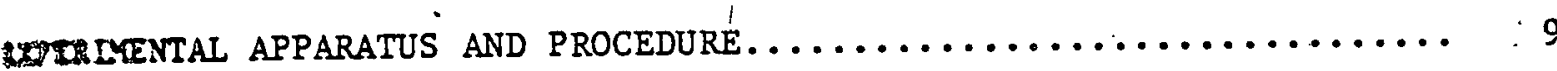

1. H1gh Pressure Apparatus........................... 9

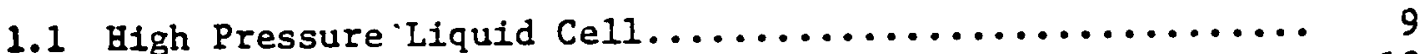

1.2 High Pressure Solid Stace Cell................... 12

2. Optical Emission Apparatus....................... 13

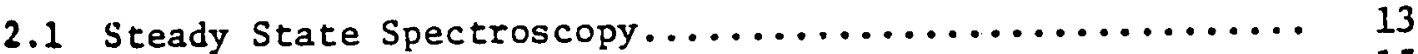

2.2 Lifetime Measurements....................... 15

WCOSITY EFFECT ON FLUORESCENCE EFFICIENCY

\# cetstal VIOLET AND AURAMINE $0 \ldots \ldots \ldots \ldots \ldots \ldots \ldots \ldots \ldots \ldots \ldots \ldots \ldots$

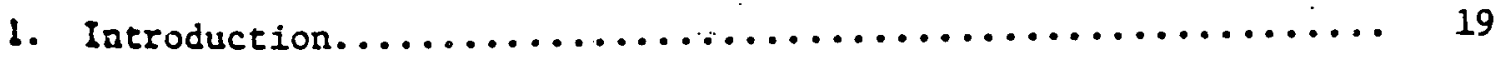

2. Experimental Procedure......................... 21

3. Results and Discussion......................... 23

WHSSTY EEFECT ON THE QUENCHING OF

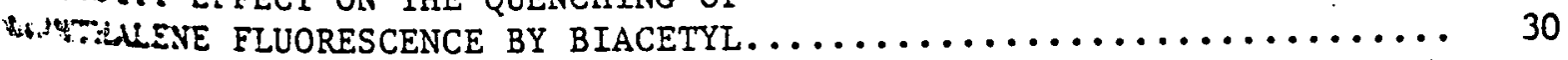

1. Introduction.............................. 30

¿. Experimental Procedure........................ 30

1. Resultes and Discussion........................ 32 
$\because: S C O S I T I$ EFFECT ON FLUORESCENCE AND

AN:OOISOAERIZATION OF TRANS-STILBENE

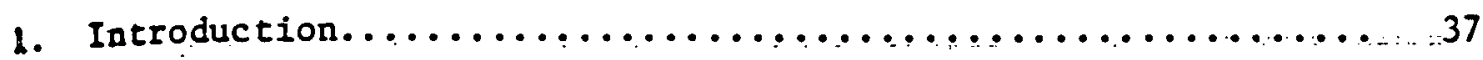

2. Experimental Procedure....................... 41

2.1 Materials............................. 41

2.2 Atmospheric Fluorescence Yields................ 43

2.3 High Pressure Fluorescence Yields.................. 44

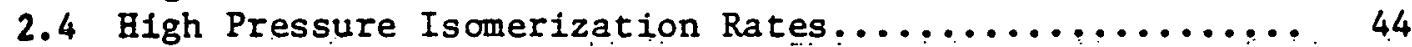

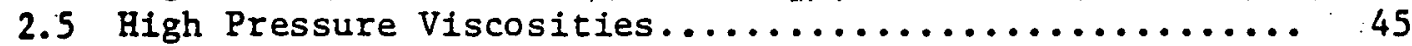

2.6 Fluorescence Lifetimes...................... 45

3. Results and Discussion....................... 46

3.1 Fluorescence Quantum Yields and Lifetimes........... 46

3.2 Initial Isomerization Rates................... 54

4. Conclusions.............................. 56

MoTOPHYSICS OF POLYENES AT HIGH PRESSURE................ 58

1. Introduction............................ 58

2. Experimental Procedure...................... 61

2.1 Matertals............................. 61

2.2 Atmospheric Quantum Yields.................... 62

2.3 H1gh Pressure Emission Experiments................ 63

2.4 High Pressure Excitation Experiments............... 64

2.5 Fluorescence Lifetime Measurements............... 64

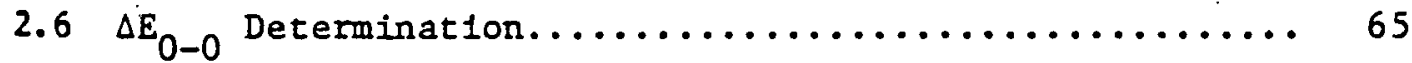

2.7 Refractive Indices........................ 66

2. Results and Discussion........................ 66

4. Conclusion $\ldots \ldots \ldots \ldots \ldots \ldots \ldots \ldots \ldots \ldots \ldots \ldots \ldots \ldots \ldots \ldots \ldots \ldots$

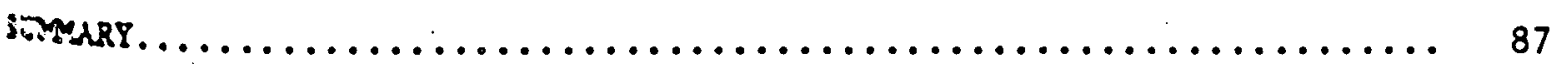

ist OF REFERENCES $\ldots \ldots \ldots \ldots \ldots \ldots \ldots \ldots \ldots \ldots \ldots \ldots \ldots \ldots \ldots \ldots \ldots$

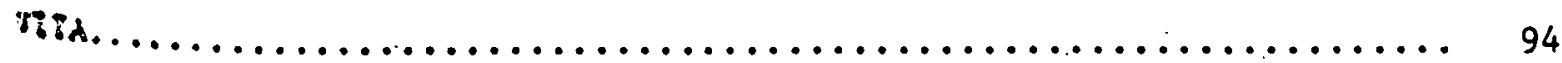




\section{INTRODUCTION}

A simple photophysical process begins with the absorption of a juscum of light to form an electronically excited state. The zelease of occurs on a time scale ranging from thousands of years (a. phenomenon anted has been used in archeological dating) to shorter than several 1) econds $\left(10^{-12}\right.$ seconds). Three primary mechanisms result in the release If energy for organic compounds: the emission of light, chemical reaction, aon-radiative transitions. Because these processes occur competitively, Mals efficiencies are interrelated.

The scientific value in understanding photophysical processes is mormous. The optical properties of luminescent materials such as dyes and grosphors are intimately associated with the function of devices such as f:corescent lamps, light-emitting diodes and lasers. Photochemical teactions represent another area of proved and growing importance for which aplications of current interest are abundant. Photochemical synthesis biso provides a means of producing compounds which are not readily manuSctured by conventional thermal routes.

Most of the work described here deals with the effect of solvent mocost on the non-radiative deactivation rates from electronically milzed states. Pressure was ut1lized to attain high viscosities in s.gnic solvents at room temperature. Studies of viscosity dependent irscosses in fluid media are usually carried out by varying the composition the temperature of the solvent. The problem then arises of saparating 2.h olscosity dependence from purely temperature and/or solvent effects. the we of pressure allows a significant range of viscosities to be 
s:tatned in a single solvent at a single temperature. If a wider range of rescostities is desired, chemically similar solvents for which the attainable riscosities overlap can be utilized. In this way, a very large viscosity rage can be investigated at one temperature with only a $f \in w$ solvents.

The following section gives a brief account of the background and seoretical basis of high pressure research and organic photophysics in peneral. Next, the high pressure emission apparatus and sample preparation are described. Experimental techniques for recording and analyzing both sceady state and emission lifetime experiments are included in the tlscussion. The following three sections deal with the effect of solvent itocosity on the photophysics of seyeral organic solutes. In the last section, the effect of pressure on the radiative and non-radiative deactivation rates for several linear polyenes is investigated. 
GENERAL BACKGROUND AIND THEORY

¿. Alstorical Review and Background

1.1 High Pressure Research High pressure has become an important isol for the investigation of interatomic interactions and the electronic -: ruccure of condensed media $[1,2]$. Pressure can signifiçantì alter mean Leterstomic distances in solids and liquids and thereby affect the numerous inalcal and physical properties which are dependent on these distances. The unit of pressure used here is the kilobar (kbar), which is Anflaed as $10^{9}$ dynes $/ \mathrm{cm}^{2}$, or about 986.9 atmospheres. Bridgman [3] first ercended the range of accesstble pressures to about $100 \mathrm{kbar}$ in 1941 by *afar a two stage piston-cylinder apparatus [4]. This employed the "ascade" principle by enclosing a small piston and cylinder assembly reh in progressively larger cylinders so that each member in the series of rested vessels is subject only to the difference in stress between the tateraal and external cells. Practical design considerations limit the Lulce to two stages.

Bridgman has also been credited with the principle of massive - topport. This principle states that a material can be locally stressed ias beyond the yield point if the surrounding support material is below its - Leld point.

Drickamer et al. [5,6] have constructed supported taper cells which Fily the principle of cascading and massive support. The cells permit Dilical study of small sample volumes at pressures up to $150 \mathrm{kbar}$. Recent HIf cations have extended the temperature range from $77^{\circ} \mathrm{K}$ to $450^{\circ} \mathrm{K}$ ishout restricting the pressure range [7]. The development of 
1:sand-anvil type cells has enabied investigators to extend the pressure se for optical work to 1.7 megabar [3].

liaterials under high pressure have been probed by electrical Pestonce, X-ray diffraction, Mossbauer resonance and ultra-violet (IVV), * blbie and infrared (IR) spectroscopy: Much of this work and its apllcations has been presented in the monograph by Drickamer and Frank [2]. dittional reriews of high pressure techniques are also available [9-12].

1.2 Optical Spectroscopy In modern absorption spectroscopy, the sorbance of a material is generally recorded as a function of wavelength. We phenomenon which results in this absorption is the transition betweer ground state, which is almost always a singlet state, and an inetrontcally excited state. When electron spins are paired, the state wald to be a singlet state. If a set of unpaired electrons exists, the - lecule is said to be in a triplet state because there are three possible 3la ortentations; however, these orientations are indistinguishabie in the stance of strong electric or magnetic fields. Transitions between singlet Ats iriplet states are said to be "forbidden" because electromagnetic tadion tation only weakiy coupled to the spin vector.

The wost readily observed absorption transitions are those between sround state and exct.ted singlet states. Because of the forbidden fariure of the transition involved, singlet-triplet absorption can only be served for very pure samples, and in spectral regions which are not masked 3 ine more intense singlet-singlet absorptions. Euission spectroscopy *hen ylelds information about the nature of states which are not apparent has sorption spectra. In particular, the radiative transition from an Histed triplet state to the ground state (phosphorescence), and the trans: iva from an excited.singlet state to the ground state (fluorescence) often In:Ur wich comparable intensities. Kasha [13] generalized that irrespective 
1t we scate 1nitially excited, the emission usially occurs only fron the :mestered state of a given multiplicity.

Several methods have been employed to investigate relaxation. aschcs frow excited states. The most commonly used technique is the arvation of emfssiun intensities and lifetimes. This yields information swt both radiative and non-radiative transition rates from emitting osazes. Non-emitting states can also affect the photopinysics and have sore Luvestgated in a variety of ways. For example, the recert developinent asers with short duration (<10 psec), high intensity puises has enabled abervation of transient absorption associated with repopulation of the pound state. Energy transfer and chenical querching studies are other sphalques which have found application in the investigation of decay Howataus. Birks has edited comprehensive reviews on the subject of theophysics [14] and reviews of photochemisiry appear annually [15].

\section{¿.. Hescence of Organic Molecules}

\subsection{Photophysical Processes and Parameters Rad1ative transitions} xis between states of different energy. In complex molecules there are iso rediationless transitions which occur between different electronic - sisen of the same energy induced by intramolecular vibrations and prurtasions by surrounding solvent molecules. A spin-allowed radiationless itation between two states of the same multiplicity is called internal armarsion (IC). A spin-forbidden radiationless transition between two a:e:ou of different multiplicity is called intersystem crossing (ISC). A the fntial excitetion or after a raciationless transition, the tocule is usually in a vibrationally excited level of a particular Higatronle state. In a condensed phase, the excess vibrational energy 
1. qulckly dissipated ( $10^{-12}$ to $\left.10^{-13} \mathrm{sec}\right)$ and all photophysical processes stit: from an equilibrated system of molecules.

Flgure 1 shows scheinaticaliy the photophysical processes that cail arru in an organic molecule in dilute solution following excitation into lowest excited singlet state $S_{1} \cdot s_{1}$ can decay: (a) by $s_{1} \rightarrow s_{0}$ \&wescence with rate $k_{f}$; (b) by ISC to a vibrationally excited level of $T_{I}$ SAllosed by vibrational relaxation to $\mathrm{T}_{1}$ with race $\mathrm{k}_{\mathrm{ISC}}$; or (c) by IC to a - bistionally excited level of $S_{0}$ followed by vibrational relaxation to $s_{0}$ What sace $k_{I C} \cdot T_{1}$, from (b), decays: (d) by $T_{1} \rightarrow S_{0}$ phosphorescence viti 17s: $p_{p}$; or (e) by ISC to a vibrationally excited level of $s_{0}$ followed by Wtyrastonal relaxatjon to $S_{0}$. Fluorescence, phosphorescence, ISC, and IC ar the rate-determining processes, since vibrational relaxation is so weh fasier.

The $S_{1}$ decay rate is given by

$$
k_{\text {tot }}=k_{f}+k_{I S C}+k_{I C} \equiv 1 / \tau_{f}
$$

ste if is the observed $S_{1}$ lifetime. The fluorescence efficiency from $S_{1}$ 5.3 fuer by

$$
\phi_{f}=k_{f} /\left(k_{f}+k_{I S C}+k_{I C}\right) \equiv k_{f} \tau_{f} \equiv \tau_{E} / \tau_{0}
$$

Whe $\tau_{0}\left(m i / k_{E}\right)$ is the so-called natural radiative lifetime.

2.2 The Fluorescence Rate Parameter A thecretical expression for a. Liag been derived from the Einstein radiation relation using the zerc-order Do oppentieimer approximation $[16,17]$

$$
k_{f}^{\text {theor }}=2.88 \times 10^{-9} \frac{n_{E}^{3}}{n_{A}}<\bar{v}_{F}^{-3}>_{A V}^{-1} \rho \frac{\varepsilon(\bar{v}) d \bar{v}}{\bar{v}}
$$


E

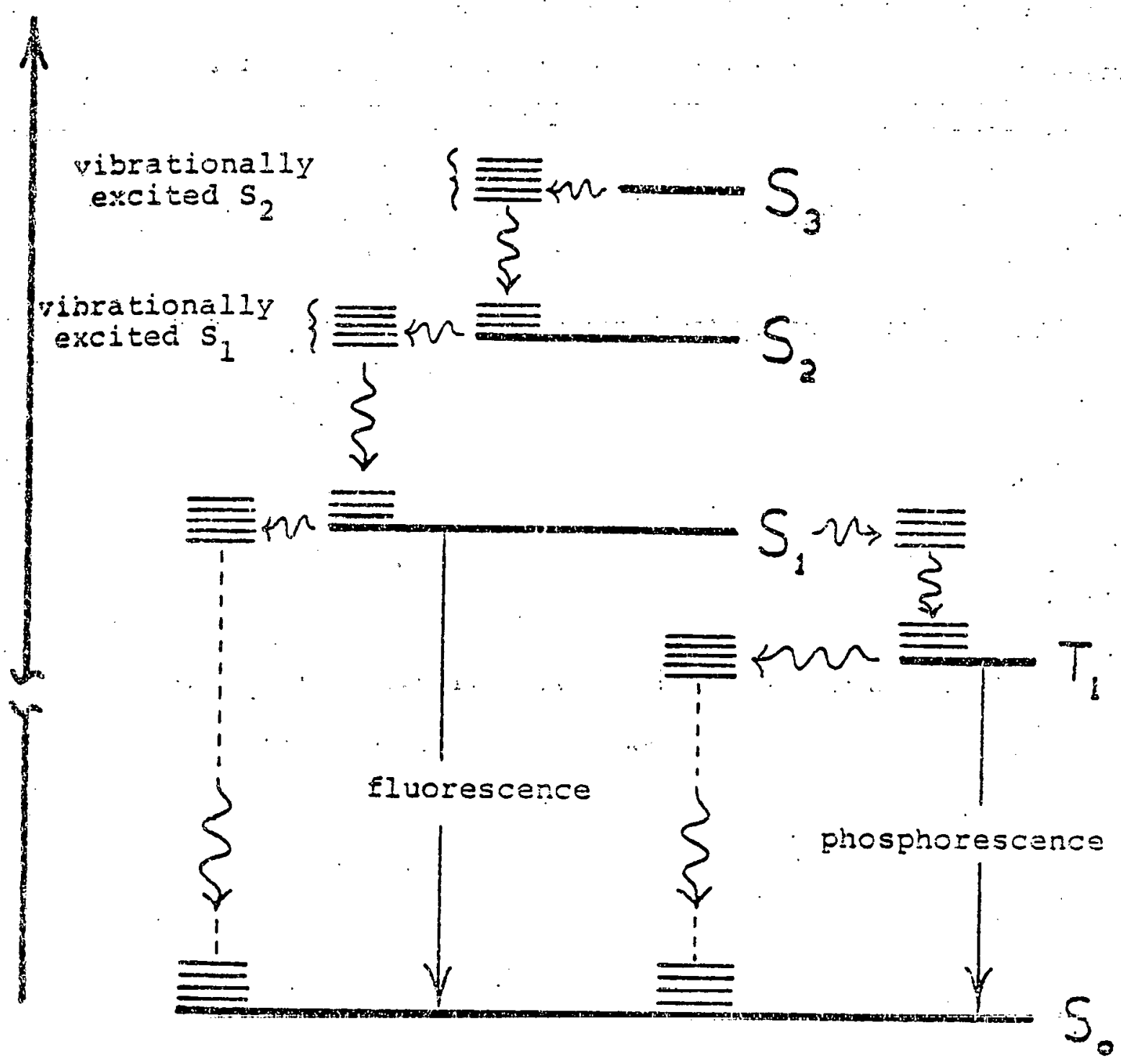

Flgure 1. Decay of Electronically Excited States (From reference 14) 
we $p_{F}$ and $n_{A}$ are the mean refractive indices of the solvent ovex the $t_{0} s_{0}$ fluorescence and $S_{0} \rightarrow S_{1}$ absorption spectra, respectively, $\therefore>\Delta V$ is the reciprocal of the average value of $\bar{v}^{-3}$ over the fluorescence perrum, $\varepsilon(\bar{v})$ is the decadic molar extinction coefficient, and the integral waka over the $\mathrm{S}_{0}+\mathrm{S}_{1}$ absorption spectrum. This expression has been monsively tested for a number of molecules and excellent agreement wesxeen the theoretical and experimental $k_{f}$ values has teen cbtained. If $a_{\Lambda}-n$, expression (3) can be simplified to

$$
-\quad k_{f}^{\text {theor }}=n^{2}\left(k_{E}^{\text {theor }}\right)_{0}
$$

( $\left.k_{f}^{\text {theor }}\right)_{0}$ is a moiecular constant, independent of solvent ard temperatoss. This relaition has been verified for sevaral solutes in different solvents over a wide temperature range [18].

For sume molecules such as biptienyl and the nigher diphenylpolyenes, stere are large discrepancies between the theoretical and observed $k_{f}$ bises. Detailed studies of these cases have revealed the presence of "todden" eiectronic states $[19,20]$. 


\section{EXPERIMENTAL APPARATUS AND PROCEDURE.}

\section{Igi Pressure Apparatus}

\subsection{Aigh Pressure Liquid Cell The high pressure liquid emission} all wed in this work is a modification of the ceil described ty won [21]. It is constructed of Vascomax steel and is equipped with wophlite windows. The cell is sketched in Figure 2. An inner cell made araless steel with fixed sapphire windows contains the sample. A -winless steel piston sealed with a teflon o-ring transmits the pressure toug the pressurizing fluid (spectral grade hexanes) to the sample. 'A in around the side wino holds the inner cell in place in the pressure: whil. The hexane is pressurized using an intensifier and is transmitted fa the cell via a high pressure line. The intensifier uses hydraulic gros to apply pressure against a $3 \mathrm{l} / 3$ inch piston. This piston pusties. ededast a one inch piston which is forced against the hexane. For experi* thes la whici accurate pressure data is needed at low pressures (less than Arue 2.5 kbar) a 50,000 psi gauge is used to monitor the hexane pressure 8:860.1y. For work at higher pressures, the applied hydraulic pressure is asd f:om a Heise Bourdon gauge and the hexane pressure obtained from a isiatsasion curve of hexane pressure versus applied pressure. The calibration mbre to checked regularly witi a manganin gauge. Details of the intensifier 1. onure seals and design are given by Okamoto [21]. The cell is operated 2.

The sample is deoxygenated by purgin: it with argon for about five whata la a nitrogen filled glove bag. The inner cell is loaded in the this sag sy setting the o-ring in position and filling the cell with 

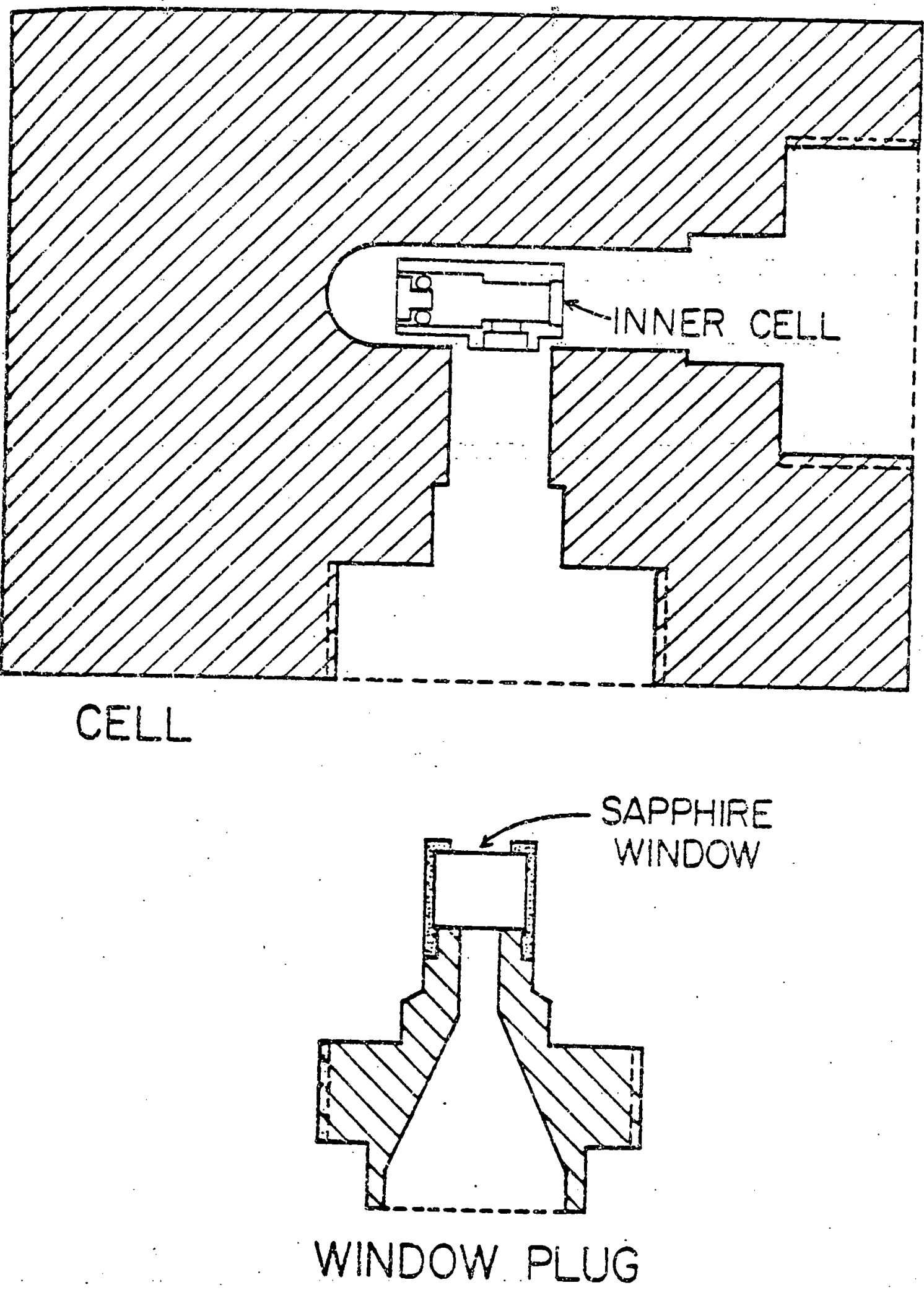

Figure 2a. High Pressure Liquid Cell. Seal. rings and inner celi positioning collar are not shown. Drawn approximately to scale. 

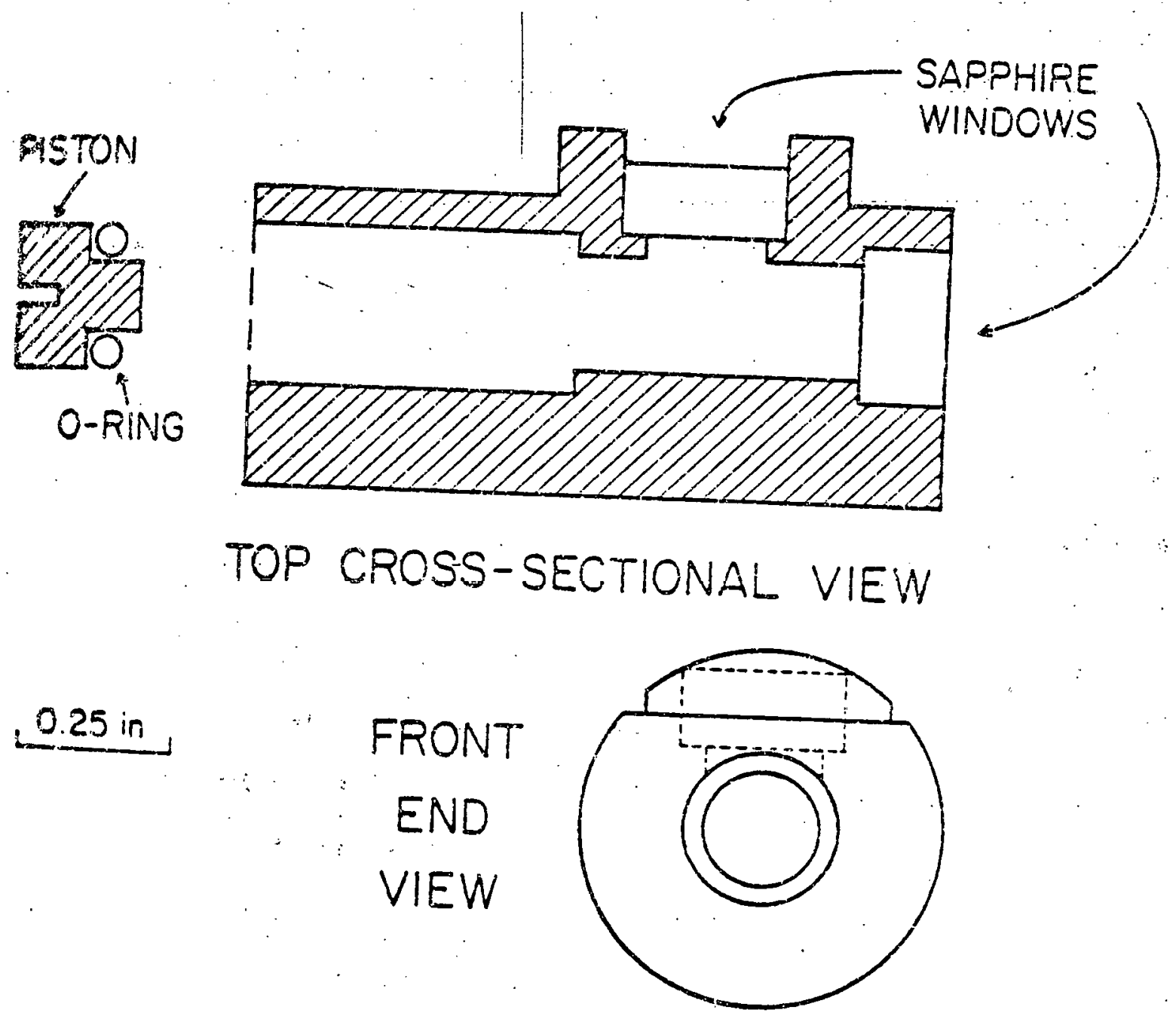

Figure 2b. Detail of Inner Cell 
6.6ple solution. The piston is then placed against the o-ring and is garsted in until the piston and o-ring snap together. The inner celi is fids temed from the glove bag, placed in the pressure cell, and the tonging collat is put into place. The side window plug and its.seal are assubled and the plug is torqued to 1200 1nch-pounds to set the seal. pressure cell is then filled with hexane. Air bubbles are removed by gateln hexane into the recesses of the cell using a Pasteur pipet with a The front window is then sealed.

1.2 High Pressure Solid State Cell The solid state high pressure phat in this work is a modification of the cell developed by Fitch, inghouse, and Drickaner [6]. For enission measurenents, the optical oriofors are located 90 degrees apart. They are filled with opiical grade ad:m chloride which is transparant to radiation in the region of interest Mate. The sodium chloride also serves as the pressure transmitting inediun. 7. cell.has a one-eighth inch diameter piston and yields an internal 98 sure up to $40 \mathrm{kbar}$. Fressure is applied to the cell by means of a tongalic press with a $41 / 2$ inch diameter ram. The external applied grofisure Is measured with a Heise Bourdon gauge.

The calibration of internal pressure versus external applied 9assure has been determined by means of the $R_{1}$ ruby fluorescence shift [22]. itia shift is $-0.75 \mathrm{~cm}^{-1} / \mathrm{kb}$ ar to $1.95 \mathrm{kbar}$ as determined by the National Wigav of Standards [23]. The calibration is given by eq (5)

$$
P_{\text {int }}(\mathrm{kbar})=0.08 \mathrm{~F}_{\text {ext }}(\mathrm{psi})
$$

\footnotetext{
"srther detalls concerning the nigh pressure cell and its calibration are iten by Drotning [22].
} 
The samples used in this work were dissolved in plastic films. For of the filns were cut into $1 / 8$ inch squares. A $1 / 8$ inch diameter \$\% $\% / 8$ snch high cylinder of sodiun chloride is carved and then cleaved usto no ialf-cylinders. The sample filo is sandwicined between the two n:-cyllnders. This composite cylinder is then inserted into the cell so wisc the front face of the film is at a 45 degree angle to the windows. the asembly is press-fused with the top piston by applying about 5 kbar of possure. A retaining ring is: then placed between the fused assembly and twatson. The pressure is cycled between a high pressure and 5 kbar; the aressure begins at $30 \mathrm{kbar}$ and is progressively lowered 5 to $10 \mathrm{kbar}$ this cycling procedure is particularly necessary for accurate 14anity measurements.

: Optcal Emission Apparatus

2.1 Steady Scate Spectroscopy The apparatus used for steady state 2.5sion measurements is shown in Figure 3. The light source for optical whation is housed in a Schoeffel LH150 lamp housing and powered by a Whaffel LPS27I Jamp Power SuppIy. All work described here was done va: alther a Hanovia 150-watt or an Illumination Industries 75-watt whtog arc lamp. Light leaving the housing is focussed into the first of

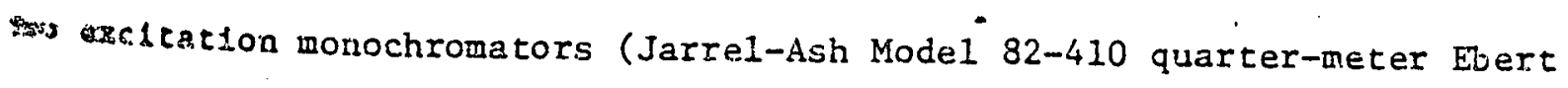
If: in canden). These monochromators contain two gratings, one blazed with a reciprocal inear dispersion (RLD) of $1.65 \mathrm{~nm} / \mathrm{mm}$ and a ung blazed at $600 \mathrm{~mm}$ with an RLD of $3.3 \mathrm{~nm} / \mathrm{mm}$. The monochromatic Iight $\rightarrow$ thin these monochromators is focussed through the high pressure entrance ostabs ovto the sample. 


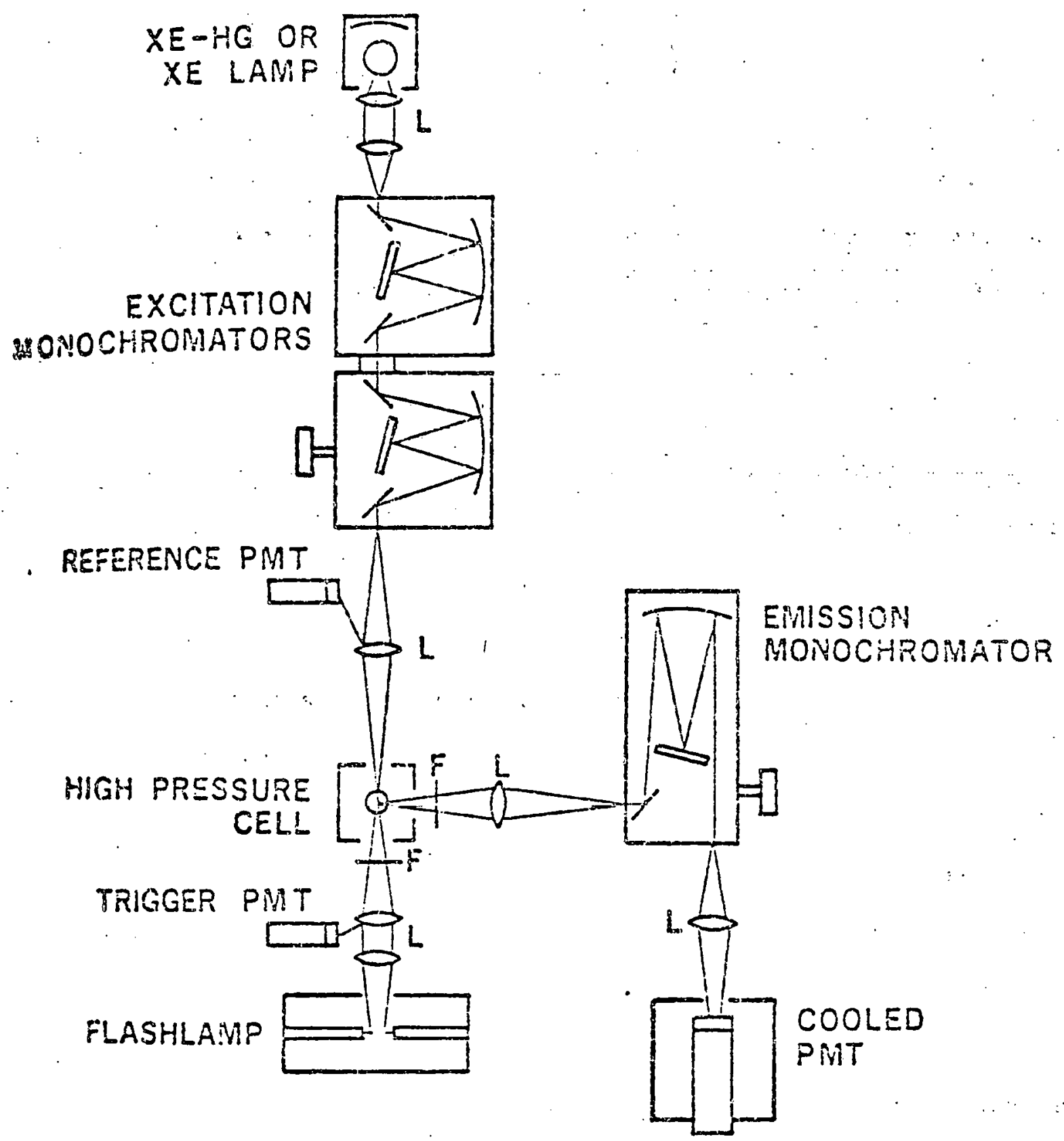

Figure 3. Emission Apparatus 
The enfted iight is observeo at a rigit angle to the incident wathe pathrough the exit window. It is first filtered, if necessary, - 200 of a number of Corning or Schott glass filters to remove reflected algig ight, which might lead to excessive scattered light or second-order warterences within the enission monochromator. After filtering, the light a ecussed onto the entrance. slit of a Bausch and Lomb half-meter A grating blazed at $500 \mathrm{~nm}$ with an $R L D$ of $3.3 \mathrm{~mm} / \mathrm{mm}$ was atroughout this work. The dispersed light exi.ts the emission wercomator through a variable slit with a typical bandpass of 5 to 10 nin is focussed on the face of a cooled EMI $9558 \mathrm{Q}$ photomultiplier tube (2) athoton counting syster, with the photons per unit time displayed sigtuliy. Data are taken in a point--by-point fashion by the photon Imatar as a function of wavelength. The data are then computer analyzed W frogran SKEW [24]. This program corrects for spectral response of tection apparatus $[22,25]$ and plots the corrected data as relative asas or quanta per unit time per unit energy interval versus energy. The idest squares fitting routine in SKEN is then used to fit one or more -4. Gausstans $[26,27]$ to the experimental data. Output from the program fasio.buss (for each peak) the absolute area of the peak, the peak location, Do pok halfwidth, and the peak skewness. Calculations are performed on a 2 C-20 computer. Additional detailed information on the apparatus is 14 Drotaing [22].

\subsection{Iifetime Measurements The apparatus used for luminescence} $\therefore 4$ ar measurements is shown in Figure 4. Several light sources are Amisisie for pulsed excitation of the sample, but the short lifetimes of 


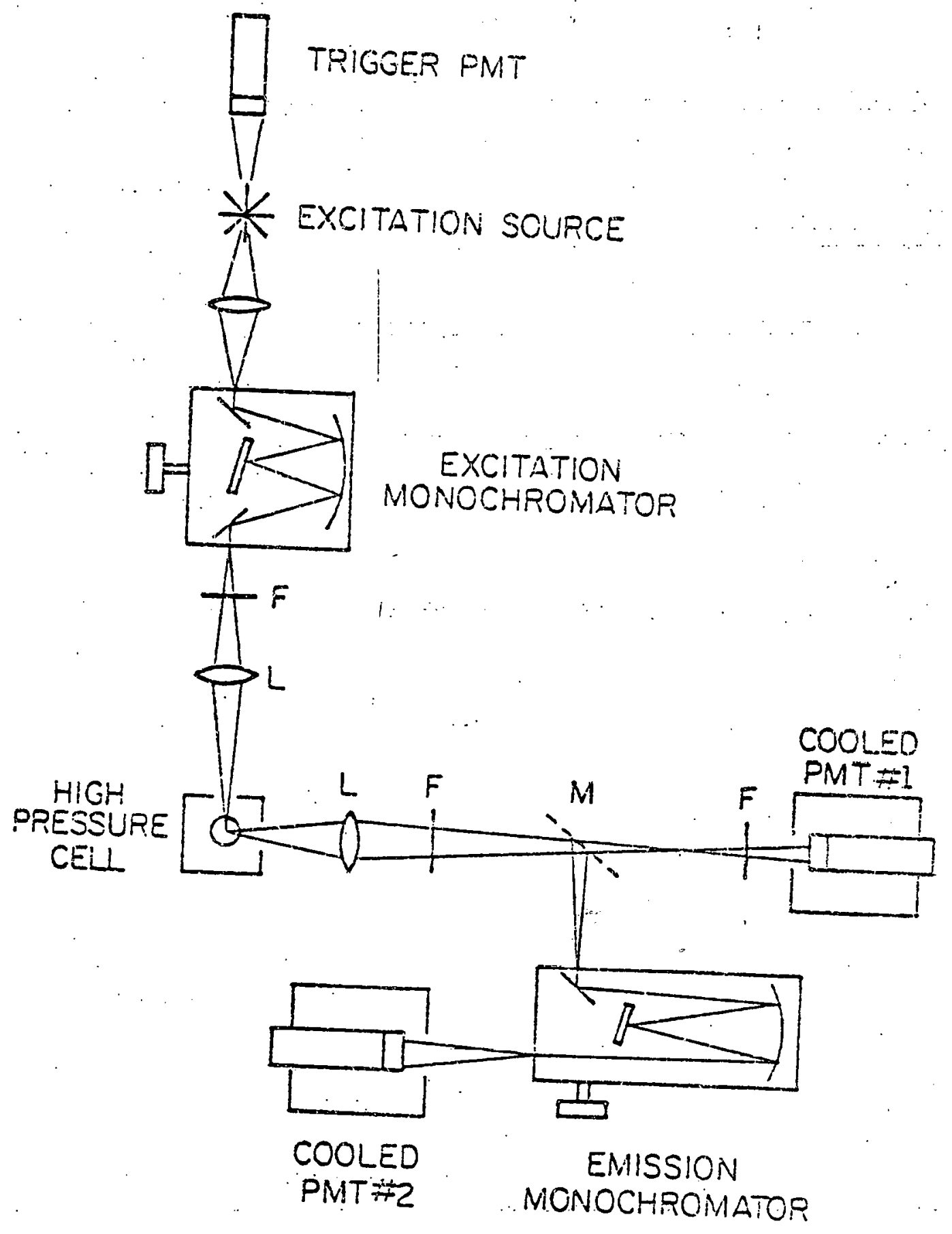

Figure 4. Transient Emission Apparatus 
nolecules studied made it necessary to use a Fhotochemical Research waclates modal 51.0 nanosecond source which car be flashed up to $20 \mathrm{kHz}$ * blash widths as short as 2 nsec. The excitation wavelength is wected ${ }^{2} y$ either a Schoeffel GM 250 quarter-neter grating monochromatcr If Schott UV bandpess reflectance filters; efther or both of which may be Triggering is provided by a 1 P 28 photomultiplier tube located in the giestamp housing.

Emisston from the high pressure cell car" be directed at two furction systems. Filters can be placed in the light path in order to wiser broad band observation at photomultiplier 11 which is directly in tow with the enission window of the high pressure cell. Alternatively, a astor way be positioned to dirent the emission into a Spex model 1870 Wedeter grating monochromator and subsequenty to photomuliplier \#2. photonltaplier tubes $9558 \mathrm{Q}$ and $9813 \mathrm{Q}$ are used; the latter tube is wevered for single photon counting due to the short rise-tine and high gain.

For the fast decays encountered in this work, it is necessary to use - isgle photon counting technique to obtain fluorescence lifetimes. theonerated output pulses from both the trigger and signal photomienpliers are amplified and converted to uniform pulses by ortec model 9302 Pissisalnarors and then fed into the "start" and "stop" inputs on an Ortec astel 467 time-to-pulse-height converter (TFHC). The resultant TPHC output Hhise. Whose height is proportional to the time between the flash and the boseged photon arrival at the signal. PM, is received by the multichannel stangser (MCA) operating in the pulse height analysis mode. One count is whe foded to the channeI number corresponding to the TPHC pulse height. itgh leveis are kept so low that only one photon is detected every "iv llashes (to mininize the probability that two or more photons will 
antrive during the measurement time), a decay curve characteristic of the seapie can be generated with 5000 to 10000 courts. The final accunulated curve is transferced to a model 33 teletype which purches the data anto paper tape. A program for iterative deconvolution supplied by PRA wased to extract lifetimes from the observed decays. 

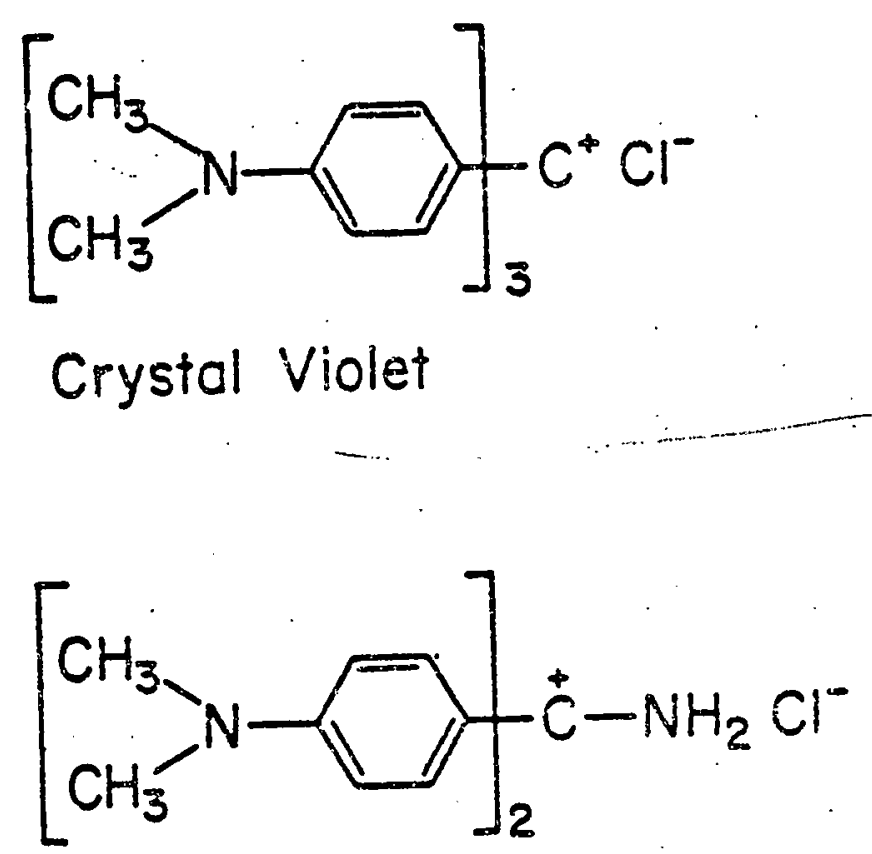

$$
\begin{aligned}
& \text { Auramine-0 dyes } \\
& \text { amines }
\end{aligned}
$$

Figure 5. Structure of Crystal Violet and Auramine 0 
VISCOSITY EFFECT ON FLUORESCENCE EFPICIENCY

IN CRYSTAI VIOLET AND AURAMINE $O$

$\therefore$ iorroduction

Many ann-rigid aromatic molecules in which the aromatic groups are atatid by bonds of partial multipie order or polyene chains exhibit a andied eahancement of fluorescence efficiency in fluid solution as the ascosity of the solvent is jncreased. This effect has been observed in at-and tri-phenylnethane dyes, the polymethine cyanine dyes, substituted amophenones, and sterically hindered stilbenes and retraphenylbutadienes. dependence of the fluorescence efficiency of the diphenylmethane dye Nasine $O$ (AO) and the triphenylmethane dye crystal violet (CV) on solvent: racosity at room temperature has been investigated using pressure to vary Hofscusity. Figure 5 shows the structure of the molecules. Mastrangleo offen [29] have recently published a similax study of these dyes, but are a much smailer range of viscosities.

Studies of viscosity dependent processes in fluid media are usually sisied out by varying the composition or the temperature of the sclvent. the problex then arises of separating the viscosity dependence from purely iperature andior solvent effects. The use of pressure allows a significant 8.5 of viscosities to be actained in a single solvent at a single :mperature. If a wider range of viscosities is desired. chemically pastar solvents for which the attainable viscosities overiap can be thisied. In this way a very large viscosity range can be investigated - one temperature with only a feit solvents. 
$\therefore$ Experimental Frocedure

In this paper pressures to 11 kbar on methanol, iso-propanol, gorbutanol, and glycerol are used to obtain solvent viscosities firom less a $10^{-2}$ polse to more than $10^{+3}$ poise at room temperature. The methano Lso-butanol (MC/B), the iso-propanol (Aldrich), and the glycerol (Wlllackrodt) were all spectral grade and showed no interfering fluorescerca an tre spectral region of interest. Care was taken to avoid absorption of arospheric water by these hygroscopic solvents. The pressure dependence of the viscosities of the solvents is given by Bridgman [30] at 30 and $75^{\circ} \mathrm{C}$. Mis data is used to correct the viscosities to ambient cemperature. The arreatly accepted value for the viscosity of glycerol at $30^{\circ} \mathrm{C}(6.29$ poise) used rather than that given by Bridguan ( 3.8 poise). The more recent work oy 20lotykh [31] on tine pressure-viscosity relation of carefully dried flycerol to $7 \mathrm{kbar}$ shows exceilent agreement with Bridgran's data.

The crystal violet (MC/B) was purified by the method of Lewis et al. 1321. The auramine O (Aldrich) was recrystallized twice froln ethanol. A11 solutions of crystal violet vere $4 \times 10^{-6} \mathrm{M}$. The auramine 0 solutions were $480^{-6}$ or $4 \times 10^{-6} \mathrm{M}$. The high pressure liquid cell and emission equipment. are. described elsewhere $[33,34]$. Cv solutions were excited into the ascrption band with maximum at about $590 \mathrm{~nm}$. For AO, the second absorption siod with maximum at about 370 nm was used: The excitation wavelengths ade adusted at each pressure to give maximum fiuorescence intensity. Be shift of the excitation maximum was never more than 8 nin over the is har viscosity range. The fluorescence intensities were obtained by Aabegration of the corrected erission spectra. All intensities wera prrected for the change in concentration due to solvent compressibility ung Bridgman's data [35]. Table I gives the position of the emission 
Table I. Peak Shifts and Half Width Charges with Fressure

\begin{tabular}{|c|c|c|c|c|c|c|}
\hline \multirow[b]{2}{*}{ ianseal Violet } & \multirow[t]{2}{*}{$0.5^{\mathrm{a}}$} & \multicolumn{2}{|c|}{$\begin{array}{c}\Delta v^{b} \\
\text { Pressure (kbar) }\end{array}$} & \multicolumn{3}{|c|}{$\begin{array}{l}\text { FWHMC } \\
\text { Pressure (kbar) }\end{array}$} \\
\hline & & $\underline{5.0}$ & 10.0 & 0.5 & $\underline{5.0}$ & 10.0 \\
\hline Qsariol & 15.94 & -0.230 & -0.410 & 2.5 & 2.6 & 2.6 \\
\hline 3s-propanot & 16.07 & -0.170 & -0.265 & 2.6 & 2.4 & 2.2 \\
\hline "ssobutano? & 16.07 & -0.230 & -0.315 & 2.6 & 2.3 & 2.3 \\
\hline ajesrol. & 15.74 & -0.100 & -0.100 & 2.9 & 2.3 & 2.1 \\
\hline grantine 0 & & & & & & \\
\hline shanol & 20.1 .4 & -0.350 & -0.615 & 3.6 & 3.1 & 3.3 \\
\hline isopropanol & $20: 31$ & -0.285 & -0.415 & 3.1 & 3.3 & 3.3 \\
\hline isobutanol & 20.27 & -0.360 & -0.450 & 3.2 & 3.3 & 3.2 \\
\hline incerol & 19.51 & -0.185 & -0.090 & 3.7 & 3.45 & 3.40 \\
\hline
\end{tabular}

. energy $\left(10^{3} \mathrm{~cm}^{-1}\right)$ at $P=0.5 \mathrm{kbar}$

so peak shift $\left(10^{3} \mathrm{~cm}^{-1}\right)$ from $0.5 \mathrm{kbar}$

"Tili widin at half maximum $\left(10^{3} \mathrm{~cm}^{-1}\right)$ 
pars at 0.5 kbar 1n each solvent for both dyes, the shift in peak position *og pressure and the change in peak width rith pressure. The shifts agree a: wh those indicated by offen et al. [29].

Sosults and Discussion

Förster and Hofiman (FH) [28] have investigated the fluorescence al iselency of several triphenylmethane dyes including $C V$ in a variety of misoats at different temperatures. They found that the only relevant asyos property was the viscosity and that for each dye there was a range 3. " "Wo" viscosities for which the quantum efficiency $\phi$ was given by * $\mathrm{Cr}^{2 / 3}$ where $\mathrm{C}$ is a constant for a particular dye. For CV, C $=2.75 \times 10^{-3}$ -2/3 and the equation holds for $n<200$ poise. At higher viscosities aproaches a limiting value $(0.35)$. Fi propose a model to explain the atemed dependence of $\phi$ on $n$ in which the dye moiecule is excited to $a$ Fack-Condon vertical state with the phenyl rings still at the ground - ara: equilibrium angle $\partial_{0}$. The rings then rotate towards a new equilibrium : $\theta_{0}^{j}$ at a rate controlled by scokes-like viscous damping. $\left(\theta-\theta_{0}^{\prime}\right)$ Wefore decreases exponentially with time with a relaxation time prosus:looal to $n$. The nonradiative viscosity dependent deactivation rate of the excited singlet is taken to be proportional to $\left(\theta-\theta_{0}\right)^{2}$. (For stilbenes, Thare:y and Muszkat [36] attribute this deactivation to the effect of $n$ on wiselng and out-of-plane bending motions of tha double bond in the These vibrations are thought to have a strong effect on the Nas-Condon factor and hence on the rate of the IC transition $s_{1}-s_{0}$.)

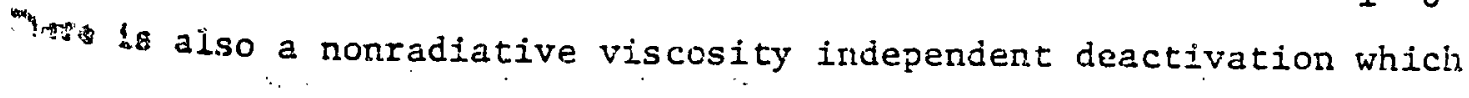
argunts for the limiting value of $\phi$ in highly viscous media. The 4. Bustre enission rate is independent of $\theta$ so $\phi$ is proportional to the as: lood grate iffetime. 
In solvents of very low viscosity, the model predicts a viscosity crupendent. minimum value for $\dot{\phi}$. FT calculate an approximate minimum $\phi$ for dyes of about $2 \times 10^{-6}$. This limiting case vas not observed. In more ofosw s Ivents in which the excited singlet is deactivated nonradiatively gaste ring rotation proceeds very far, there are two limiting cases. The at: lateresting is where deactivation by $\theta$ dependent nonradiative processes ghendates (intermediate $n$ ). This gives $\phi=\mathrm{Cn}^{2 / 3}$. The other liniting to where radiative deactivation is dominant (high $n$ ). Here $\phi=\tau_{0} / \tau_{s}$ -4tis is is the characteristic time for deactivation of the excited singlet *adative and $\theta$ independent nonradiative processes and $\tau_{s}$ is the ratural

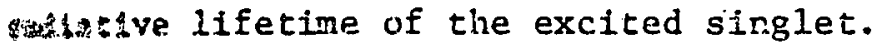

The data for $C V$ and $A O$ are shown in log-log form in Figures 0 and 7 Th data in Figure 7 has been displaced along the arbitrary intensity nos show that for log $\eta>-0.5$ the two dyes exhibit identical. 5onfence of fluorescence efficiency on solvent viscosity. Thie dashed then In Elgure 7 indicates the deviation of the 40 intensities at low $n$. ine of slope 0.7 drawn in Figure 7 shows excellent agreement with the 7ta: over 3.5 orders of magnitude in viscosity. At very low $n$ there is - 11 but definite deviation from linearity and at high $n$ the intensities 7ofe: to level off. The AO data is also linear with a slope of 0.7 over a Rana! bar range of 2.5 orders of magnitude in viscostty: It.exhibits thascal ilmiting behavior at high $n$, but much larger deviaticns from ildmaricy at low $n$. It should be noted that the deviation at low viscosicy to cosards a larger viscosity dependence of the fluorescence intensity. In cheory predicts a leveling, i.e., a lower viscosity dependence at ars ixcosities. We do not at present have an explanation for this laktepancy. Oster and Nishijima [37] have measured $\phi$ for AO in glycerol 


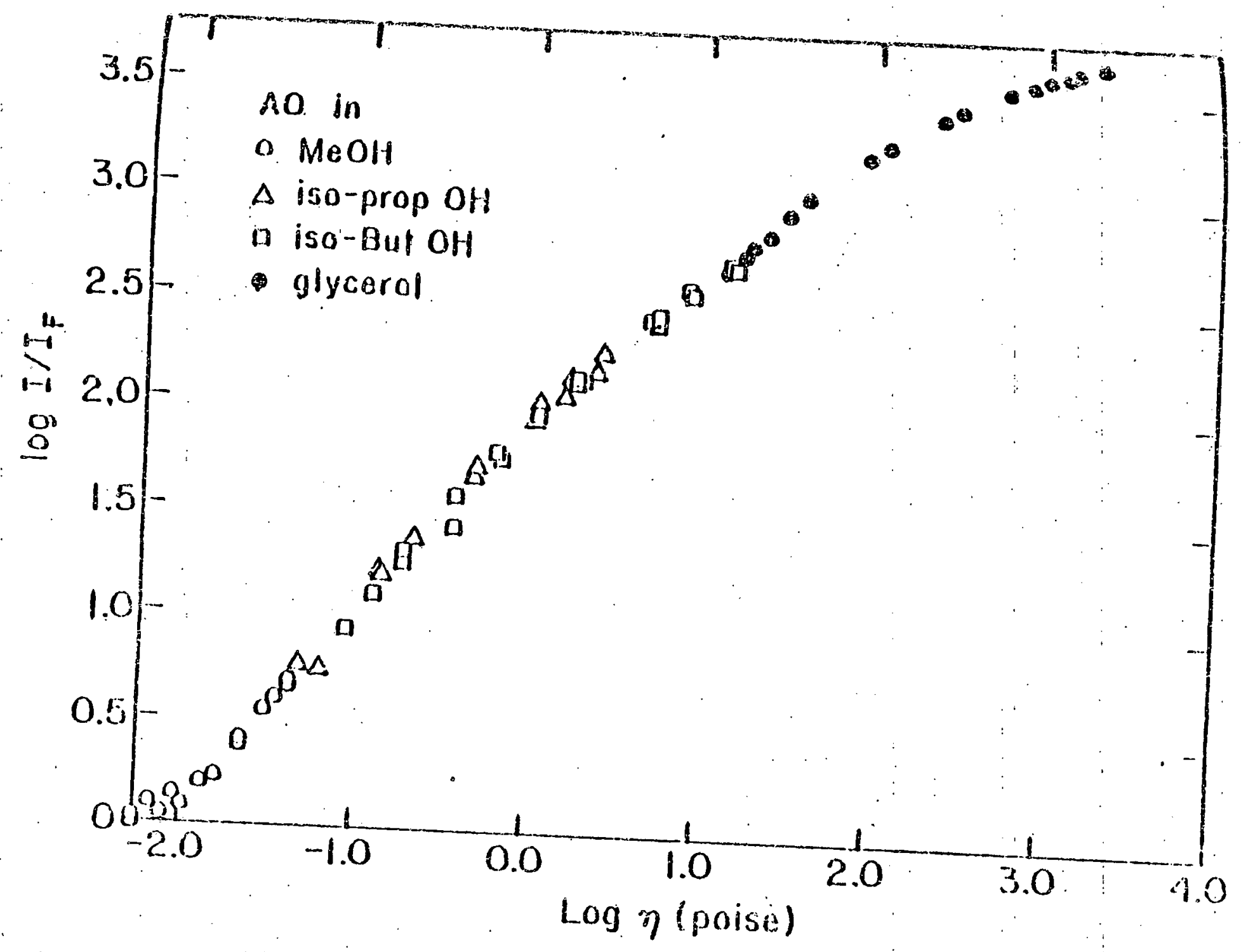

Figure 6. Log Intensty vo. Log Viscosity-Airanine 0 


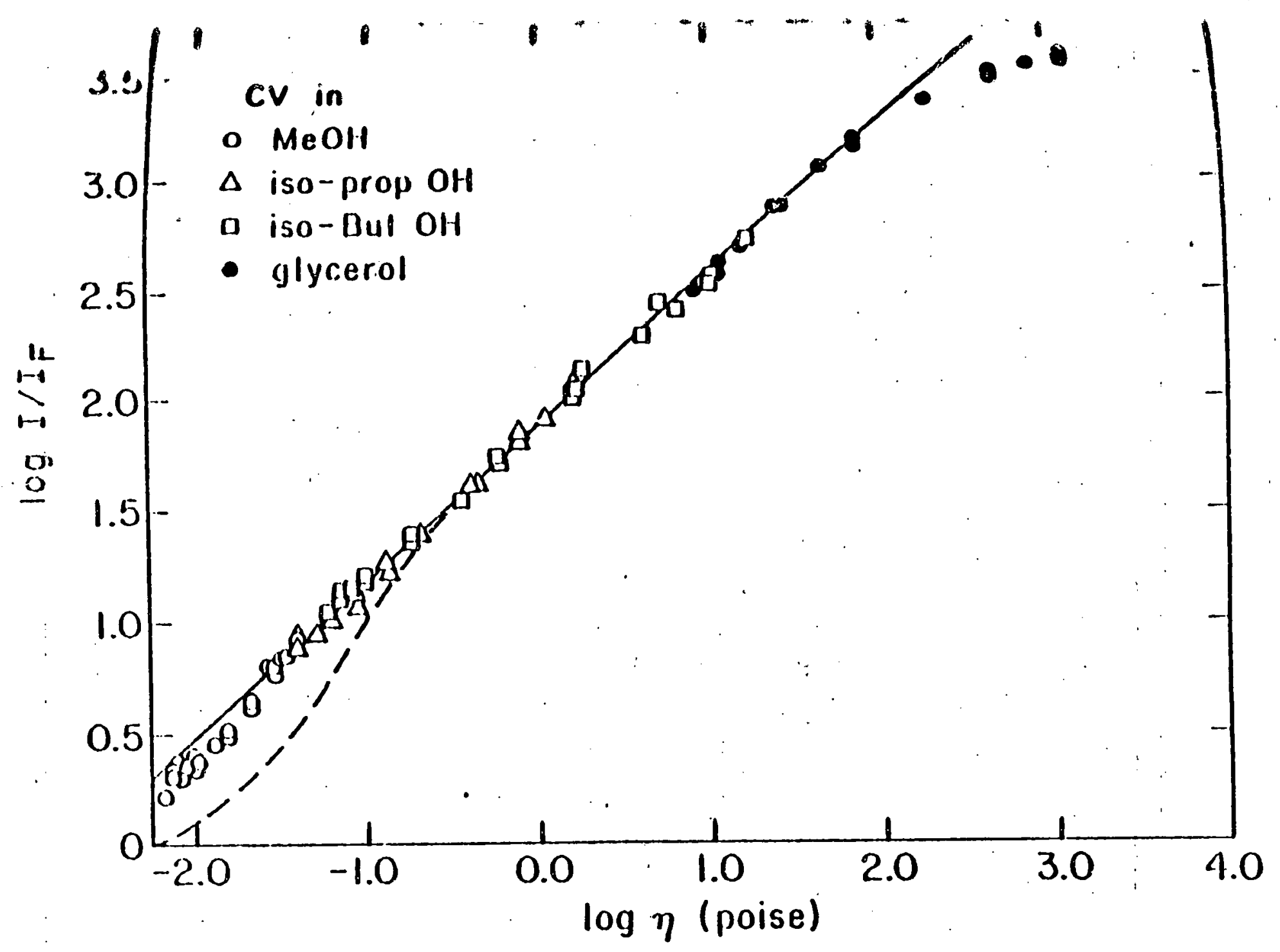

Figure 7. Log Intensity vs. Log Viscosity-Crystal Violet 
- fuction of temperature from about 5 to $35^{\circ} \mathrm{C}$. Their experimentally aloed viscosities varied from about 2 to 25 poise in this temperature Analysis of their data also shows that $\phi$ is proportional to $\eta^{2 / 3}$. model is thus shown to adequately describe the dependence of $\phi$ on $\eta$.. and CV over a large viscosity range with deviations occurring only - incosities.

Fluorescence quantum efficiencies in glycerol at $25^{\circ} \mathrm{C}(n=9.5$ poise $)$ asured relative to quinine sulfate in $1 \mathrm{~N} \mathrm{H}_{2} \mathrm{SO}_{4}(\phi=0.55)$ [38] for $\mathrm{AO}$ olatve to rhodamine B in ethanol $(\phi=0.66)$ [25] for CV as described Hereace [39]. Values obtained were 0.030 for AO and 0.019 for $\mathrm{CV}$. compare to a value for $\mathrm{CV}$ of 0.012 calculated usingtthe FE data and $s$ talue for AO of 0.022 from ref. 37 .

The theory of Förster and Hoffman does not bear directly on the mansen of the energy loss other than giving the quadratic interaction wased above. Clearly, because of the viscosity dependence it is an inemolecular process. The results do not contain any detailed information 20 sechanism but one can gain some insight from peak shifts and widuldeh changes in terms of a single configuration coordinate diagram. Theordinate in question would presumably involve the interaction of the weh nelghboring soivent molecules. The peak shift and half-width can - follows $[33,34]$ :

$$
\begin{aligned}
& \Delta h v_{e}=\frac{P q_{0}}{R}+\frac{(R-1) P^{2}}{2 w} \\
& 2 w \\
&\left(\delta E_{1 / 2}\right)_{e}=N\left|\frac{W q_{0}}{R / / 2}+P \frac{(R-1)}{w R^{3 / 2}}\right| .
\end{aligned}
$$


Bere $q_{0}$ is the displacement of the excited state potential well misive to the ground state well along the coordinate of interest at $P=0$. $\therefore$ : the force constant of the ground state, and $R=\left(w^{\prime} / w^{2}\right.$ is the ratio if exiled state to ground state force constants. $R$ and $w^{2}$ may be pressure ingendent but it is difficult to extract information on this point. Let - coosider the crystal violet data. In methanol one ouserves an essentialiy ase: red shift and a half-width independent of pressure. This would imply - agative $q_{0}$ and $R \cong 1$. As the solvents become more viscous, there is an insessing tendency for the rate of shift to decrease with increasing powure and for the half-width to decrease also as $p$ increases. Both wese observations are consistent with $q_{0}$ being negative and with an $R$ which 6. locreasingly greater than ine, i.e., the excited state potential well torees increasingly stiffer with increasing solvent viscosity. The same t: rnds are noted for auramine 0 . Since $R$ and $w^{2}$ are very probably pressure pordent, a detailed discussion is difficult.

In Figure 8 the effect of stiffening the wells is shown, everything - being constant. One must keep in mind that, because there is a shift te te emission peak to lower energy with increasing pressure and, in some sale a narrowing of the peak, the excited state potential well at high sessgure (and high viscosity) will, in fact, be displaced both vertically. Horizontally from its position at low pressure (low viscosity). In Vise 8 we do not show these displacements because we are trying to andze the effect of increasing $R$ on the barrier height for internal Mrersion. As one can see, an increase in $R$ could profoundly effect both 3. Probability of internal conversion and the reversibility of the process ralsing the energy of the intersection of the ground and excited state at: ates. 


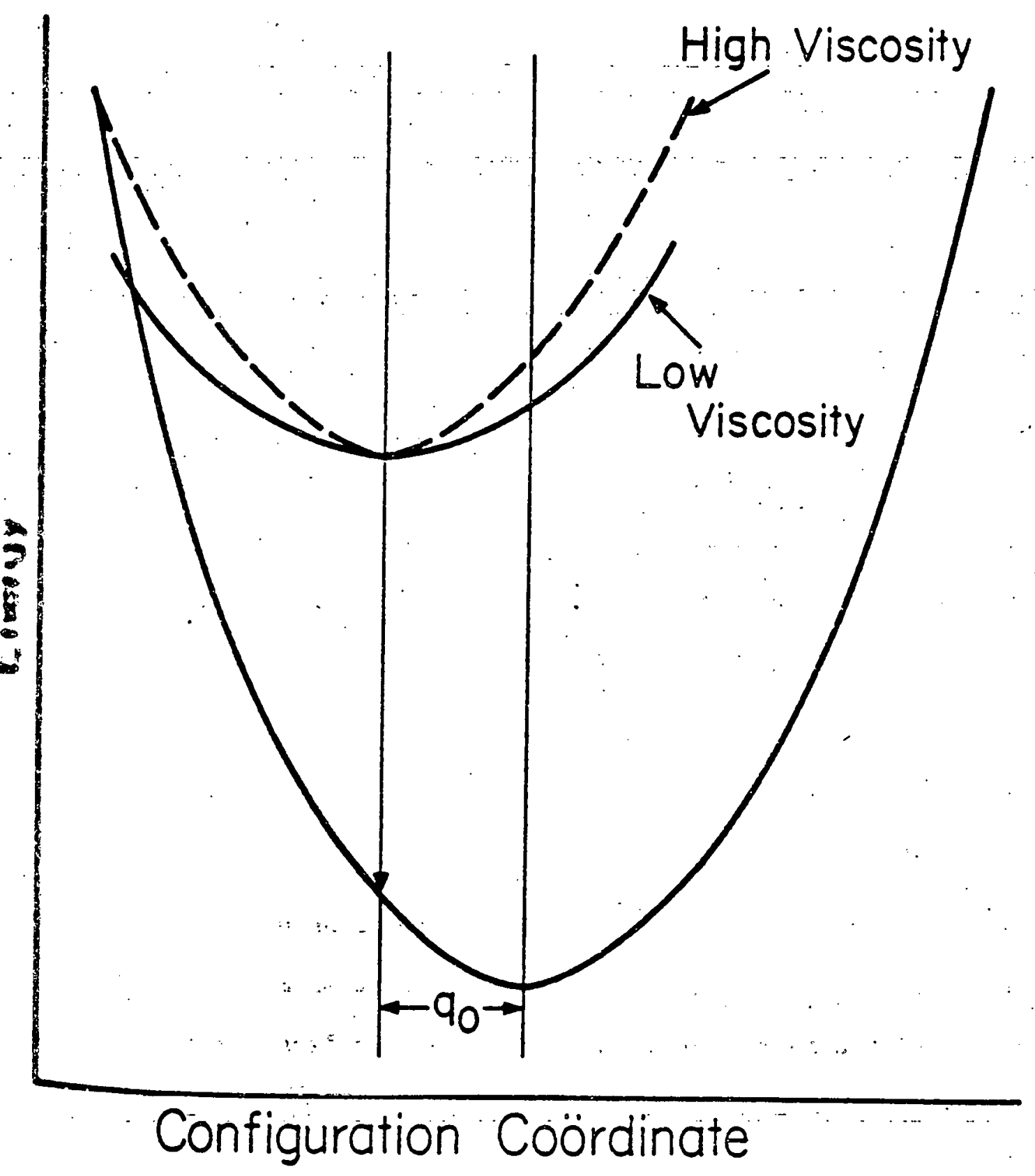

F1gure 8. Schematic Configuration Coordinate Diagram 
VISCOSITY EFFECT ON THE QUENCHING OF NAPHTHALENE FLUORESCENCE BY BIACETYL

\section{Introustion}

The quenching of naphthalene fluorescence by biacetyl in fluid solution has been shown to occur by energy transfer-from naphthalene to blacety $1 .[40,41]$. The low extinction coefficient of biacetyl rules out the posslb1lity of any appreclable long range singlet-singlet energy transfer $[41,42]$ at least up to the viscosities used in this work. The critical radius $R_{0}$ for dipole-dipole resonance transfer from naphthalene to biacetyl in methylcyclohexane $(-7 \AA)$ is about equal to the collisional Intermolecular separation $(5.8 \stackrel{\circ}{\mathrm{A}})$ calculated from the van der Waals volumes of the molecules $[43,44]$. This suggests that the quenching can be treated as a diffusion controlled process with unit quenching probability per encounter.

\section{Experimental Procedure}

In this work pressures to $10 \mathrm{kbar}$ on methylcyclohexane (MC/B Spectroquality) are used to obtain solvent viscosities from less than $10^{-2}$ to about $10 \mathrm{P}$ at room temperature. Other pressure studies of diffusion controlled energy transfer have been made, but over much smaller viscosity ranges $[45,46]$. The pressure dependence of the viscosity of methylcyclonexane to $8 \mathrm{kbar}$ is given by Bridgman at 30 and $75^{\circ} \mathrm{C},[47]$. This data was extrapolated to $10 \mathrm{kbar}$ and used to correct the viscosities to amb-ient -temperature.. Naphthalene (Aldrich,-zone-refined-99:9+ 7 ) was used as received: Biacetyl (Aldrich) was fractionally distilled under a nitrogen atmosphere and the middle fraction was retained and stored in 
the dark. The naphthalene concentrations used in the pressure experiments were $1 \times 10^{-3}$ or $2 \times 10^{-3} \mathrm{M}$. The biacetyl concentrations were $1.14 \times 10^{-2}$ or $2.28 \times 10^{-2} \mathrm{M}$. Solutions were excited at $300 \mathrm{~m}$. At the concentrations used both self-quenching of naphthalene and distortion of 1 ts fluorescence spectrum by biacetyl absorption are negligible. Soluticn degassing was accomplished by several repetitions of a vacuum freeze-thaw cycle. The high pressure liquid cell and emission equipment are described elsewhere $\{33,34]$.

The relative naphthalene fluorescence yields $I_{p}$ at each pressure were determined from the peak fluorescence intensity at $\lambda \cong 335 \mathrm{~m}$. The emission spectrum is virtually unchanged.with respect to position and shape over the $10 \mathrm{kbar}$ pressure range. All intensities and concentrations entering into the calculations are corrected for solvent compressibility using Bridgman's data [48].

In order to obtain $k_{p}$ the experimental quenching rate parameter at pressure $P$ from the pressure quenching experiments the Stern-Volmer equation is used in the form

$$
\frac{I_{P O}}{I_{P}}=\frac{1+k_{p} \tau_{p}[Q]}{1+k_{P_{0}} \tau_{P_{0}}[Q]{ }_{P_{0}}}
$$

Here the subscripts $P_{0}$ and $p$ indicate that the subscripted variables are evaluated at $I$ atm and pressure $p$, respectively. $\tau$. is the donor fluorescence lifetime in the absence of quencher. $\tau_{P_{0}}$ is taken as 109 nsec [49]. $\tau_{p}$ is calculated from the data of offen and Phillifs [50], which indicates an approximately $15 \%$ decrease in the fluorescence lifetime of naphthalene over $10 \mathrm{kbar}$. The quenching rate at 1 atm $\left(k_{p_{0}}\right)$ in methylcyclchexane was obtained from stern-Volmer experiments at a 
naphthalene concentration of $4 \times 10^{-3} \mathrm{M}$ and biacetyl concentrations up to $4.56 \times 10^{-3} \mathrm{M}$. At these concentrations only a smalil amount of incident light is absorbed by the quencher. The Stern-Volmer plots were linear in this concentration range, and gave a rate of $1.3 \times 10^{10} \mathrm{M}^{-1} \mathrm{sec}^{-1}$. The pressure runs required the use of more concentrated biacetyl solutions to insure that even at the highest viscosities there is a. reasonable probability that an excited donor molecule will encounter a quencher molecule during its lifetime. The good agreement of runs made at two biacetyl concentrations Indicates the absence of a significant internal filter effect. The emission of naphthalene without quencher $(Q=0)$ is constant to $\pm 1 \%$ over $10 \mathrm{kbar}$. The experimental and calculated parameters appear in Table II.

\section{Resuits and Discussion}

A plot of $\log k_{p}$ against $\log \eta$ is shown in Figure 9. Also shown is data from Birks and Leite [43], who determined the quenching rates for. this system is ten pure soivents and solvent mixtures of varying viscosities by relative fluorescence yield and lifetime measurements. Over much of the viscosity range there is good agreement of the quenching constants obtalned through pressure experiments on a single solvent and those from Stern-Volmer experiments on different solvents. The pressure technique has obvious advantages in that it allows a significant range of viscosities to be attained in a single solvent at a single temperature in one experiment:

It is interesting to look at what can be said about the mutual diffusion coefficient $D_{A B}$ from this data. It has been shown [51-53] that In the limit of low quencher concentrations the Stern-Volmer equation zeduces to 
Table II. Experimental and Calculated Parameters

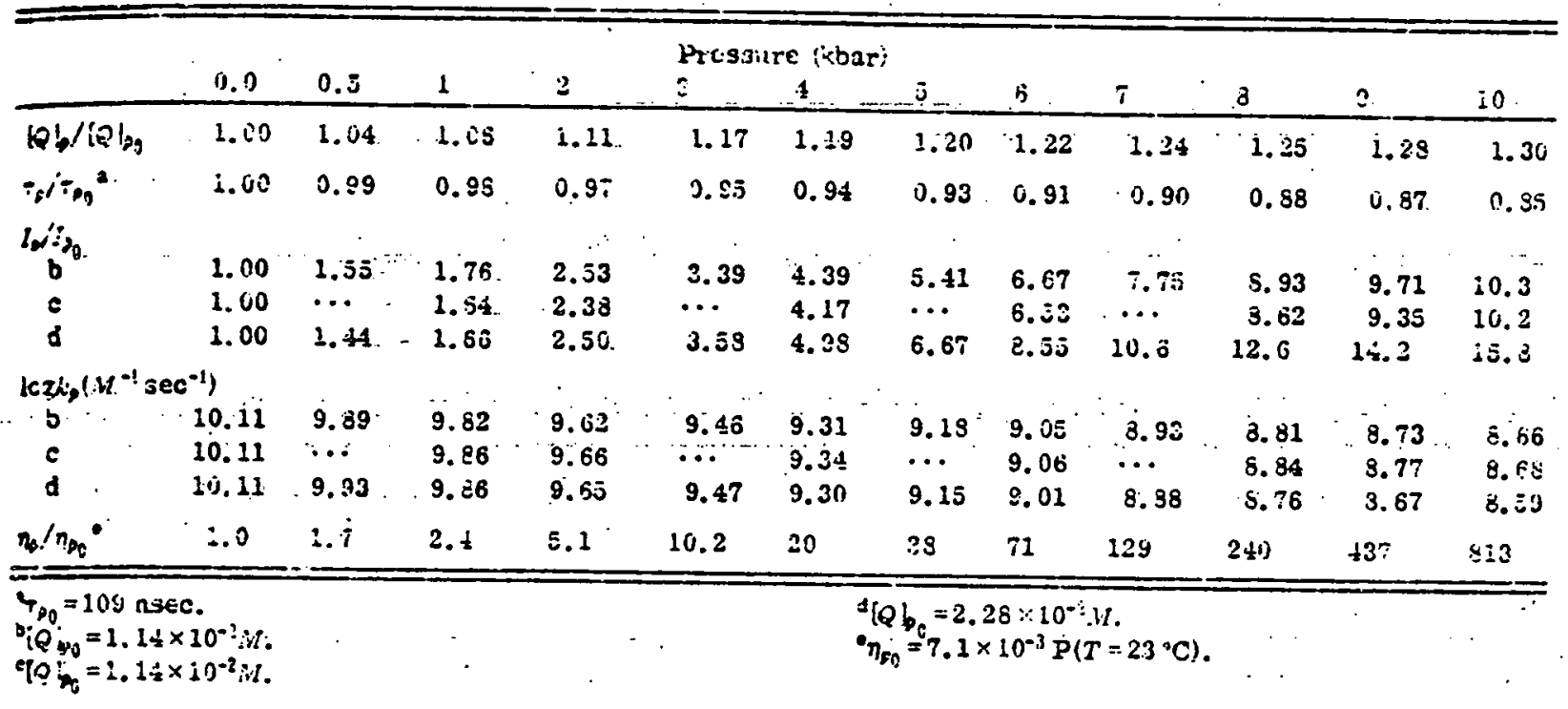




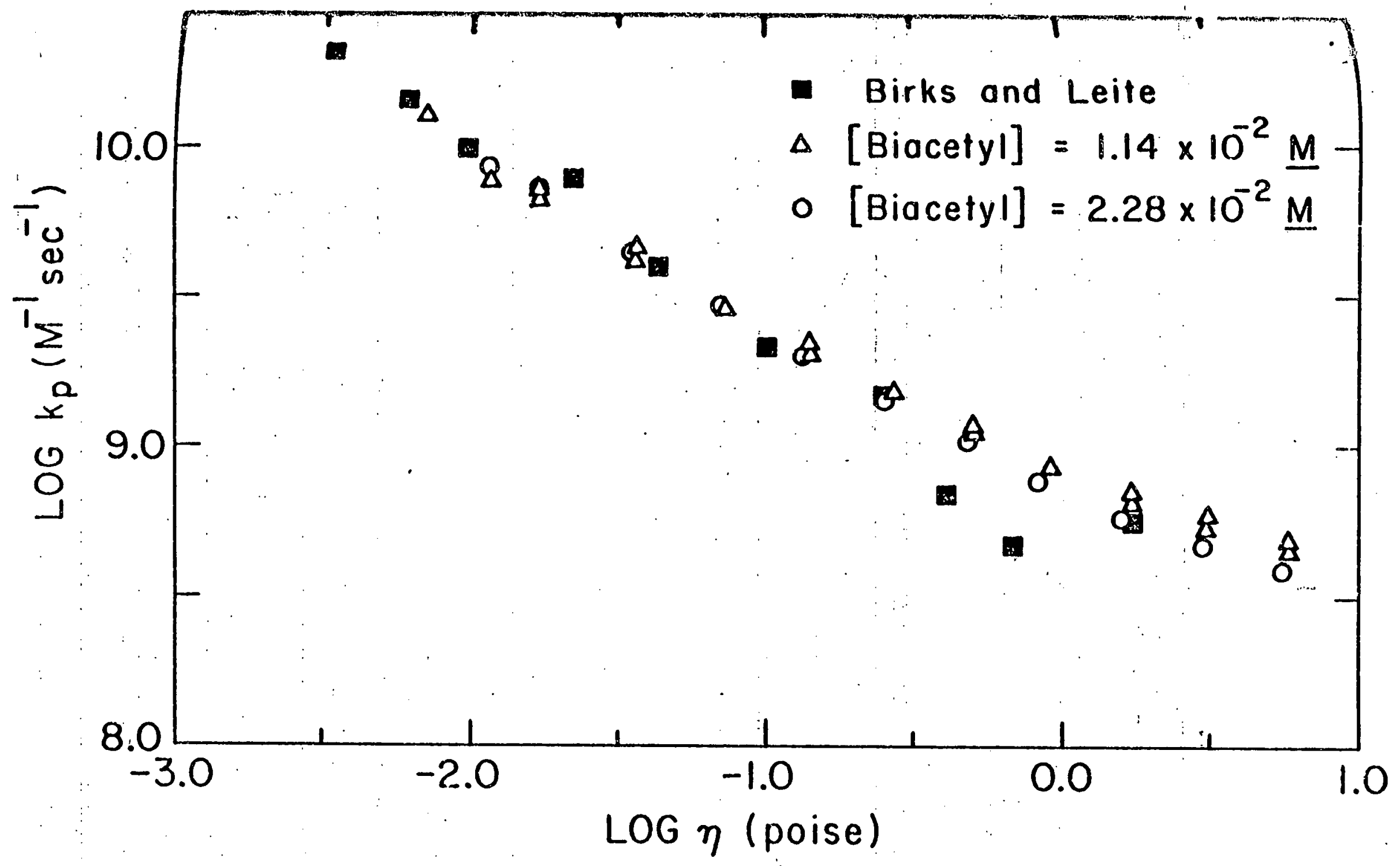

Figure 9. Plot of $\log k_{p}$ vs. $\log n$ 


$$
\frac{I_{0}}{I_{1}}=1+4 \pi \mathrm{N}^{\prime} R D_{A B} \tau_{0}[Q]\left[1+\frac{R}{\left(D_{A B} \tau_{0}\right)^{I / 2}}\right] \text {, }
$$

where $N^{\prime}$ is the number of particles per $m$ mole and $R$ is some interaction distance. Thus, the experimentally obtained quenching constants stoould be given by

$$
k_{\exp }=4 \pi N^{\prime} R D_{A B}\left[1+\frac{R}{\left(D_{A B} \tau_{0}\right)^{1 / 2}}\right]
$$

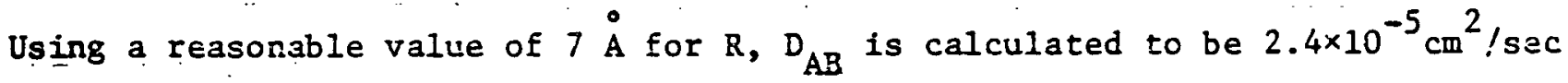
for $\eta=0.7 \mathrm{cP}(P=1 \mathrm{~atm})$ and $5.8 \times 10^{-7} \mathrm{~cm}^{2} / \mathrm{sec}$ for $\eta=550 \mathrm{cP}(P=10 \mathrm{kbar})$. This compares to values of $2.7 \times 10^{-5}$ and $3.4 \times 10^{-8} \mathrm{~cm}^{2} / \mathrm{sec}$ calculated from the Stcokes-Einstein equation with slip.

$$
D_{A B}=D_{A}+D_{B}=\frac{k_{B} T}{4 \pi n}\left(\frac{1}{r_{A}}+\frac{1}{r_{B}}\right)
$$

taking $r_{A}=I_{B}=3.5 \AA$. If the Stokes-Einstein equation is valid and if $D_{A B}=D_{A}+D_{B}$, then Eq. (10) predicts that for low viscosities where the term in parentheses is about equal to 1 the slope of a plot of logk exp against $\log n$ should be -1 . The observed inftial slope is -0.65 . In order to account for this and similar discrepancies observed by other workers Alwattar et al. [54] assert that the Stokes-Einstein equation is inadequate when applied to particles of molecular size. However, self-diffusion and viscosity data on tetramethylsilane and benzene obtained by Parkhurst and Jonas [55] over a $5 \mathrm{kbar}$ range indicate that the Stokes-Einstein equation Is adequate for self-diffusion. Another possibility is that $D_{A B} \neq D_{A}+D_{B}$. If the solutions are thermodynamically nonideal, factors of the form alna/2lnX should be included, where $a$ is the activity and $x$ the mole 
36

fraction. At the high dilutions used here this could be a very large factor and one sensitive to the solution properties.

Nemjek and Ware [49] have used fluorescence decay measurements to

obtain the encounter: radius and mutual diffusion coefficient of a donoracceptor pair by analysis of the nonexponential decay of the donor fluorescence in a viscous solvent. A high pressure study of this type would provide information on the viscosity dependence of these parameters and: allow comparisons with results from steady-state quenching experiments. 
VISCOSITY EFFECT ON FLUORESCENCE AND PHOTOISOMERIZATION OF TRANS-STILBENE

\section{Introduction}

The photoisomerization of stilbene is of considerable interest from both a theoretical and a practical point of view, particularly as a prototypical example of polyenes such as vitamin $A$ and the visual pigments which play an important role in photobiology. Iight absorption in the stilbene system is followed by a rapid change in molecular configuration due to twisting about the double bond. This change in molecular geometry upon excltation gives rise to the unusual emission properties cbserved in stilbene and the polyenes. Such a process involving rotation about a double bond has the advantage of possessing a reaction coordinate easily separable from other molecular coordinates, thereby facilitating theoretical description.

Early work by Dyck and McClure [56] and Malkin and Fischer [57] on the temperature dependence of trans-stilbene fluorescence and isomerization quantum yields established that almost all decay from the first excited trans singlet $\left({ }^{1} t^{*}\right)$ can be accounted for by fluorescence or by crossing. into the state from wich subsequent isomerization occurs. Great controversy arose over the identification of the process competing with fluorescence from $1_{t}^{*}$. Förster [58] proposed a model in which the process was assigned to intersystem crossing (ISC) into the triplet stilbene manifold $\left({ }^{3} t^{*}\right)$ followed by isomerization via a triplet state common to both isomers. Saltiel [59] assigned the competing process to activated rotation about the central bond to forr a twisted (perp) singlet $\left({ }_{p}^{*}\right)$ from which 1somerization occurs by efficient internal conversion to the 
gound state $\mathrm{S}_{0}$. This singlet mechanism (eq. 12-16) has recelved adoitional meoretical and experimental support and is the currently accepted model Lor direct trans-stilbene photoisomerization.

$$
\begin{aligned}
& 1_{t}+h v \rightarrow 1_{t}^{*} \\
& \left.1_{t} * k_{t}\right|_{t}+h v \\
& 1_{t} *{ }_{t p}^{k} 1_{p}^{*} \\
& 1_{t} * k_{i s} 3_{t}^{*} \\
& 1_{p}{ }^{*} k_{d}{ }^{1}{ }_{t}+(1-\alpha)^{1}
\end{aligned}
$$

A consequence of this mechanism is the prediction of very short Lffetimes for stilbene fluorescence at moderate temperatures. This is in coflict with recently reported fluorescence lifetime work by Birch and 3irks [60] in which a two component exponential decay was reported. At room resaperature the long component was found to be $1.65 \mathrm{nsec}$ and the short caponent less than $0.2 \mathrm{nsec}$ in methylcyclohexane/isohexane. In order to vecount for this, it was proposed that during the singlet $\left(S_{1}\right)$ lifetime, Mermal equilibrium is established between $i_{t}{ }^{*}$ and $i_{p}{ }^{*}$ by reversible internal sonversion across the potential barrier. Preliminary fluorescence data by ieschke and co-workers [61] seem to indicate such an equilibrium between a livorescing and a non-fluorescing state. However, a recent picosecond - Pudy [62] of the effect of temperature on trans-stilbene fluorescence Afetimes (In which a careful search for a long decay component was made) oid our observations on these lifetimes at room temperature in various oilferts show only a single very short simple exponential decay. "Until irreher data are available to resolve this question, we assume that the 
$I_{t}{ }^{*}+{ }_{p}{ }^{*}$ internal conversion is effectively unidirectional as originally proposed by Saltiel. A smail degree of reversibility would not affect the general conclusions reached herein.

Two pieces of evidence were instrumental in establishing the singlet mechanism. One was the observation by Saltiel and Megarity [63] that the effect of azulene on the photostationary states for direct stilbene photoisomerization is small and independent of solvent viscosity, while the effect of azulene on sensitized stilbene photoisomerization is large and viscosity dependent. In the sensitized experiments the azulene acts as an efficient acceptor of triplet excitation from ${ }^{3}{ }_{t}^{*}$ at the diffusion controlled rate resulting in a large enhancement of the amount of trans isomer in the photostationary state mixture. The small viscosity independent enhancement of the trans isomer in the direct isomerizations is attributed to long range singlet-singlet energy transfer. These - experiments established that ISC is not an important (<5\%) decay path for unperturbed trans-stilbene in non-viscolis solvents at room temperature.

The second key piece of evidence for the singlet mechanism was the observation by Saltiel and D'Agostino [64] that fluorescence and isomerization yields remain coupled in a highly viscous solvent upon lowering the temperature. On the basis of these experiments they postulated the existence in viscous solvents of a viscosity dependent barrier to ${ }_{t}^{*} \rightarrow_{p}{ }^{*}$ rotation giving an overall activation energy for this process of $E^{\neq}=E_{t}^{\neq}+E_{v}^{\neq}$where $E_{t}^{\neq}$is the inherent thermal barrier and $E_{v}^{\neq}$is the viscosity dependent barrier. The individual activation energies were then extracted by use of the Arrhenius and Andrade equations to anaiyze the dependence of the fluorescence quantum yields upon temperature and upon 
viscosity (at varying temperature and at constant temperature using glycerol/water mixtures).

The ordering of the lowest energy excited singlet states of the a.1-trans polyenes has been the subject of much study $[65,66]$. In these molecules the excited $\pi \pi^{*}$ states are of either $A_{g}$ or $B_{u}$ symmetry and the only allowed electric dipole transitions from the $\mathrm{A}_{\mathrm{g}}$ ground state are to $u$ states. It was thought that the excited $A_{g}$ state would be located at much higher energy than the $B_{u}$ state due to its doubly excited character, but recent theoretical work has shown that when doubly excited configurations are included in the configuration interaction this state exists at an energy much lower than previously supposed [65-67]. In fact these calculations predict that in the higher polyenes the doubly excited A singlet should be the lowest singlet lying just below the singly excited $B_{u}$ state [66]. The $B_{u}$ state has considerable Rydberg character while the excited $A_{g}$ state is covalent suggesting that the $B_{u}$ state is much more sensitive to solvent changes than is the $A_{g}$ excited state [65]. The very strong solvent dependence of the quantum yields and fluorescence lifetimes of all-trans-1,6-diphenyl-1,3,5-hexatriene (DPH) has been attributed to the modification of the energy gap between these states by solvent polarizability $[68,69]$.

Orlandi and Siebrand [70] have proposed a potential energy diagram for trans-stilbene isomerization based upon such a low energy doubly excited singlet state. This $\mathrm{A}_{\mathrm{g}}$ state which for trans-stilbene arises from an electronfic excitation mainly localized in the ethylenic fragment, has higher erergy than the lowest $B_{i}$ state for planar geometry, but lower energy for twisted geometries. The two potentials intersect at some angle $\theta=\theta_{s}<90^{\circ}$ leading to a reversal of the state order. Birch and 
Birks have used this potential energy diagram in their discussion of stilbene isomerization. Birks [71] has recently presented this semi-

- emplrical model in more detail and appiled it to the higher polyenes. Figure 10 shows schematically the angular dependence of the ground and exclted singlet state potentials in trans-stilbene based on this model. In this report we investigate the effect of solvent viscosity on fluorescence and isomerization quantum yields of stilbene at room temperature by using high pressure to alter solvent viscosities. Viscosities from less than $10^{-2}$ poise to more than $10^{3}$ poise were obtained by application of pressures to $11 \mathrm{kbar}$ on organic solvents. The use of pressure allows a clean separation of the viscosity effect from purely temperature and solvent effects - both of which are important in this system.

\section{Experimental Procedure}

2.1 Materials trans-stilbene (Aldrich) was recrystallized twice from $\mathrm{CHCl}_{3} / \mathrm{EtOH}$ and then sublimed. Analysis by glpc showed no volatile impurities other than a trace of cis-stilbene. A pure sample of cis-stilbene was obtained by preparative glpc. $600 \mathrm{ml}$ of spectral glycerol (Mallinckrodt) was mixed with $200 \mathrm{~m} l$ water and filtered through activated charcoal to remove UV absorbing impurities. The anhydrous glycerol was recovered by fractional distillation at high vacuum. Methancl, isobutanol, n-hexane, and $\mathrm{MCH}$ were a.11 MC/B fluorometric solvents and were used without further purification in the fluorescence experiments. HEN (Aldrich) and paraffin oil (Amoco 非1-U.S.P.) were used to attain high viscosities in a non-polar solvent. The HMN was used without further purification. The paraffin oil was stirred 12 hours over fumirg sulfuric acid $\left(30 \% \mathrm{sO}_{3}\right)$, washed, neutralized, and filtered through slica gel and alumina. This 


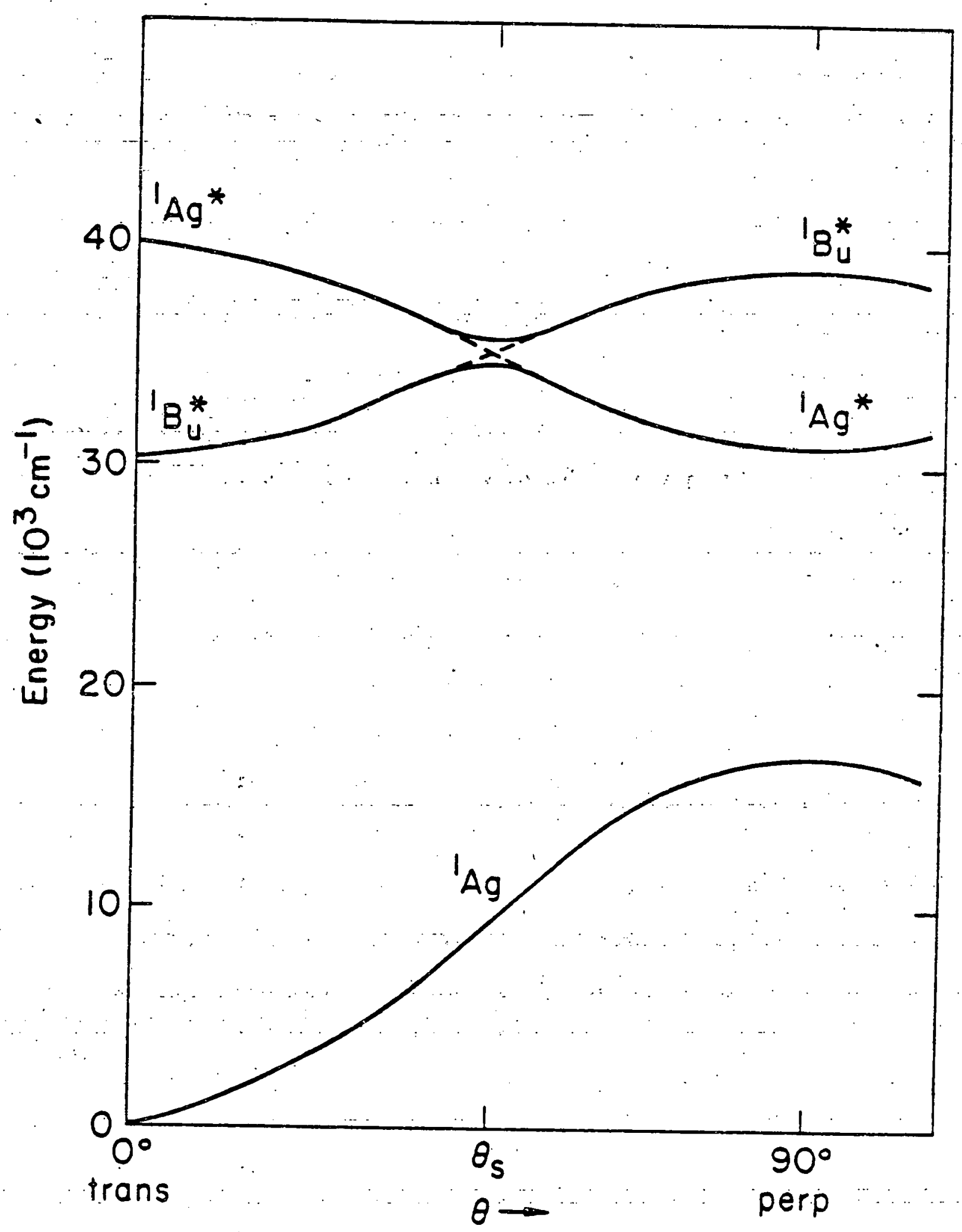

Figure 10. Potential energy diagram of ground and two lowest excited singlet states of trans-stilberie as a function of rotation angle $\theta$. After refs. 60 and 71 . 
treatment reduced the fluorescence background by a factor of about 20 for $313 \mathrm{~m}$ irradiation. The alcohols for the isomerization experiments were distilled over BaO to remove trace acidic impurities which catalyzed cis to trans isomerization upon concentration of the irradiated solutions. The MCH was distilled to remove small amounts of high boiling substances which laterfered with the glpc analysis.

\subsection{Atmospheric Fluorescence Yields Fluorescence quantum yields at} atmospherlc pressure for trans-stilbene in methanol were obtained relative to quinine sulfate in $1 \underline{\mathrm{N}} \mathrm{H}_{2} \mathrm{SO}_{\dot{4}}\left(\phi_{f}=0.55\right) \quad[38]$ at $23^{\circ} \mathrm{C}$. Fluorescence spectra of stilbene and the standard were taken on a previously described emission spectrometer $[33,34]$ using photon counting at very low excitation intensities. Loss of fluorescence intensity while the spectrum was being taken (due to trans to cis photolsomerization) was negligible. The relative fluorescence intensities were obtained by integration of the corrected emission spectra. Refractive index corrections were made to adjust for the differenc solvents used with the standard and the stilbene. solution. Concentrations of solutions were adjusted so that optical densities were approximately equal at the exciting wavelength (295 nm) and the fluorescence intensities were corrected for small differences in optlcal density. Fluorescence quantul yields for trans-stilbene in other solvents were determined by comparison with the quantum yield in methanol. Th1s was done on an uncorrectëd fluorometer (Farrand Mk II) by monitoring the emission intensity at the wavelength of maximum intensity in each solvent and assuming that the intensity is proportional to the area of the : enission spectrum in that solvent. (Emission spectra changed only slightly In position and half-width in the solvents studied.) Refractive index corrections were made as above. 
2.3 High Pressure Fluorescence Yields The high pressure liquid cell and associated emission equipment have been described elsewhere... $[33,34]$. Trans-stilbene solutions $\left(4 \times 10^{-6} \mathrm{M}\right)$ were excited into the absorption bend with maximum at about $308 \mathrm{~mm}$. The excitation wavelength (bandwidth $0.5 \mathrm{~mm}$ ) was adjusted at each pressure and for each solvent to give maximum fluorescence intensity. The shift of the excitation maximum was never more than $3 \mathrm{~nm}$ over the 11 kbar pressure range. Photon counting at very low. excitation intensities was used to minimize trans to cis isomerization. In order to further reduce the time that the solution was irradiated during a pressure run, only the emission intensity at the wavelength of maximum Intensity was taken at each pressure. This emission intensity was corrected for photomultiplier and monochromator response, and taken to be proportional to the area of the emission spectrum at that pressure. The emission spectrum undergoes a red shift with increasing pressure, but the halfwidth 1s little changed. Intensities were corrected for the increase in solution concentration due to solvent compressibility using Bridgman's data [35,47]. The compressibility of n-heptane was used. for tim and paraffin ofl was assumed to be $85 \%$ as compressible as $n$-heptane. It is unlikely that these estimated values differ by more than $10 \%$ from the actual compressibilities. No correction for the approximately $10 \%$ increase in refractive index [86] from atmospheric pressure to $11 \mathrm{kbar}$ has been applied to the high pressure intensity data. The design of the collection optics in the high pressure emission equipment makes this correction negligible.

2.4 High Pressure Isomerization Rates Solutions at pressure were 1rradlated in a cylindrical stainless steel inner cell designed for high pressure absorption work [21] with path length of about $1.5 \mathrm{~cm}$. The sapphire window assembly at one end of the cell was replaced with a 
pollshed stainless steel plunger to reflect exciting light tack into the solution. It was verified that the extent of photoisomerization ivas directly proportional to irradiation time for small conversions showing the absence of any appreciable dead volume in the cell. All solutions were deoxygenated by bubbling argon through them for several minutes. Transstilbene solutions $\left(4 \times 10^{-6} \mathrm{M}\right)$ were irradiated at the wavelength of maximum emission intensity for each pressure and solvent as determined in the fluorescence experiments. Cis-stilbene solutions $\left(1 \times 10^{-5} \mathrm{M}\right)$ were irradiated at $277 \mathrm{~mm}$... A solution was brought to pressure, irradiated for the time necessary to bring about approximately $10 \%$ isomerization at $0.5 \mathrm{kbar}$, the pressure was released, and the sample set aside while the process was.. repeated at another pressure. After several pressure runs, the solutions were concentrated on a hotplate under a stream of argon. This treatment was shown not to affect cis/trans ratios if carefully done. The solutions were then analyzed by glpc for the per cent conversion (glass $3 \mathrm{ft} \times 1 / 8$ in column of $3 \% \mathrm{SE}-30$ on Chromosorb. P, T. $155^{\circ} \mathrm{C}$ ).

\subsection{High Pressure Viscosities The pressure dependence of the} viscosities of the solvents in Figure 11 is given by Bridgman at 30 and $75^{\circ} \mathrm{C}$ [47]. The Andrade equation is used to correct the viscosities to ambient temperature at each pressure. The currently accepted value for the viscosity of glycerol at $30^{\circ} \mathrm{C}(6.29$ poise $)$ is used. rather than that used by Bridgman (3.8 poise) which he took from the International Critical Tables. The more recent work by Zolotykh [31] on the pressure-viscosity relation of carefully dried glycerol to 7 kbar shows excellent agreement with Bridgman's data.

2.6 Fluorescence Lifetimes The picosecond laser, streak camera, and digitizing system have been previously described [87]. The $\mathrm{Nd}^{3+}$ : YAG 
laser 4 th harmonic $(265 \mathrm{~nm})$ was used to excite trans-stilbene $\left(5 \times 10^{-5} \mathrm{M}\right)$ In varfous solvents at room temperature. Streak camera optics were quartz, allowing observation of the entire trans-stilbene fluorescence"spectrum. Ten decay curves were obtained in each solvent, summed, and fitted to a single exponential decay. In each case a good fit was obtained.

\section{Results and Discussion}

\subsection{Fluorescence Quantum Yields and Lifetimes Fluorescence lifetimes}

and quantum yields obtained for trans-stilbene in various solvents at $23^{\circ} \mathrm{C}(\lambda$ exc $295 \mathrm{~nm})$ are shown in Table III. Also shown are quantum yield data from Saltiel's work. Agreement between the two sets of data is very good. Figure 11 shows the fluorescence quantum yield as a function of solvent viscosity at room temperature in several solvents. Figure 12 is a plot of $\phi_{f}$ versus $P$ in $2,2,4,4,6,8,8$-heptamethylnonane (HMN) and paraffin 011 - solvents for which the pressure dependence of viscosity is not known. The $10 \mathrm{kbar}$ point in $\mathbb{E M N}$ was disregarded as it seemed inconsistent with the other data. This was the last point taken and it is likely that some photolsomerization occurred resulting in a low $\phi_{f}$. Solutions were decxygenated although fluorescence yields in solution are almost unchanged even under an oxygen atmosphere. ${ }_{\phi_{f}}^{\mathrm{Ar}} / \phi_{\mathrm{f}}{ }^{0}=1.03 \pm 0.02$ in n-pentane; [68] $\phi_{f}^{A r} / \phi_{E}{ }^{0_{2}}=1.01 \pm 0.02$ in paraffin oil (this work).

The dependence of the fluorescence yields on viscosity indicates the presence of a viscosity barrier to $1_{t}^{*} \rightarrow 1_{p}^{*}$ rotation even in the nonviscous solvents studied. There is also an inherent thermal barrier to the twist which is not addressed in these experiments. It should be noted that even quite non-viscous solvents such as the commonly used $1: 1$ methylcyclchexane/methylcyclopentane (MCH/MCP) mixture become significantly 
Table III. Fluorescence Quantum Yields and Lifetimes at $23^{\circ} \mathrm{C}$

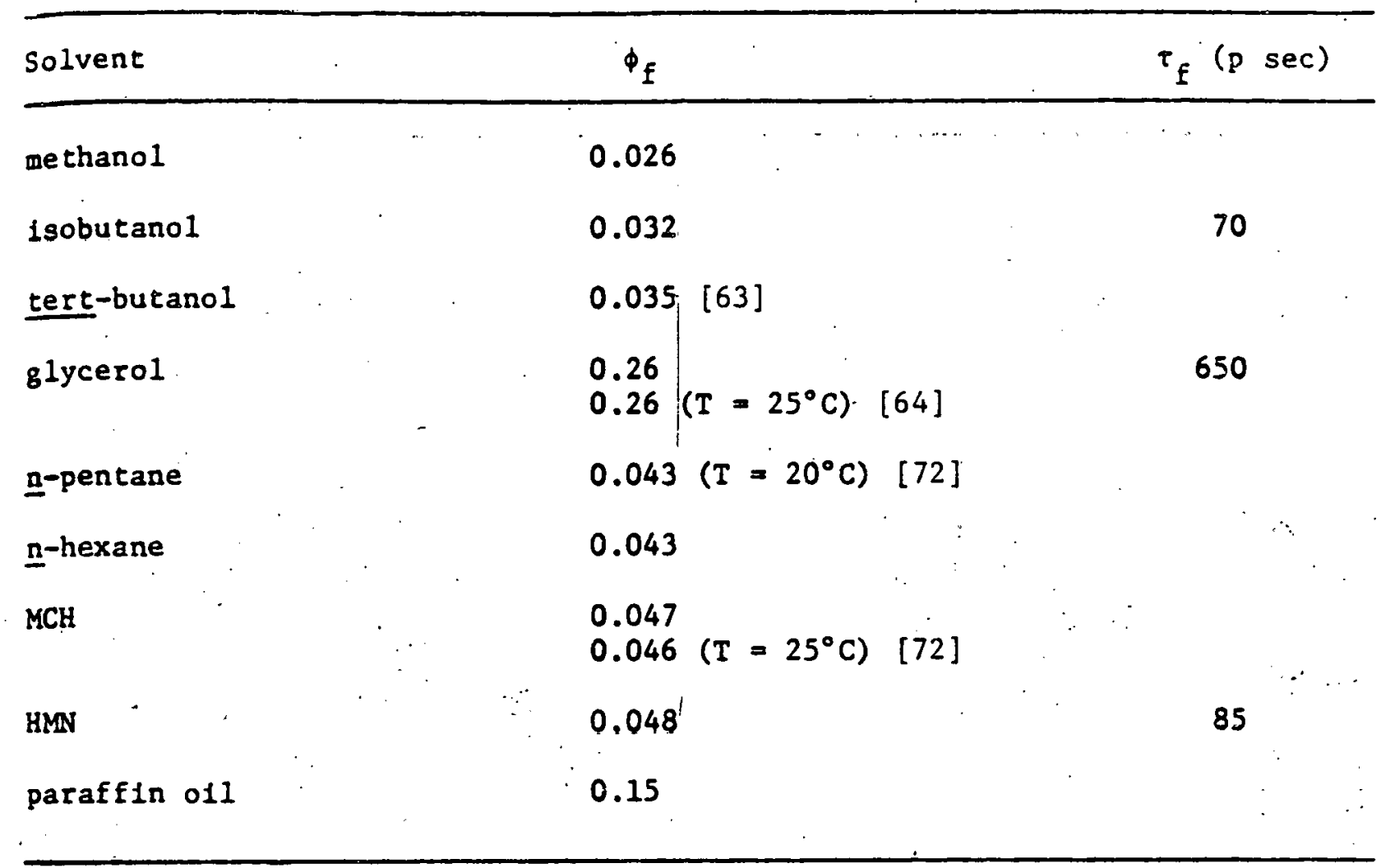




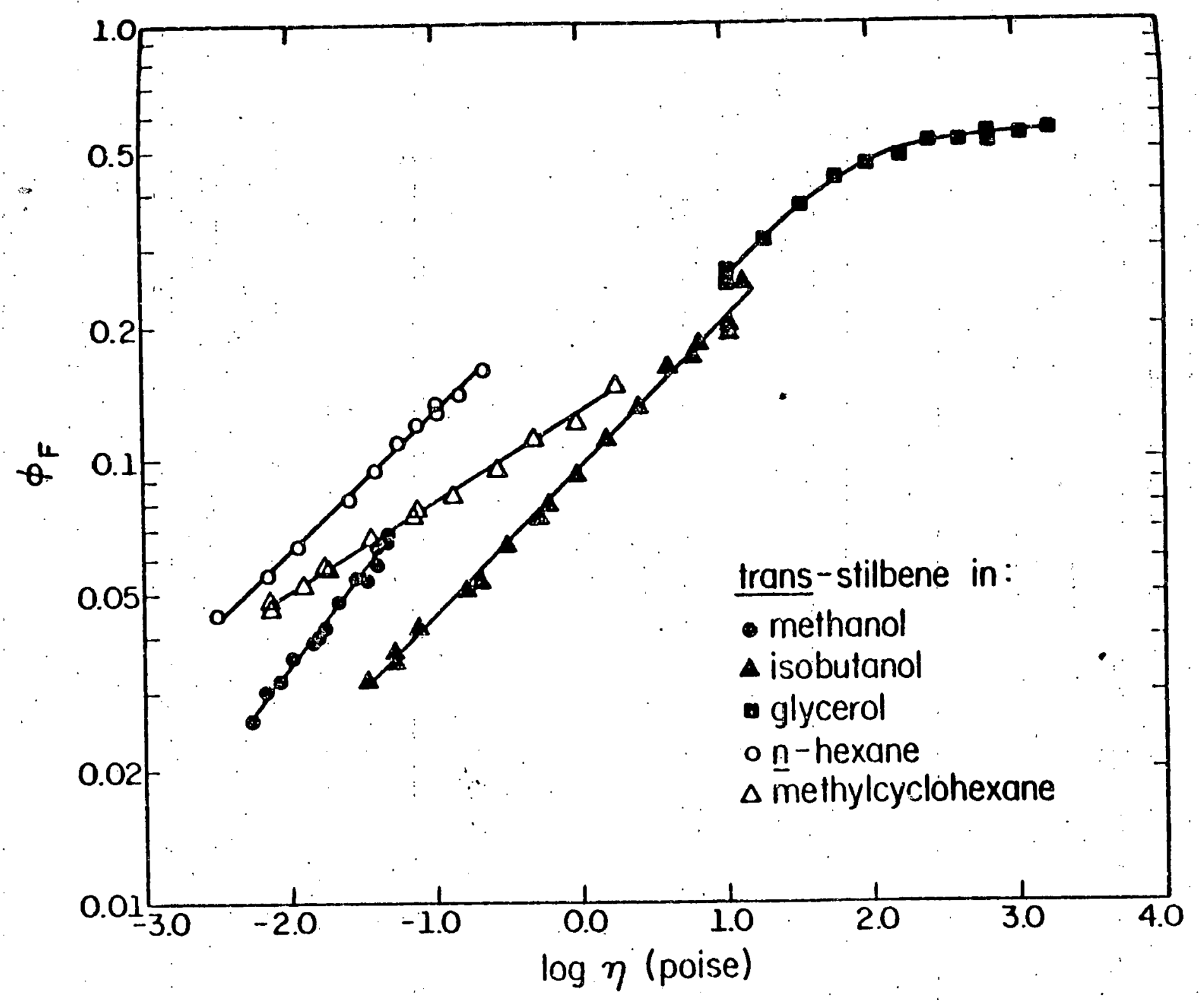

Figure 11. $\phi_{f}$ Vs. log viscosity: trans-stilbene in several solvents. 


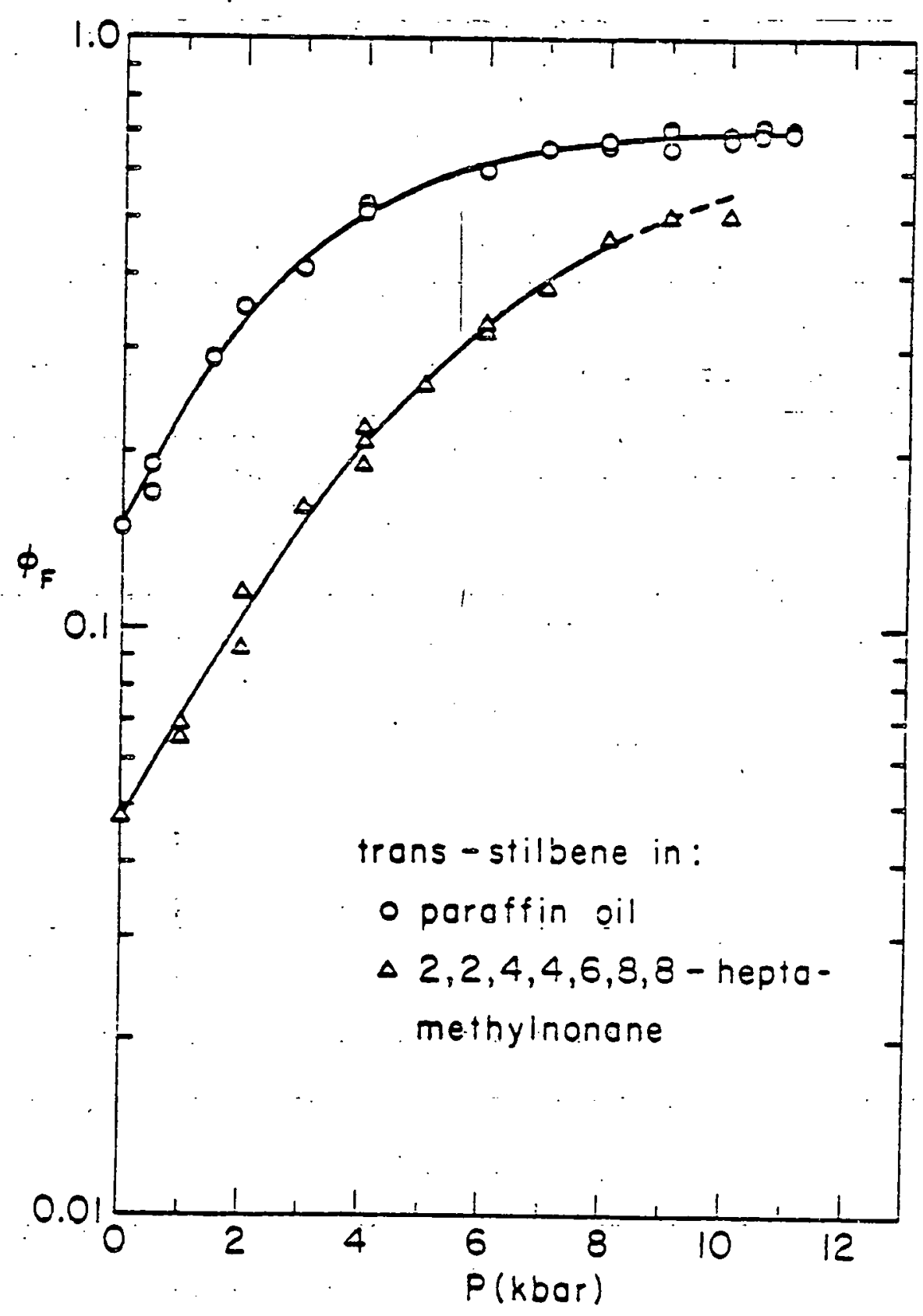

Flgure 12. \$f vs. pressure: trans-stilbene in paraffin oil and in $2,2,4,4,6,8,8$-heptame thylnonane 
wre viscous at low temperatures. For example, MCH/MCP attains a viscosity about $10^{4}$ poise at $-175^{\circ} \mathrm{C}$ [73]. When a solvent such as this is used in - lov temperature fluorescence yield experiment to extract the thermal uelvation energy via an Arrhenius plot, the observed $\phi_{f}$ must contala both armal and viscosity dependent contributions.

In order to explain the $\eta^{2 / 3}$ dependence of the fluorescence yield to the triphenylmethane dyes, Forster and Hoffman [28] proposed a model th whtch the phenyl rings rotate to a new equilibrium position after acitation at a rate controlled by Stokes-like viscous damping. The nonndlative, viscosity dependent deactivation rate of the excited singlet saken to be quadratically proportional to the angle of ring rotation. 3though this model accounts for the emission quantum yields, it predicts a Iuoresence decay of the form $\exp \left(-b t^{3} / n^{2}\right)$ where $b$ is a constant.

Lover, a simple exponential decay has been observed in the triphenylmethane to malachite green [74]. It is difficult to sae how any model in which there is a time dependent rate of excited state deactivation couid give Hse to a simple exponential fluorescence decay as observed in trans-stilbene and malachite green. We, therefore, assume that the rate of viscosity lepeadent ${ }^{1}{ }_{t}{ }^{*}$. deactivation is time independent and assign 1 the value $k_{c}$. Hether or not this is also the rate of rotation about the central bond $k_{t p}$ postulated by Birch and Birks [60]; Saltiel and D'Agostino [64], and others, is unknown.

It is evident from Figure 11 that in addition to the viscosity wondence of the fluorescence yields, there is also a strong solvent tonjence: For example, at a viscosity of 0.1 poise in isobutanol, MCH, n-haxane, the fluorescence yields are $0.045,0.080$, and 0.13 , espectively. This large enhancement of $\phi_{f}$ in hydrocarbon solvents over 
that in polar solvents has received little attention: Saltiel and Megarity [63] noted the low $\phi_{f}$ in the viscous tert-butanol in comparison to the higher $\phi_{f}$ in the non-viscous n=pentane, but at-tached-no particular. significance'? it. A similar solvent effect has been observed in trans-1,1,4,4-tetrapheny 1-2-methylbutadiene [75] and in DPH [76].

The solvent effect can be rationalized in terms of Birk's potential diagram (Figure 10). An increase in solvent polarizability decreases the $\mathrm{I}_{\mathrm{B}}^{*}$ energy thereby lowering the $\mathrm{S}_{1}$ potential barrier to rotation. This increases the rate of non-radiative ${ }^{1}{ }_{t}{ }^{4}$ deactivation resulting in a lower $\phi_{f}$. Also the angle $\theta_{s}$ at which the avoided crossing occurs increases -making viscosity more effective at hindering deactivation of ${ }^{1}{ }^{*}$. in a polar solvent than in a non-polar solvent. This may explain the large slope of the $\phi_{f}$ versus $\log n$ plot for the highily polair methanol. As expected, the absorption spectrum of trans-stilbene undergoes a bathochromic shift of about $175 \mathrm{~cm}^{-1}$ upon changing the solvent from a hydrocarbon to glycerol due to stabilization of the excited state by the more polar solvent. [64]. - The findings for the two hydrocarbon solvents $n$-hexane and $M C H$ are rather puzzling. The data show that the slope is larger in n-hexane. The smaller - $\phi_{f}$ in MCR could be due to its greater molecular polarizability (note that at low viscosities the difference in $\phi_{f}$ is not large). Phenomonologically, this indicates that an increase in viscosity is much less effective in hindering twisting in. MCH than it is in n-hexane. This may perhaps be connected with the shape of the molecule -- the other solvent molecules. are much pore "cylindrical" than $\mathrm{MCH}$.

From our $\phi_{f}$ and $\tau_{f}$ data at room temperature we calculate the radiative rate $k_{f}$ as $4.0 \times 10^{8} \mathrm{sec}^{-1}$ in glyceroi; $4.6 \times 10^{8} \mathrm{sec}^{-1}$ in isobutanol; and $5.6 \times 10^{8} \mathrm{sec}^{-1}$ in HMN. A theoretical value of $k_{f}$ in 
p-pentane of $5.9 \times 10^{8} \mathrm{sec}^{-1}$ has been obtained by Marinari and Saltiel [77] from the integrated absorption spectrum using the Birks-Dyson relation [17]. The small solvent dependence observed is supported by the relative Insensitfvity of the trans-stilbene absorption and fluorescence spectra to solvent changes [63]. A similar insensitivity to pressure is the fustlfication for taking $k_{f}$ to be pressure indeperident.

Figures $I I$ and 12 show that at the highest viscosities attained, $\phi_{f}$ has reached a limiting value in glycerol and paraffin oil. The $\phi_{f}$ in $H M N$ shows signs of limiting at some value near that for the paraffin oil. At these high viscosities the excited trans-stilbene molecule experiences hindrance to twisting from the walls of its now rigid solvent cage. The rotational deactivation path from ${ }^{1} t^{*}$ is closed off and the excited wolecule either fluoresces or undergoes ISC to ${ }^{3} t^{*}$. The cessation of nolecular twist in the excitad singlet is consistent with the observation that the excited state absorption of $1_{t}{ }^{*}$ shows no decay in the 120 psec after excitation in a polymethylmethacrylate (PMMA) matrix in contrast to the iast decay observed in n-hexane solution. It should be noted that the complete inhibition of the $i_{t}^{*}+1_{p}^{*}$ rotation does not necessarily mean that trans to cls photoisomerfzation has also ceased. As Birks has pointed out [78], isomerization via a triplet mechanism could still occur. The reduction in the rate of the process ${ }^{3} t^{*} \rightarrow{ }^{3}{ }^{*}$ would be less important than in the corresponding singlet process because of the longer ${ }_{t}^{*}$ lifeSuch a triplet mechanism is operative in the trans to cis photoframertzation of the styrylnaphthalenes $[79,80]$ which occurs even in rigid meda such as polystyrene [31]. A similar triplet mechanism for isomerizaElon also seems to be operative in trans-stilbene at high viscosities and 
gt room temperature: Irradiation at these viscosities leads to loss of fluorescence intensity indicative of trans to cis isomerization.

The rate of. ISC at room temperature $k_{\text {is }}$ can be calculated from the Ilditing $\phi_{f}$ values at high viscosity by use of eq. 17.

$$
\left(\ddot{\phi}_{f}\right)_{n \rightarrow \infty}=k_{f} /\left(k_{f}+k_{i s}\right)
$$

Calculated $k_{\text {is }}$ values are $3.3 \times 10^{8} \mathrm{sec}^{-1}$ in glycerol and $2.4 \times 10^{8} \mathrm{sec}^{-1}$ in paraffin oil (using $k_{f}=5.6 \times 10^{8} \mathrm{sec}^{-1}$ in this solvent). The difference between these values is probably not significant, but both are much larger than the generally quoted values. These range from about $2 \times 10^{7} \mathrm{sec}^{-1}$ (the value for $B$-styrylnaphthalene) [82] to about $6.4 \times 10^{7} \mathrm{sec}^{-1}$ (from computer assisted curve fitting of $\phi_{f}$ vs $T$ ) [72]. However, the large $k_{i s}$ values obtained are not in conflict with the photochemical behavior of trans-stilbene at room temperature (see below). The near untiy $\phi_{f}$ in hydrocarbon solvents at $-190^{\circ} \mathrm{C}$ [36] is explained by assuming that $k_{\text {is }}$ decreases as the temperature is lowered. At these low temperatures the trans to cis isomerization yield $\phi_{t \rightarrow c}$ is $\operatorname{small}\left(\phi_{t \rightarrow c}=0.006\right.$ at $\left.-183^{\circ} \mathrm{C}\right)$ [57] so $\mathrm{k}_{1 \mathrm{~s}}^{\circ}$ can be calculated as above. At about $-190^{\circ} \mathrm{C}, \mathrm{k}_{\mathrm{f}}^{0}=5.8 \times 10^{8} \mathrm{sec}^{-1}$. from low temperature $\phi_{f}[36]$ and $\tau_{f}[62]$ data giving $k_{i s}^{0}=3.1 \times 10^{7} \mathrm{sec}^{-1}$. knowing $k_{f}, k_{i s}$, and $\phi_{f}$ at some viscosity allows calculation of the rate of configuration dependent ${ }^{1}{ }^{*}$ decay.$\left(k_{c}\right)$ via the relation:

$$
\phi_{f}=k_{f} /\left(k_{f}+k_{i s}+k_{c}\right)
$$

In $n$-hexane at atmospheric pressure and room temperature, $k_{c}$ is $1.2 \times 10^{10} \mathrm{sec}^{-1}$. Values in the other non-viscous solvents studied are not Iar different. Calculation of the ISC quantum yield $\phi_{\text {is }}$ in these. solvents shows that only about $2 \%$ of the ${ }^{1} t^{*}$ states undergo ISC to ${ }_{t}^{*}$. This is well below the $5 \%$ ISC yield which could have been detected in. 
Megarity and Saltiel's azulene quenching experiments [63]. In glycerol $k_{c}$ is $8.1 \times 10^{8} \mathrm{sec}^{-1}$ giving an ISC yield of $21 \%$. Thus, the triplet mechanism plays a significant role in trans-stibene photoisomerization in glycerol and other viscous solvents at room temperature.

Since tine yield of cis- and trans-stilbene from ${ }^{1} \mathrm{p}^{*}$. and ${ }^{3} \mathrm{p}^{*}$ are identical [83], measurements of the photostationary states in a particular solvent give no information on whether the isomerization proceeds via a singlet mechanism; a triplet mechanism, or both similtaneously. This explains why the-same photostationary states are observed in glycerol and. in non-viscous solvents. The use of a triplet interception method to determine the ISC yield in glycerol would be extremely difficult as the high viscosity would result in a much smaller rate of triplet quenching and thereby cause only slight trans enhancement for reasonable quencher concentrations. The high pressure technique described here seems the best way to approach the problem.

\subsection{Initial Isomerization Rates In Figure 13 the effect of viscosity} on the initial rate of trans to cis phetoisomerization relative to the Initial rate at a viscosity corresponding to a pressure of 0.5 kbar is shown in several solvents at room temperature. The data represent the relative rates during the first $10 \%$ of the trans to cis conversion. Also shown are data obtained for the cis to trans conversion in isobutanol. The fraction (about 0.1 ) of exclted cis molecules which undergo photocyclization and oxidation by traces of oxygen giving phenanthrene seemed little affected by pressure and was ignored in the calculation of the relative rates.

Although there is a fair amount of scatter in the data, several. conclusions can be drawn. In all solvents studied, the rate of trans to cls ccnversion decreases at the highest solvent viscosities showing. that $\phi_{f}$ 


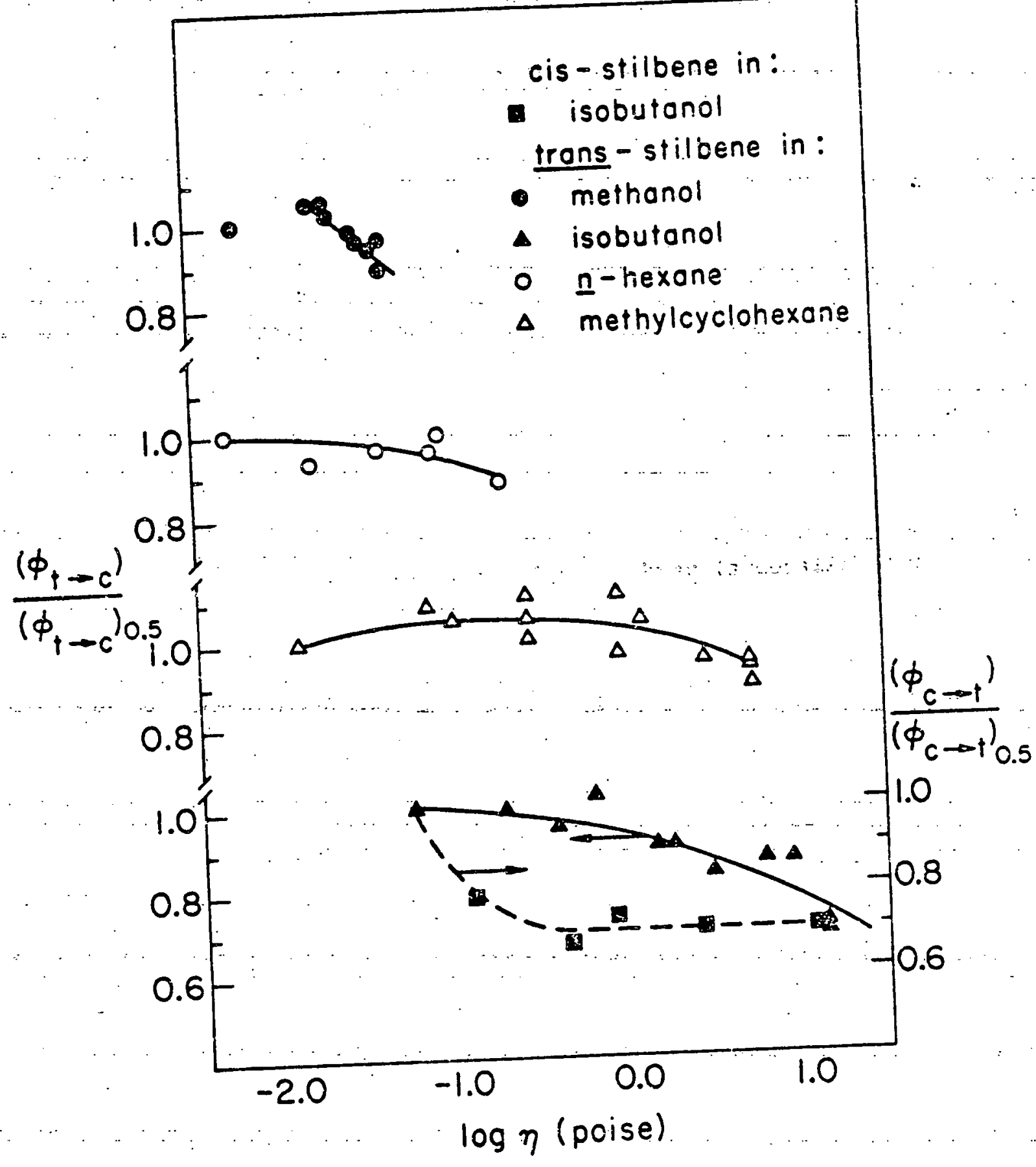

Figure 13. Rëlative $\phi_{t \rightarrow c}$ vs. log viscosity in several sclvents and $\phi_{c \rightarrow t}$ in isobutanol. 
and $\phi_{t \rightarrow c}$ are indeed coupled in moderately viscous media at room temperature in accordance with the singlet mechanism (eq. 12-16). The slope of the $\phi_{t \rightarrow c}$ vs. log plot is greater in methanol than in the other solvents. This is consistent with the large viscosity effect on $\phi_{f}$ in methanol as discussed above -- solvent viscosity is more effective at hindering $1_{t}{ }^{*} 1_{p}^{*}$ in polar solvents. In some cases it appears that at intermediate pressures (2-5 kbar) $\phi_{t \rightarrow c}$ actually increases as the viscosity increases. A Iikely explanation is that pressure alters the cis/trans decay ratio from $1_{p}^{*}$ further in favor of the cis isomer $(1-\alpha=0.59$ in non-viscous solvents at atmospheric pressure) [83]. At higher viscosities the decrease in the rate of twist giving rise to ${ }^{1}{ }^{*}$ overpowers the increase in cis/trans decay ratio from $1_{\mathrm{p}}{ }^{*}$ resulting in a lower $\phi_{t \rightarrow c}$. The fast drop in the rate of the cis to trans conversion between 0.5 and 4 kbar is consistent with an Increase in the cis/trans decay ratio in this pressure range. From 5 to $10 \mathrm{kbar}, \phi_{\mathrm{C} \rightarrow \mathrm{t}}$ seems independent of both solvent viscosity and pressure. The viscosity independence is in agreement with the results of Gegiou, Muszkat, and Fisher [84] in glycerol at temperatures down to $-80^{\circ} \mathrm{C}$ implying that the rate of the process $1_{c}{ }^{*}+1_{p}{ }^{*}$ is much less sensitive to solvent viscosity than that of $1_{t}{ }^{*} \rightarrow 1_{p}{ }^{*}$. This is illustrated by the observation that the $c i s$ to trans conversion occurs rapidly in a PMMA matrix at pressures to $100 \mathrm{kbar}$ as shown by the rapid growth of trans-stilbene fluorescence intensity upon irradiation [85].

\section{Conclusion.}

Trans-stilbene direct photoisomerization proceeds predominately via the singlet mechanism (ISC yield $z 2 \%$ ) in nonviscous solvents at room temperature. As solvent viscosity is increased at room temperature, 
1somertzation via the iriplet mechanism becomes increasingly competitive due to inhibition of the $1_{t}{ }^{*}{ }^{1}{ }^{*}$. process. In glycerol at room temperature about $21 \%$ of the ${ }^{1}{ }^{*}$ states undergo ISC to ${ }^{4} t^{*}$. If the ${ }_{t}{ }^{*} \rightarrow^{1} t$ radiationless decay is negligible as suggested by the identical photostationary states observed for perhydro- and perdeuterio- stilbenes with high energy sensitizers [59] then $21 \%$ of the isomerization occurs via the triplet mechanism in glycerol. The ability of-high pressure to alter solvent viscosities at one temperature is a very useful tool in the investigation of photochemical processes involving changes in molecular geonetry upon excitation. 
PHOTOPHYSICS OF POLYENES AT

HIGH PRESSURE

4. Intraduction

Linear conjugated polyenes have a characteristic strongly allowed $\pi \pi$ * Frasesten $\left({ }^{\star} \mathrm{B}_{\mathrm{u}}+\mathrm{A}_{\mathrm{g}}\right.$ in point group $\left.\mathrm{C}_{2 \mathrm{~h}}\right)$ in the near $\mathrm{UV}$ or visible region. models of polyene electronic structure incorporating only singly exziteed configurations predict that this strongly allowed transition is hosest in energy followed at higher energies by two states of A symetry 7ow thansitions from the $\mathrm{A}_{\mathrm{g}}$ ground state are symetry forbidden. Many of the linear polyenes fluoresce and interpretation of the fluorescence the basts of the above state ordering leads to certain anomalies. The oberved fluorescence Iifetimes of the diphenylfolyenes are found to longer than the lifetimes calculated from the absorption intensities cof the $\bar{B}_{\mathrm{u}}+\mathrm{A}_{\mathrm{g}}$ transition. Also anomalous are the large Stokes shirts and the dery diferent solvent shifts of absorption relative to emission.

The observation in 1972 by Hudson and Kohler [88] of a structured weak absorption at an energy lower than that of the strong absorption and whe pubilication by Schulten and Karplus [89] of the results of an MO ailation including CI with all singly and doubly excited states led to a ifumental re-evaluation of polyene photophysics. The calculations fridicated that a low energy singlet $\mathrm{A}_{\mathrm{g}}$ state is a general feature of itrones and in some cases could be the lowest excited singlet. zandsors and Kohler assigned the weak absorption $(f \approx 0.05)$ to the symetry ifociditen ${ }^{*} A_{\delta}+A_{g}\left(S_{1} \rightarrow S_{0}\right)$ transition. They proposed that the Sransition responsibie for fluorescence is ${ }^{*} A_{g} \rightarrow A_{g}\left(S_{1} \rightarrow S_{0}\right)$ which gains 
oscillator strength through intensity borrowing from the allowed ${ }_{\mathrm{B}}+\mathrm{A}_{\mathrm{g}}$ $\left(s_{2} \rightarrow s_{0}\right)$ transition.

The apparent anomalous fluorescence behavior of linear polyenes is eastly explai..ed by this model. The discrepancy between the observed and calculated natural fluorescence lifetimes is due to the different states involved in absorption and emission. The large stokes shifts which increase with polyene length are only the energy difference between the ${ }^{*}{ }_{\mathrm{u}} \cdot\left(\mathrm{S}_{2}\right)$ and ${ }^{*} \mathrm{~A}_{\mathrm{g}}\left(\mathrm{S}_{1}\right)$ states. The large absorption shifts are consistent with the large dipole transition moment for the ${ }^{*_{\mathrm{B}}} \rightarrow \mathrm{A}_{\mathrm{g}}\left(\mathrm{S}_{2} \rightarrow \mathrm{S}_{0}\right)$ transition. The much smaller solvent and temperature shifts of the fluorescence spectrum are a reflection of the small transition dipole for the ${ }^{*}{ }_{g} \rightarrow A_{g}\left(S_{1}+S_{0}\right)$ transition.

Hudson and co-workers $[88,90]$ have shown that for many polyenes the positions of the 0-0 absorption and fluorescence bands in solution are given by an expression of the form $\nu=\nu_{0}-a K$ (19) where $\nu_{0}$ is the energy of the transition in the gas phase; $\alpha$ is the solvent polarizability $\left(n^{2}-1\right) /\left(n^{2}+2\right)$ and $n$ is the solvent index of refraction, and $K$ is a constant related to the oscillator strength of the transition. The strong absorption occurs in solution $2000-3000 \mathrm{~cm}^{-1}$ to the red of its gas phase position glving a value for $K$ of about $10^{4} \mathrm{~cm}^{-1}$ per unit change in $\alpha$. values of $K$ obtained from plots of fluorescence frequency vis $\alpha$ are typicaliy a factor of 5 - 20 smaller [88]. Thereiore as $\alpha$ is increased, the 0-0 energy gap $\Delta E_{0-0}$ between the allowed ${ }^{*}{ }_{\mathrm{u}}\left(\mathrm{S}_{2}\right)$ and forbidden ${ }^{*} \mathrm{~A}_{\mathrm{g}}\left(\mathrm{S}_{1}\right)$ state rapidiy decreases. Since this gap is only $1000-2000 \mathrm{~cm}^{-1}$ in the lower polygenes, a significant perturbation can be introduced by fairiy small changes in $\alpha$. 
Andrews and Hudson [91] have used a perturbation theory approach to derive an expression for the solvent dependence of the radiative rate of a foxbidden transition in the presence of vibronic mixing. Their. expressir? has the form

$$
k_{E}=\frac{9 n^{3}}{\left(n^{2}+2\right)^{2}} \frac{\Gamma^{2}}{\left(\Delta E_{0-0}\right)^{2}}
$$

here $\Gamma$ is a constant for a given molecule and $\Delta E_{0-0}$ is the energy difference between the 0-0 bands of absorption and emission. As mentioned above, $\Delta E_{0-0}$ is a strong function of solvent a so that eq. 20 predicts a radiative rate which is very sensitive to solvent polarizability. Analysis of radiative rate data for DPH and trans-retinol in several solvents and over a large temperature range gave quantitative agreement with theory.

Bitrks and co-rorkers $[68,69]$ have used a similar expression

$$
k_{f}=\frac{k_{f 2 \nabla^{2}}}{\left(\Delta E_{0-0}\right)^{2}}=\frac{a^{2} k_{f 20^{v^{2}}}}{\left(\Delta E_{0-0}\right)^{2}}
$$

to describe the solvent and temperature effect on the $S_{1} \rightarrow S_{0}$ radiative rate $k_{f}$ in $D P H$ and $D P O$. In this expression $v$ is the matrix element coupling the $s_{1} \rightarrow s_{0}$ and $s_{2} \rightarrow s_{0}$ transitions. $k_{f 2}$ is the $s_{2} \rightarrow s_{0}$ radiative rate in cyclohexane obtained from the experimental absorption spectrum via the Birks-Dyson relation [17]. $k_{f 20}\left(=k_{f 2} / n^{2}\right)$ has been observed to be iadependent of solvent and temperature for many organic solutes in several solvents [18]. Plots of $k_{f}$ vs $\left(\frac{n}{\Delta E_{0-0}}\right)^{2} \equiv B$ were found to be linear giving v values of $745 \mathrm{~cm}^{-1}$ for $\mathrm{DPH}$ and $500 \mathrm{~cm}^{-1}$ for $\mathrm{DPO}$. As $\mathrm{S}$ increased from about $20 \times 10^{-8} \mathrm{~cm}^{2}$ to about $85 \times 10^{-8} \mathrm{~cm}^{2}$, the radiative rate fur DPH increased from about $3 \times 10^{7} \mathrm{sec}^{-1}$ to about $12 \times 10^{7} \mathrm{sec}^{-1}$. For DPO, B ranged from 
about $15 \times 10^{-8} \mathrm{~cm}^{2}$ to $30 \times 10^{-8} \mathrm{~cm}^{2}$ while $k_{f}$ ircreased irom about

$0.7 \times 10^{6} \mathrm{sec}^{-1}$ to $2.1 \times 10^{7} \mathrm{sec}^{-1}[69]$.

We report here the results of high pressure spectroscopic studies on DPH, DPO; and retinyl acetate in which pressure is used to modulate the energy gap between the borrowing and lending states through its efiect on the solvent-chromophore dispersion interactions. Studies were made to 10 kbar in fluid solution and to $40 \mathrm{kbar}$ in polymer filims . The use of high pressure allows a wide range of $\alpha$ to be attained at room temperature in a single solvent. In addition, pressure studies in plastic media permit.. the attainment of nigher $\alpha$ values than are available by the temperature varlation method.

\section{Experimental Procedure}

2.1 Materials DPU (Aldrich) was recrystallized twice from benzene/hexane and DPO (Aldrich) twice from toluene. Al1-trans retinyl acetate (Sigma) was purified by liquid chromatography on silica gel. After removal of solvent the oily yellow liquid was crystallized and recrystallized from metharol giving fine yellow crystals which were stored under high vacuum in the dark. Methylcyclohexane (MC/B Spectroquality), toluene (Baker Photrex), and perfluoro-n-hexane (Pierce) were used as received. None exhibited significant fluorescence in the spectral region of interest. The polymethylmethacrylate (PMMA) and polystyrene (PS) used in this work were prepared and purified by Mitchell. [92]. Plastic films of about $0.02 \mathrm{~cm}$ thickness contairing the solutes under study were prepared by dissolving the solutes and polymer in methylene chloride and evaporating the solvent over several days under a stream of nitrogen. All films were prepared and stored at room temperature and in the dark. 

dense 9,10-diphenylanthracene film in FiMA $\left(\phi_{f}=1.0\right)$ [93]. The films were held at an angle of $45^{\circ}$ to the incident light and fluorescence was also observed at this angle. Schott cutoff filters were used to prevent scattered exciting light from reaching the detector. DPE and RAc films were excited at $345 \mathrm{~nm}$, and DPO Eilms at $375 \mathrm{~nm}$.

\subsection{High Pressure Emission Experiments The high pressure liquid}

cell and associated emission equipnent have been described elsewhere [2.1]. Polyene solutions $\left(5 \times 10^{-7} \mathrm{M}\right.$ to $\left.1 \times 10^{-6} \mathrm{M}\right)$ were excited into the most intense absorption band. The excltation wavelength (bandpass 0.5 nn) was adjusted at each pressure and for each solvent to give maximum fluorescence intensity. The shift of the excitation maximum was fairiy large over the 10 kbar pressure range necessitating the correction of the cuserved fiucrescence intensities for the output of the xenon lamp-monochromator: combination. The fluorescence incensities were obtained as abcve. Ail intersities were corrected for the change in concentration due to solvent compression. The compressibility of methylcyclohexane (MCH) was taken from sridgman [48]. The Tait equation was used to calculate the compressions of toluene and perfluoro-n-hexane. For toluene the Tait $B$ and $C$ constants of Andersson [94] were used. For perfluoro-n-hexane the 1 atm compressibility was estimated from the value given for perfluoro-n-heptane by Smith and Hildebrand [95] by laultiplying this value by the ratio of the compressibility of n-hexane to that of $n$-heptane. The Tait $C$ was taken to be 0.21 which is the usual value for non-polar liquids. All polyene solutions were deoxygenated as above.

The soild state high pressire cell used for attaining pressures from 4 to $40 \mathrm{kbar}$ has been described elsewnere [6]. The optically derse films used had concentrations between 2 and $5 \times 10^{-3} \mathrm{M}$. 


\subsection{High Pressure Excitation Experiments The high pressure}

apparatus is as above. Polyene solutions were between $5 \times 10^{-7}$ and $1 \times 10^{-6} \mathrm{M}$. The concentrations of the optically dilute polyene films were between 2 and $5 \times 10^{-5} \mathrm{M}$. At each pressure the emission monochromatcr was set at the wavelength of maximum emission and the excitation monochromator was scanned from $300 \mathrm{~nm}$ to longer wavelengths. Cutoff fiiters were used to block scattered exciting light. The observed fluorescence intensities were corrected for the output of the xenon lamp-monochromator combination at each excitation wavelength. The correction factors were obtained by using oftically dense PMA films containing various organic fluorophores as quantum countars. The most useful were azulene (250 nn to $340 \mathrm{nnr}$ ) and dearboethoxyaminoazuiene (290 nm. to $460 \mathrm{~nm})$. A comparison between the dicarboethoxyaminoazulene film and a $3 \mathrm{~g} / 1$ solution of rhodamine $\mathrm{B}$ in ethylene glycol both observed at $45^{\circ}$ to the front surface showed agreement to $5 \%$ Irom 290 to $390 \mathrm{~nm}$ and to $10 \% \mathrm{frcm} 400$ to $460 \mathrm{~nm}$. The 1 stm excitation spectra are virtually identical in shape and in position of the band maxima with the corresponding absorption spectra. The same agreement was cbserved between high pressure absorption and excitation spectra in the folymer f1Ims. A correction for the optical characteristics of the apparatus was determired each time that an excitation spectrum was taken." A skewed Gaussian was fit. to each spectrum as above. Solutions were deoxygenated.

\subsection{Fluorescence Lifetime Measurements Fluorescence lifetimes}

were deterwined by the single-photon technique. The basic set-up has been described [96]. A PRA model 510 nanosecond flashlamp was used for excitation. Fluorescence was isolated with cutoff filters and viewed at $90^{\circ}$ to the direction of excitation by an EMII 98130 fast photomultiplier. A Schoeffel high intensicy monochromator was used to excite DPO and RAC 
golutions at the nitrogen 381 and 337 bandheads respectiveiy. For DPH a deuterium flash at $350 \mathrm{~nm}$ was used. Lifitimes were obtained by Iterative deconvolution using a program obtained from PRA. lieasurements were made on deoxygenated solutions $\left(1 \times 10^{-6}\right.$ to $\left.5 \times 10^{-6} \mathrm{M}\right)$ and on the optically dense films.

$2.6 \Delta E_{0-0}$ Determination In all cases the shift in the 0-0 absorption band with pressure was obtained by fitting the excitation spectra with a skewed Gaussian curve and assuming the shift in the Gaussian maximum was the same as the shift of the 0-0 band. The relative intensities of the different maxima changed little with pressure. Up to $10 \mathrm{kbar}$ in the Iiquid cell for DPH and DPO, the fluorescence bands were sufficiently weli resolved to be taken directly from the observed spectra. A computer fit. was not used because there was a significant redistribution of intensity Into the higher energy vibronic bands with pressure causing large apparent blue shifts. Pressure broadening of the vibronic bands in the polymer films at high pressures (> $16 \mathrm{kbar}$ ) made it very difficult to determine the $0-0$ band location in emission. In these cases, shifts obtained from computer fits and shifts cbtained by eye from the broad spectral maximum were averaged. The experimental values of $\Delta E_{\max -\max }$ at each pressure were normalized to the known 1 atm values of $\Delta E_{0-0}$. These vaiues were calculated using experimental values for the 0-0 band absorption maxima in each solvent studied determined on a Cary 14, and Birks' values of $V_{F}^{0}=24800 \mathrm{~cm}^{-1}$ for DPH and $22035 \mathrm{~cm}^{-1}$ for DPO [69]. In the absence of any vibratlonal structure in the $R A c$ spectra, $\Delta E_{0-0}$ was crudely approximated by subtracting cne-half the sim of the widths of the absorption and erission spectra. 
2.7 Refractive Indices The pressure dependence of refractive 1ndex Eex Eqiuene has been measured by Vedem and Linguwan [86]. For MCH the Ghange in ferfactive index with pressure was asgumed to be the same as fef heheg tage and was also Eaken

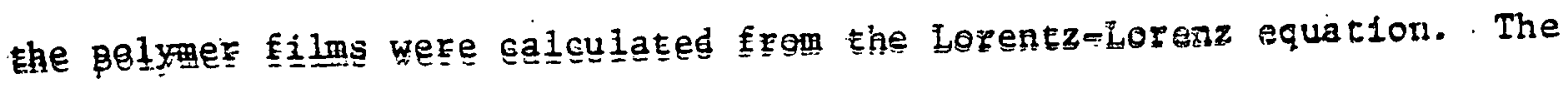

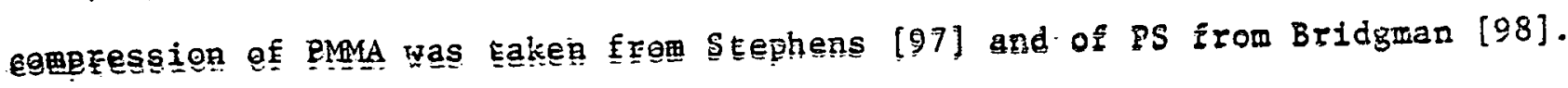

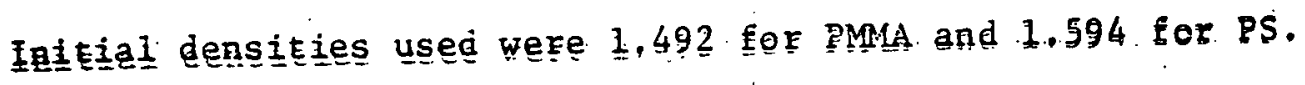

\section{Resultes and Biseussion}

Table IV sumarizes the 1 attm fluorescence quanrum yleld, lifetime, and $\Delta E_{Q=0}$ values obtainged for each polyene

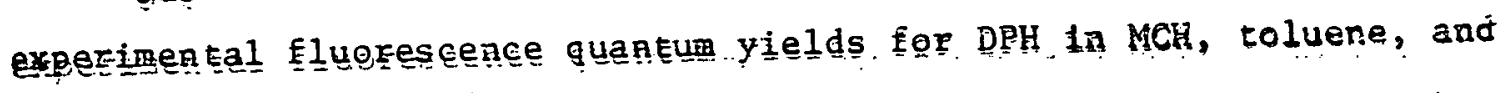
$e_{6}{ }_{14}$ are a factor of $1.25 \pm 0.04$ greater than those for DPH in MCH, beszene, and $e_{6}^{2} 14$ given in

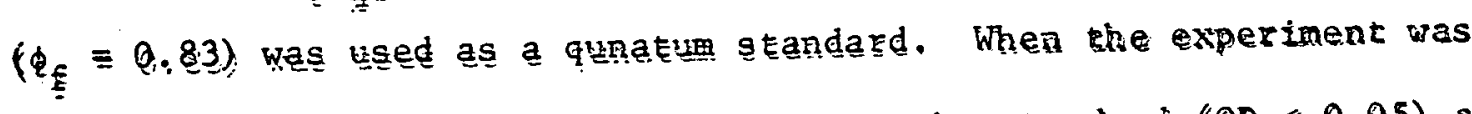
Fepeated using $9.10=$ diphenylantheacene as the standard (OD $<0.05)$ a Elyogescence yield of 0.63 was found for DPH in MCH in good agreement rith Fef g9. QuF Eesultss are similar to those obtained by berman [100] and Bixks and Dyson [17]: DPH lifeEimes and beth DPo yields and lifetimes in Elutid solution afe in excellent agreement with literature values $[68,69,99]$.

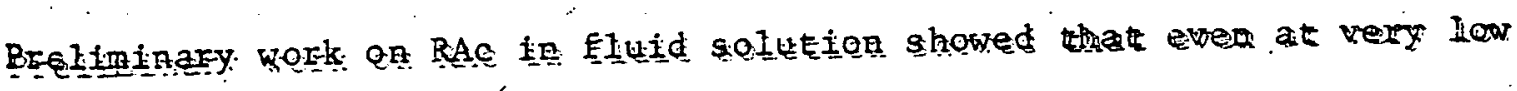

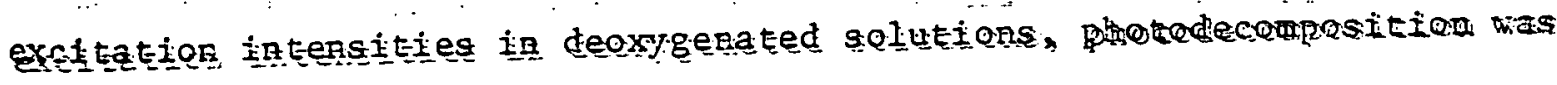

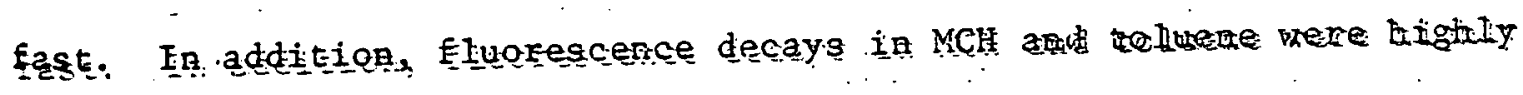
2gn-exponential. Therefore thise polixene was studied aty in poiymer fitms Whase it showed excaltert photostability and flupescence decays were exponentiar. No references to polyene yields or lifetime wher dissoltred in polymeric media could be located in the literature. 
67

Table IV. 1 Atm Fluorescence Yields, Lifetimes, and $\Delta E_{0-0}$ Values

$$
\begin{aligned}
& \phi_{f} \quad \tau_{f} \text { (nsc) } \quad \cdot \Delta E_{0-0}\left(10^{3} \mathrm{~cm}^{-1}\right)
\end{aligned}
$$

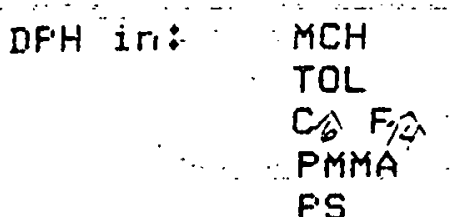

$$
\begin{aligned}
& 0.83 \quad 13.2 \\
& 1.97 \\
& 0.87 \\
& 6.1 \\
& 1.55 \\
& 0.64 \\
& 31.2 \\
& 3.133 \\
& 5.6 \\
& 1.25 \\
& \begin{array}{ll}
\text { IFO in: } & \begin{array}{l}
\text { MuCH } \\
\text { TiL } \\
\text { aMA }
\end{array} \\
& \text { Ff }
\end{array} \\
& 0.09 \\
& 6.6 \\
& 3.12 \\
& 7.2 \\
& 7.1 \\
& 2.72 \\
& 0.11 \\
& 7.0 \\
& 2.40 \\
& 0.11 \\
& 8.7 \\
& 5.7 \\
& \text { PS } \\
& \begin{array}{ll}
0.09 & 8.7
\end{array} \\
& 3.1
\end{aligned}
$$


The peak positions obtained by computer fitting of a skewed Ganssian enrve to the corrected excitation spectra are plotted versis solvent a in Figure 14: The plots are fairly linear (correlation coefficient >.99) in accordance with eq 19. Slopes are 14600 for DPH and DPO, axd 29300 For RAc. These compare to slopes of 10600 for DPE [91] and 10909. For octatetraene [101] from solvent and temperature variation studies. A slope of about 6500 for RAc can be obtained from data in ref 102. The reason.for the very large pressure-induced shifts in RAc is uniknown.

Figure 15 shows the shifts of the excitation and ewission spectra for DPL and DPO to $10 \mathrm{~kb}$ ar versus solvent compression. The much larger shift of absorption relative to emission is quite evident. Also of interest are the aimost identical absorption shifts of DPH and DPO in the solvents studied. In Figures 16 and 17 are shown the shifts to $40 \mathrm{kbar}$ in FMA and PS. The absorption shifts for DPO and RAC are much larger than the emission whifts. However, this is not the case for DPH. The DPH enission shift is comparable to the absorption shift and even appears to be increasing faster than the absorption shift at high pressures. This shift is much larger than any attainable for DPH by solvent variation or low temperature experiments and is unexpected. One possibility based on Birks' [103] general model for polyenes of potential interaction of the ${ }^{*} A$ and ${ }^{*} B$ potentials via a vibrational mode of $b_{u}$ symetry, is that sufficiencly high pressures distort the potential surfaces so as to cause increased mixing of the ${ }^{*} A$ and ${ }^{*}$ wavefunctions resulting in a more " $B$-like" $S_{1}$ potential. In general, shifts are larger in the more polarizable PS than in PIIA.

Figure 18 exhibits the effect of solvent compression on the absolute fluorescence yields and lifetimes of $\mathrm{DPH}$ in $\mathrm{MCH}$ and toluene. DPH yields 


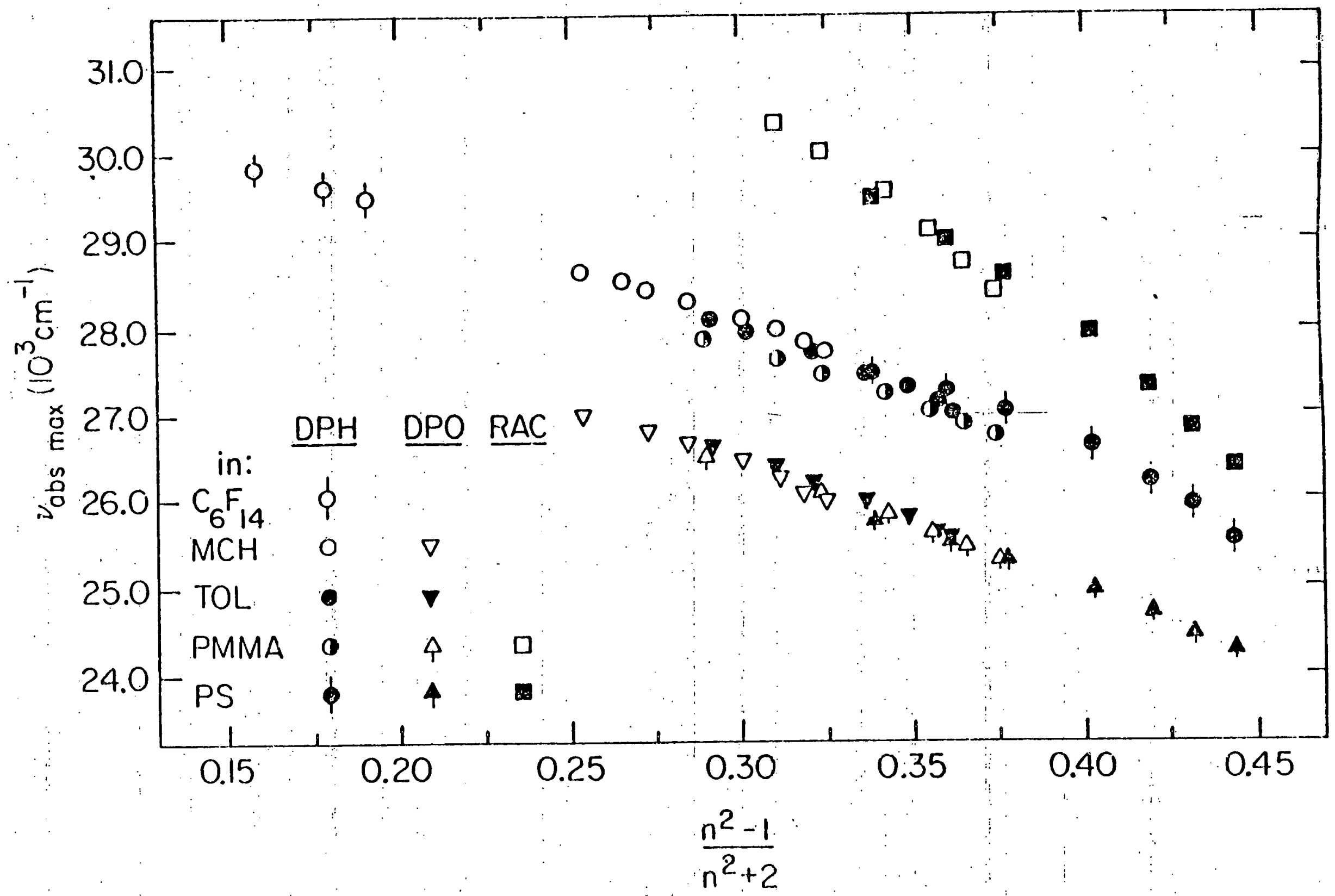

옹

Figure 14. linergy of Absorption Spectrum Centrold vs. Solvesit a 


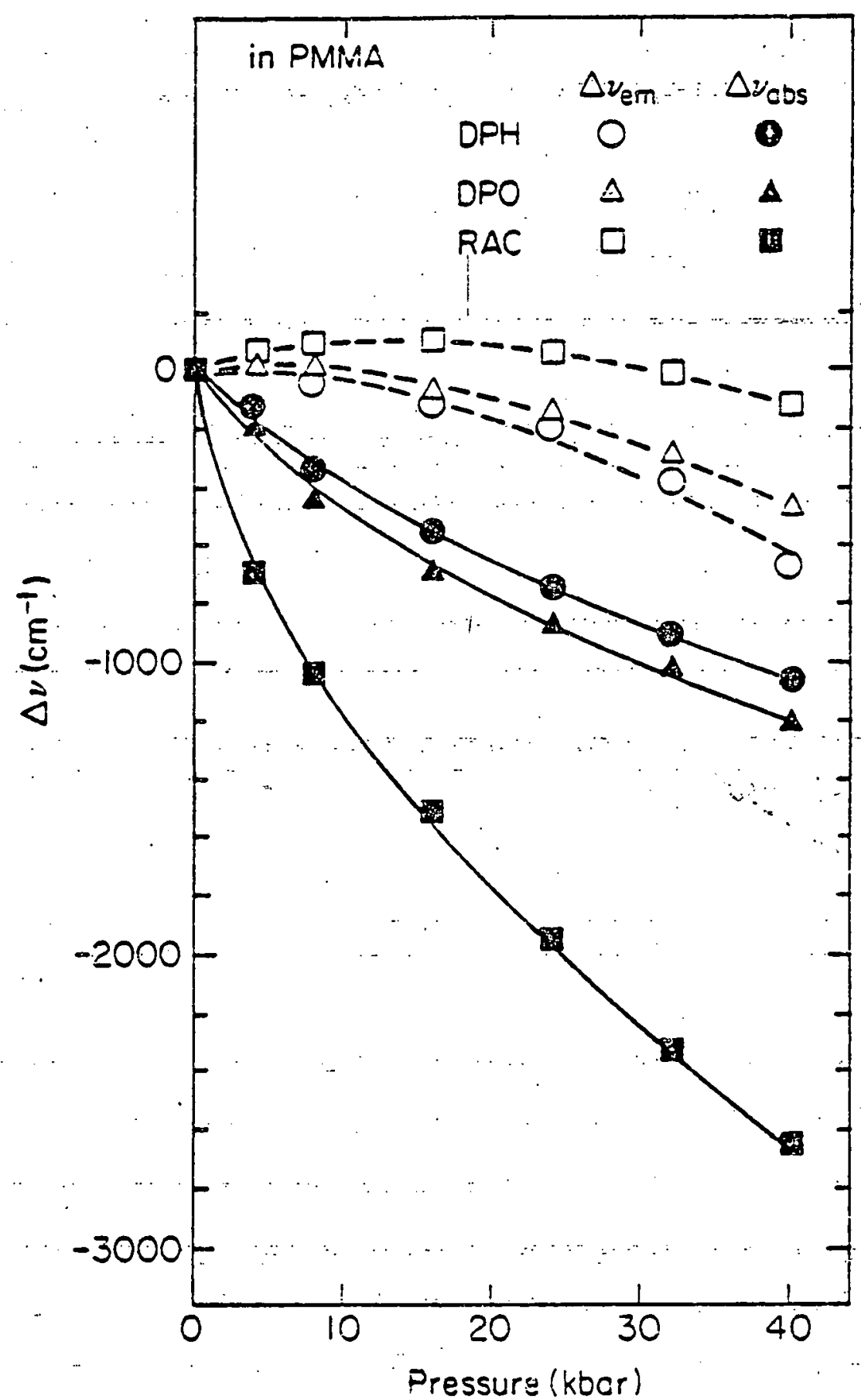

Figure 16. Absorption and Emission Shifts in PMAA 


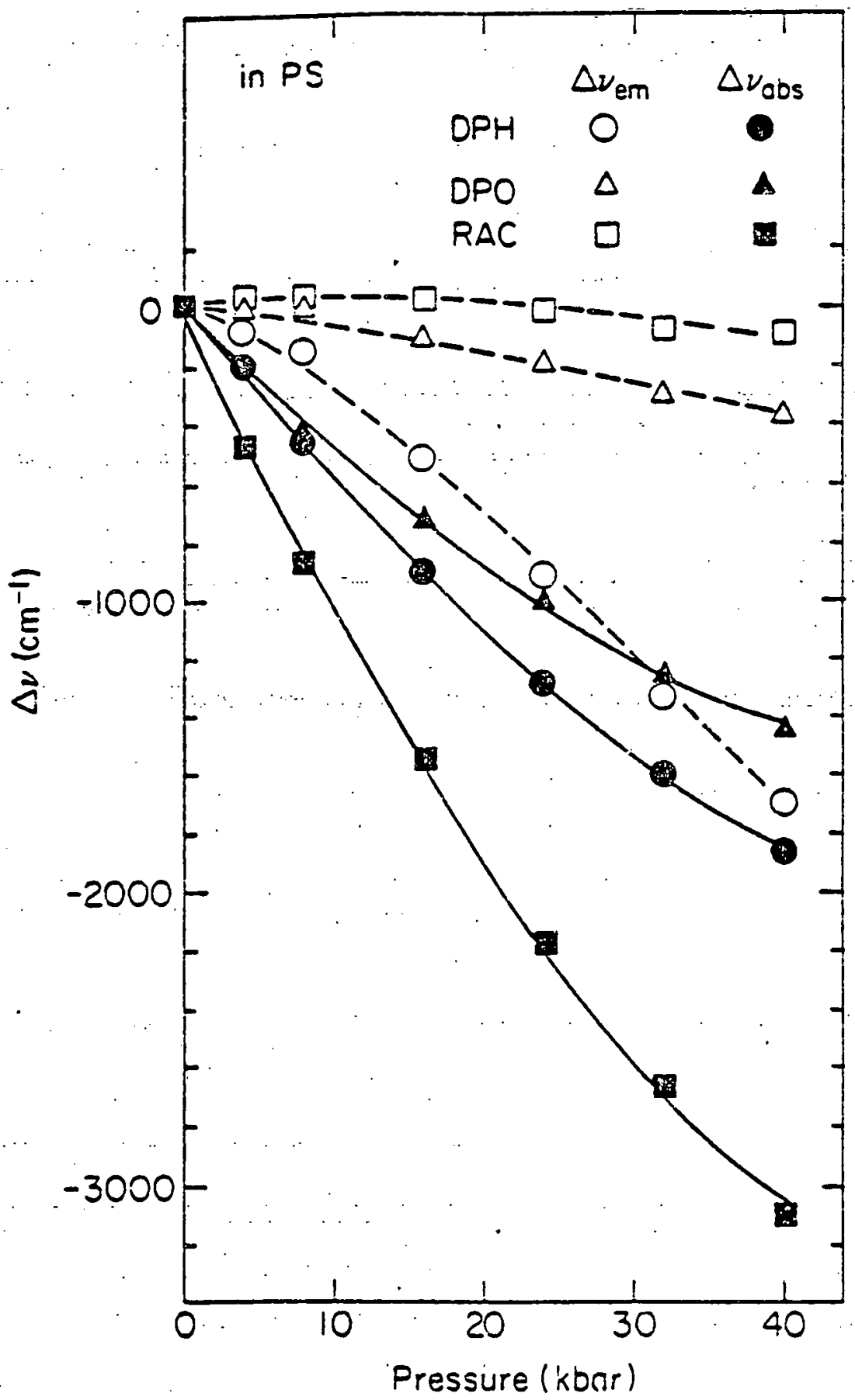

Figure 17. Absorption and Emission Shifts in PS 


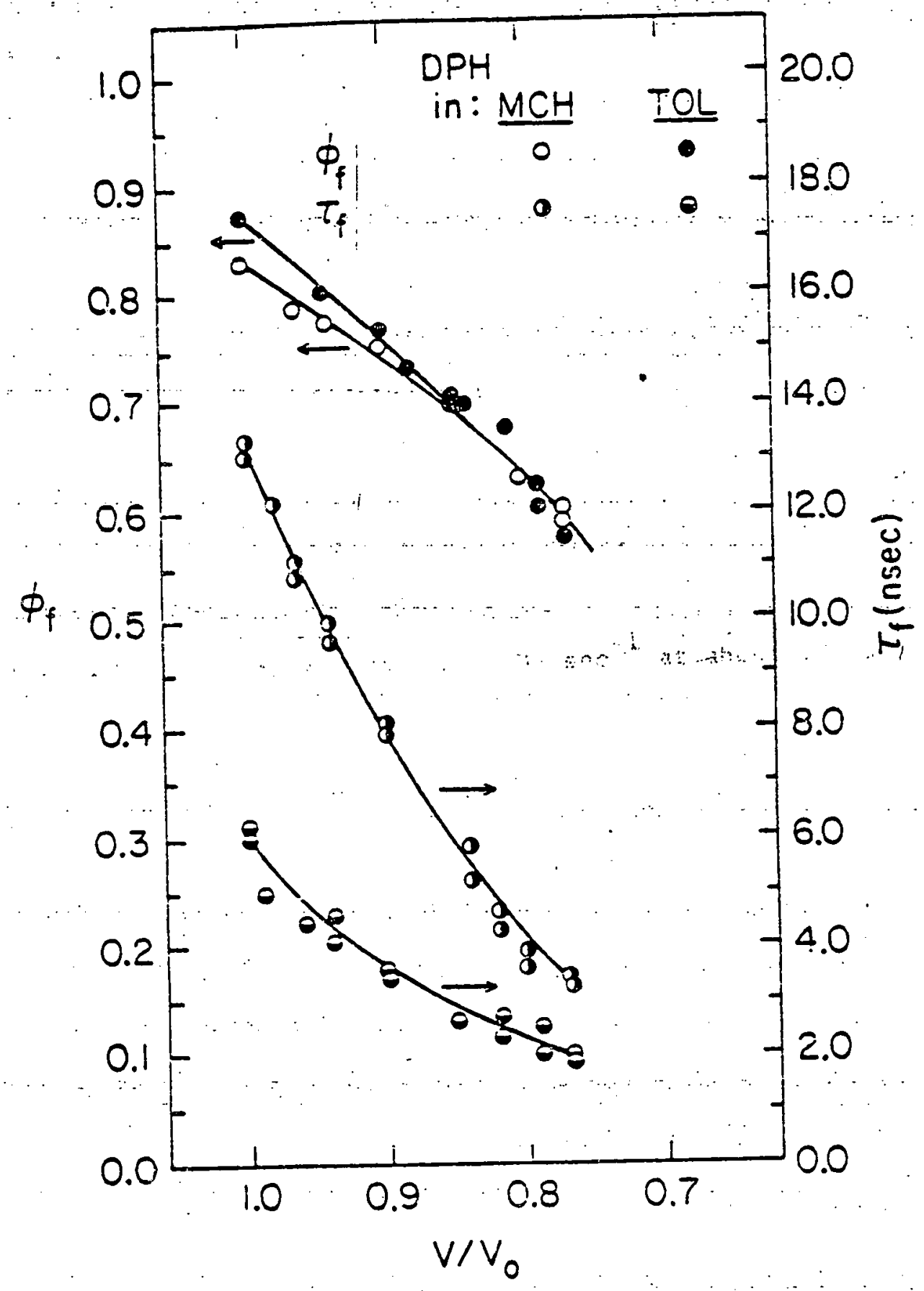

Figure 18. DPH Fluorescence Yields and Lifetimes
vs. Solvent Compression 
decrease about $30 \%$ in the 10 kbar pressure range. while the lifetime drops - to $1 / 4$ of its 1 atm value in $\mathrm{MCH}$ and to $1 / 3$ of 1 ts 1 atm value 10 toluene. It.is Interesting to compare these data with those obtained by Cehelnik and co-workers [99] in $\mathrm{MCH}$ at temperatures from $100^{\circ} \mathrm{C}$ to about $-100^{\circ} \mathrm{C}$. The solvent volume contraction in this range is approximately the same as that produced by a pressure of $10 \mathrm{kbar}$. However, the effect on $\phi_{f}$ and $\tau_{f}$ is quite different. $\phi_{f}$ increases by a factor of about 2 while $\tau_{f}$ decreases about $20 \%$. The radlative rates $\left(=\phi_{f} / \tau_{f}\right)$ in both experiments therefore increase by about the same factor as predicted by the Lorentz-Lorenz equation and eqs 19 and 20 . The striking differences in the observed behavior of $\phi_{\dot{f}}$ and $\tau_{\dot{f}}$ must be ascribed to large pressure and/or temperature effects on the non-radiative rates. For-example; in MCH the non-radiative rate $k_{n r}\left(=1 / \tau_{f}-k_{f}\right)$ decreases from $4.2 \times 10^{7} \cdot \sec ^{-1}$ at about $100^{\circ} \mathrm{C}$ to about $0.8 \times 10^{7} \mathrm{sec}^{-1}$ at $-100^{\circ} \mathrm{C}$. When roughly the same volume decrease is obtained upon application of $10 \mathrm{kbar}$ pressure, $\mathrm{k}_{\mathrm{nr}}$ increases from about $1.1 \times 10^{7} \mathrm{sec}^{-1}$ to about $12.1 \times 10^{7} \mathrm{sec}^{-1}$. The nature of the non-radiative transition in the high pressure experiments is not clear. It is unlikely to be $S_{1} \rightarrow S_{0}$ internal conversion because" the theoretical value for the internal conversion rate $k_{I C}$ is only about $10^{6} \mathrm{sec}^{-1}$ for a molecule such as $\mathrm{DPH}$ with an $\mathrm{S}_{1}$ energy of about $25000 \mathrm{~cm}^{-1}$. In the simplest diphenylpolyene, trans-stilbere, the dominant $s_{1}$ radiationless transition is the thermally activated internal rotation around the central ethylenic bond [60]. Birks and co-workers [69] have proposed a similar pathway for DPH. Such a model is consistent with the observed decrease in $k_{n r}$ as the temperature is lowered. In stilbene, however, the rate of the internal rotation has also been found to be significantly viscosity-dependent $[64,104]$. As solvent viscosity is increased by high pressure or other means, the rate 
of rotation decreases and at very high viscosities, ceases entirely [104]. The increase in. MCa viscosity in $10 \mathrm{kbar}$ is sufficient to cause a factor of about 4 decrease in $k_{n r}$ for stilbene. For the same increase in viscosity, a factor of 10 increase in $k_{n r}$ is observed for DPH. The same large increases in $k_{n r}$ are observed in the plastic films. It therefore seems likely that high.pressure is opening an important new radiationless pathway in DPH. One possibility is intersystem crossing to the triplet manifold. This would require that: the 1 atm $s_{1}+T_{1}$ yields $\left(\phi_{\text {ISC }} \approx 0.02\right) \cdot[105]$. Increase dramatically with pressure. No experimentally significant change in $k_{n r}$ was observed for DPO in fluid solutions. In the polymer films, $k_{n r}$ for DPO increased from about $1.3 \times 10^{8} \mathrm{sec}^{-1}$ at 1 atm in both PMMA and PS to $1.8 \times 10^{8} \mathrm{sec}^{-1}$ in PMMA and $2.9 \times 10^{8} \mathrm{sec}^{-1}$ in PS. FCr RAc, $k_{n r}$ increased from about $1.0 \times 10^{8} \mathrm{sec}^{-1}$ in both PMMA and PS to $1.4 \times 10^{8} \mathrm{sec}^{-1}$ in PMMA and $2.0 \times 10^{8} \mathrm{sec}^{-1}$ in PS.

Figure 19 shows $\phi_{f}$ and $\tau_{f}$ for DPO in the liquid cell. $\phi_{f}$ increases by about $70 \%$ while $\tau_{f}$ decreases about $5 \%$ over the 10 kbar pressure range. Figures 20 and 21 are plots of $\phi_{f}$ and $\tau_{f}$ vs pressure in the plastic films. For DPH, $\phi_{f}$ shows an initial decrease with pressure followed by an increase. $\tau_{\mathrm{f}}$ decreases rapidly with pressure as it did in fluid solution. At high pressuzes in PS, $\tau_{\mathrm{f}}$ seems to reach a limiting value of about 1.7 nsec. The. changes in $\phi_{f}$ and $\tau_{f}$ for DPO in the plastics are qualitatively similar to those observed in the liquid cell only of greater magnitude. RAc.shows a moderate gain in $\phi_{f}$ finally levelling off and perhaps even decreasing slightly at the highest pressures. ' $\tau_{f}$ is observed to increase slightly at Low pressure, but to decrease at a rate about equal to that of DPO at higher pressures. 


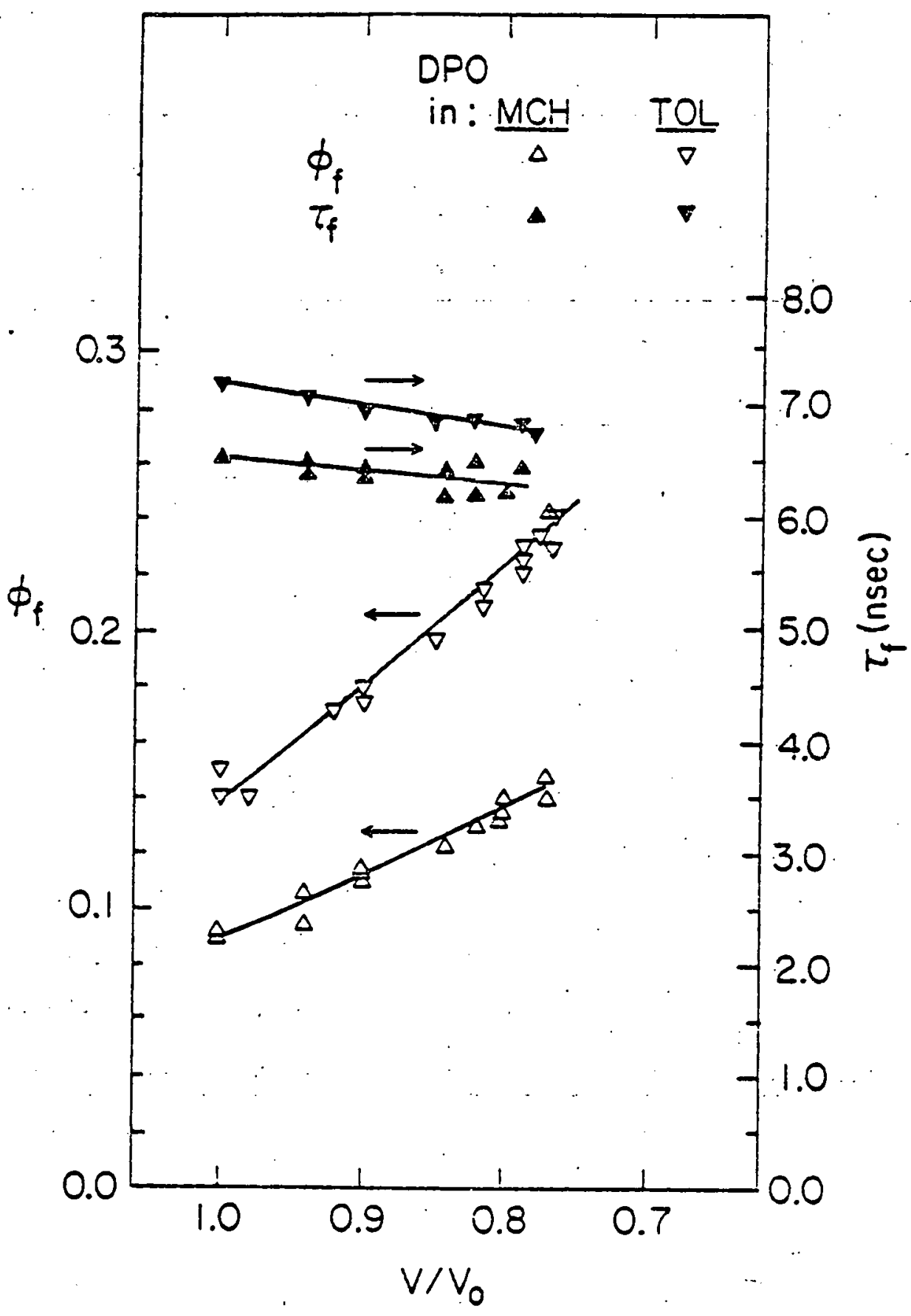

Figure 19. DPO Fluorescence Yields and Lifetimes vs. Solvent Compression 


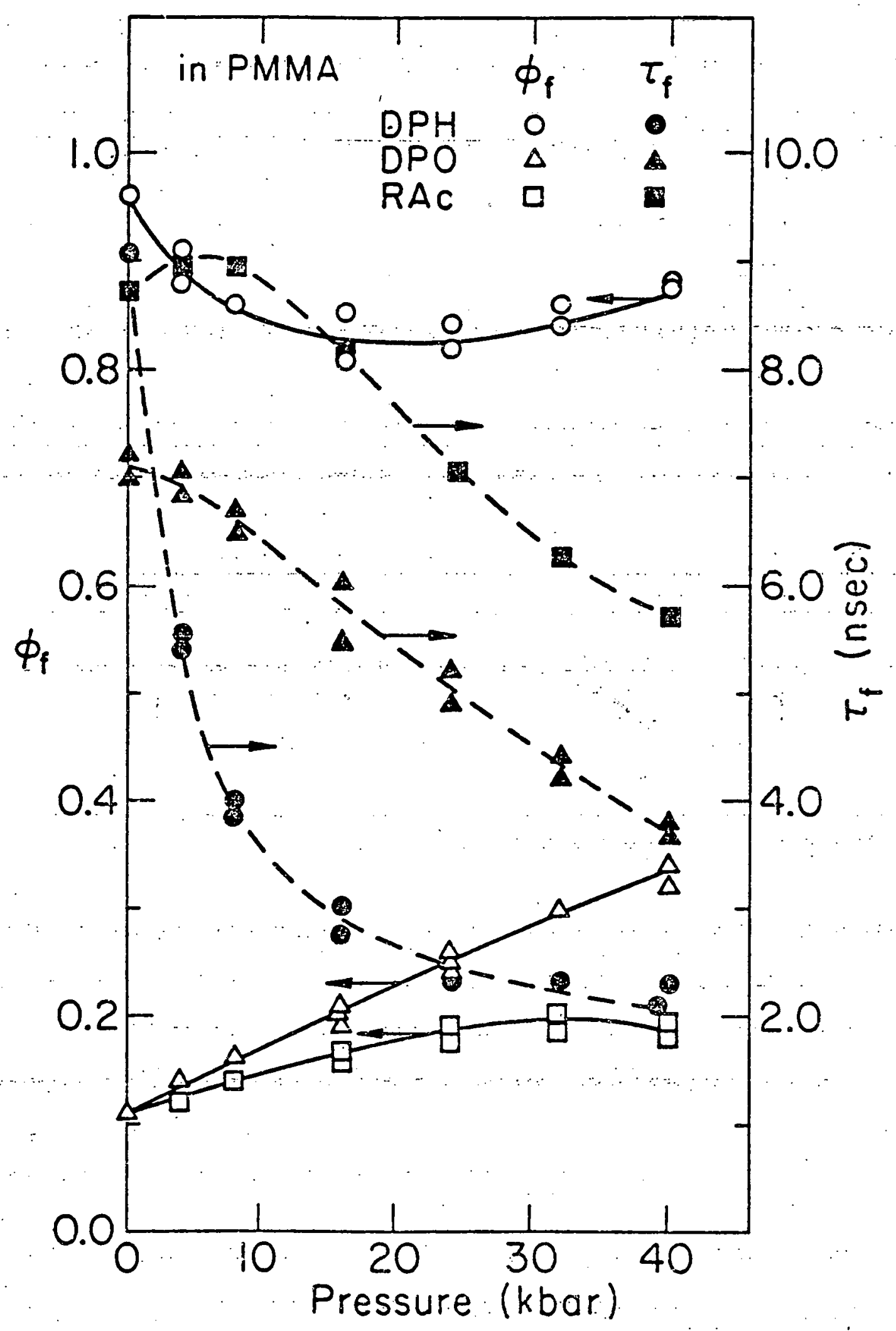

Figure 20. Polyene Fluorescence Yields and Lifetimes in PMMA vs. Pressure 


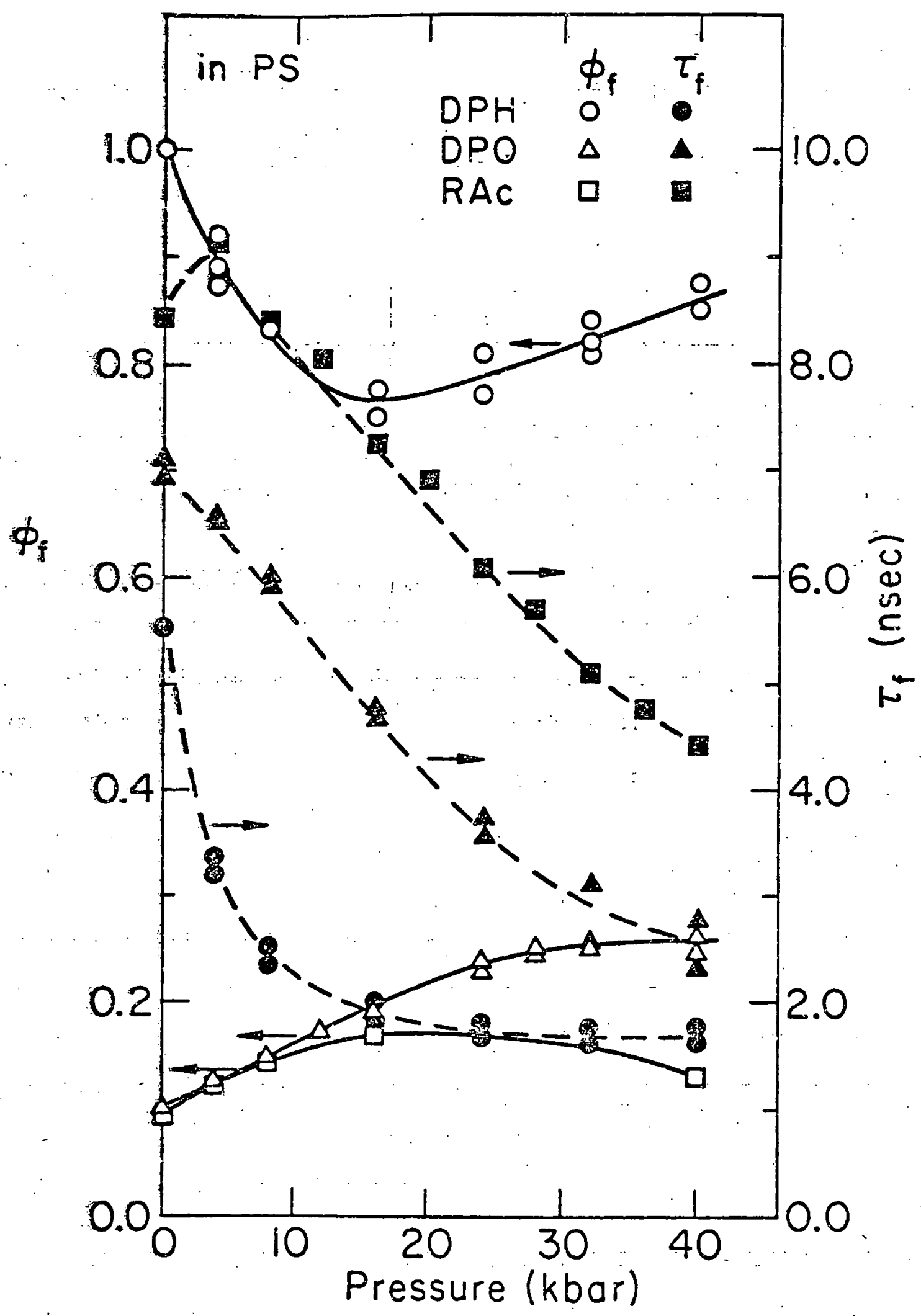

Figure 21. Polyene Fluorescence Yields and Lifetimes in PS vs. Pressure 
Figure 22 presents quantum yields, fluorescence lifetimes, - and the shifts in absorption and emission for DPH in perfluoro-n-hexane to $10 \mathrm{kbar}$. At room temperature this solvent freezes at a pressure between 1.5 and 2.5 rbar. There was considerable variation of freezing pressure within these linits from run to run. The 1 atm $\tau_{f}(31.2 \mathrm{nsec})$, is considerably larger than that observed in other solvents. As pressure is applied, it rapidly decreases until at about 1.5 kbar it is 22 nsec. "Upon further application of pressure the solvent freezes and $\tau_{\tilde{f}}$ suddenly drops to about $11 \mathrm{nsec}$ and continues to decrease as the ice is further compressed. There is also a discontinuous red shift of about $1500 \mathrm{~cm}^{-1}$ in the position of the absorption maximum upon freezing.

In Figures 23 and 24 are shown the effect of pressure on the radiative rates $k_{f}$ for each polyene in each solvent. In each case $k_{f}$ increases with pressure. This is in accord with eq 21 since the $0-0$ gap between $S_{1}$ and $S_{2}\left(\Delta E_{0-0}\right)$ in the right hand denominator of eq 21 is decreasing with pressure. of lesser importance is the increase of $n$ with pressure. The highest values of $k_{f}$ for DPH and DPO observed in the pressure experiments are approximately 5 times larger than the highest $k_{f}$ attainable by other methods.

Figures 25 and 26 plot $k_{f}$ vs $B$. Figure 25 shows data for DPH and DPO in the liquid cell" all to $10 \mathrm{kbar}$ except for DFH in $\mathrm{C}_{6} \mathrm{~F}_{14}$ (which freezes above $1.5 \mathrm{kbar}$ ) and DPH in toluene. For DPH in toluene only the 1 atm and $0.5 \mathrm{kbar}$ points are shown. At higher pressures $\Delta E_{0-0}$ becomes so small ( $650 \mathrm{~cm}^{-1}$ at $9 \mathrm{kbar}$ ) that 3 blows up. The dashed lines are the best fit to temperature and solvent variation data from reference 69. They are extended to the limit of the data in reference 69. The close agreement between cur data and Birks' for DPH is somewhat fortuitous since our $\phi_{f}$ 


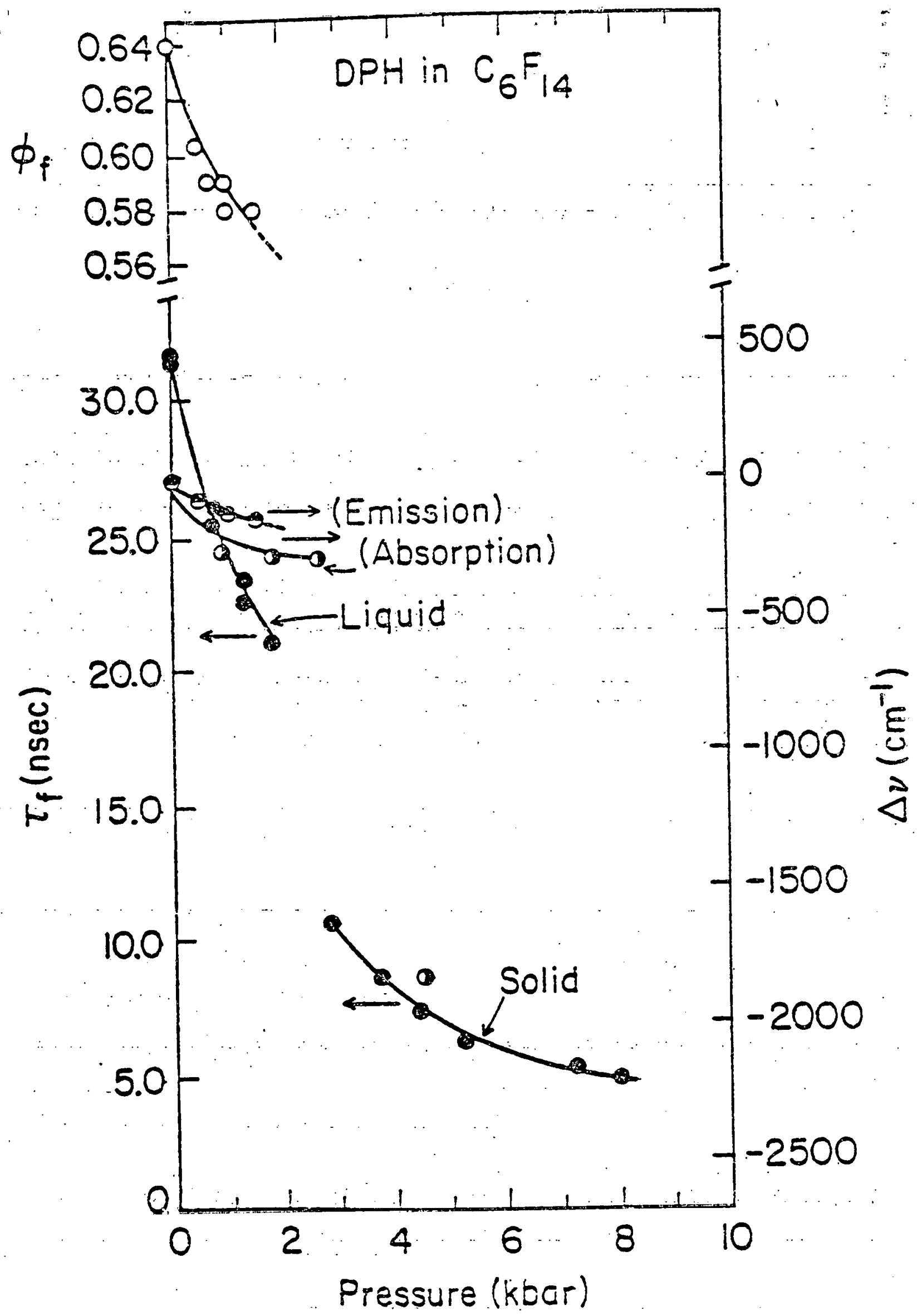

Figure 22. DPH Fiuorescence Yields, Lifetimes, and Shifts in $C_{6}{ }^{F} 14$ 


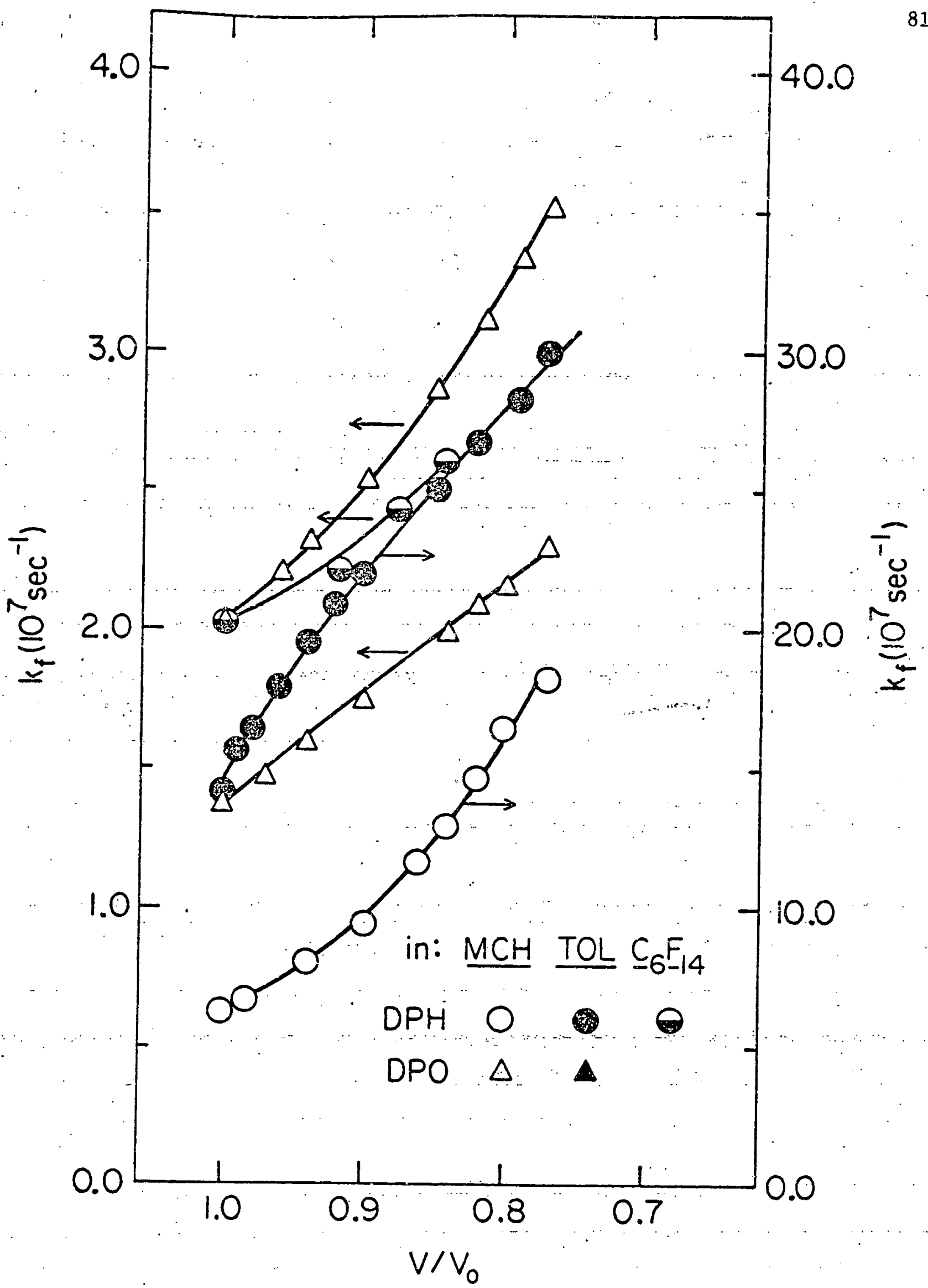

Figure 23. Polyene Radiative Rates in Fluid Solution vs. Solvent Compression 


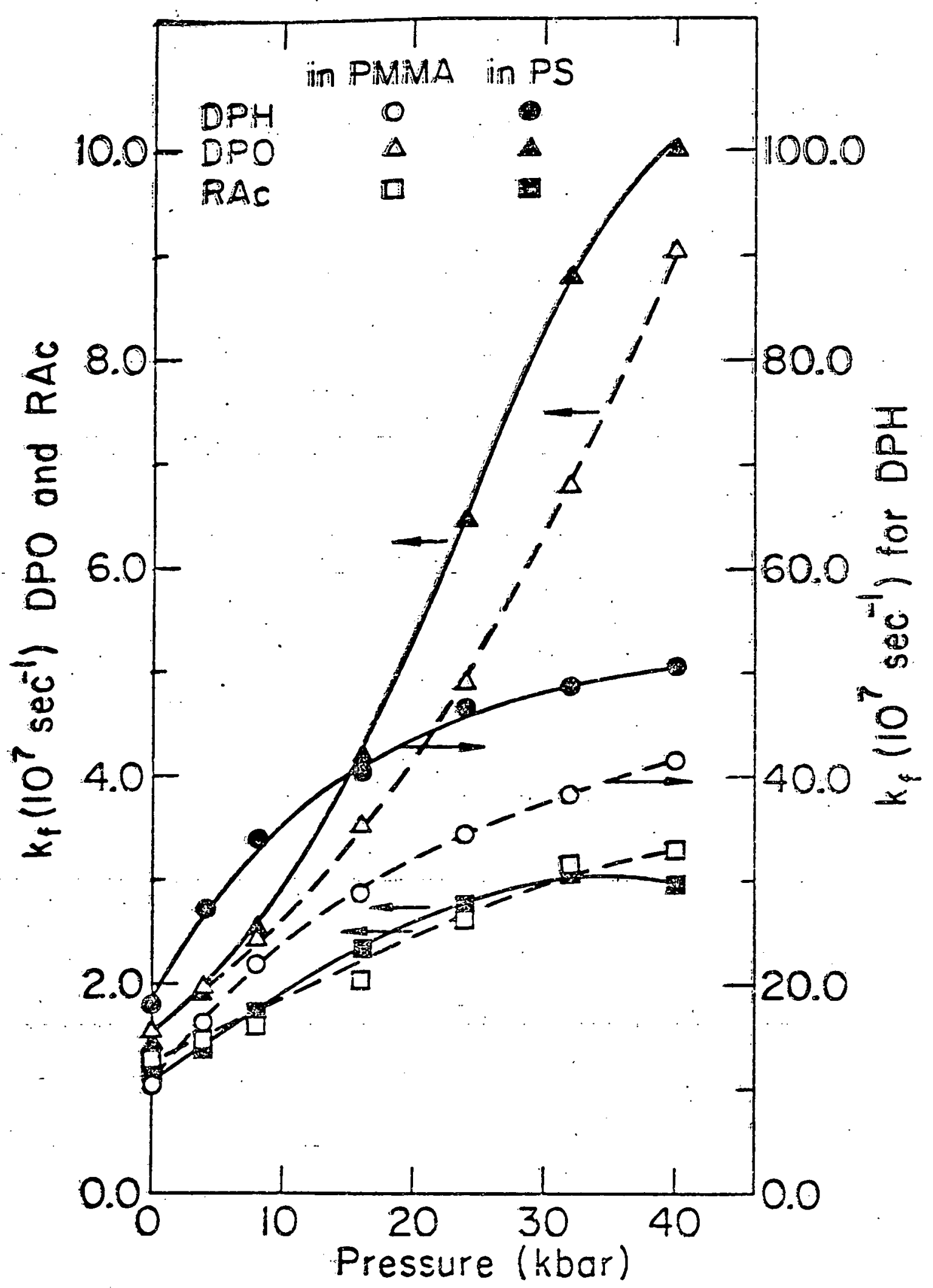

Elgure 24. Polyene Radiative Rates in Plastic Media vs. Pressure 


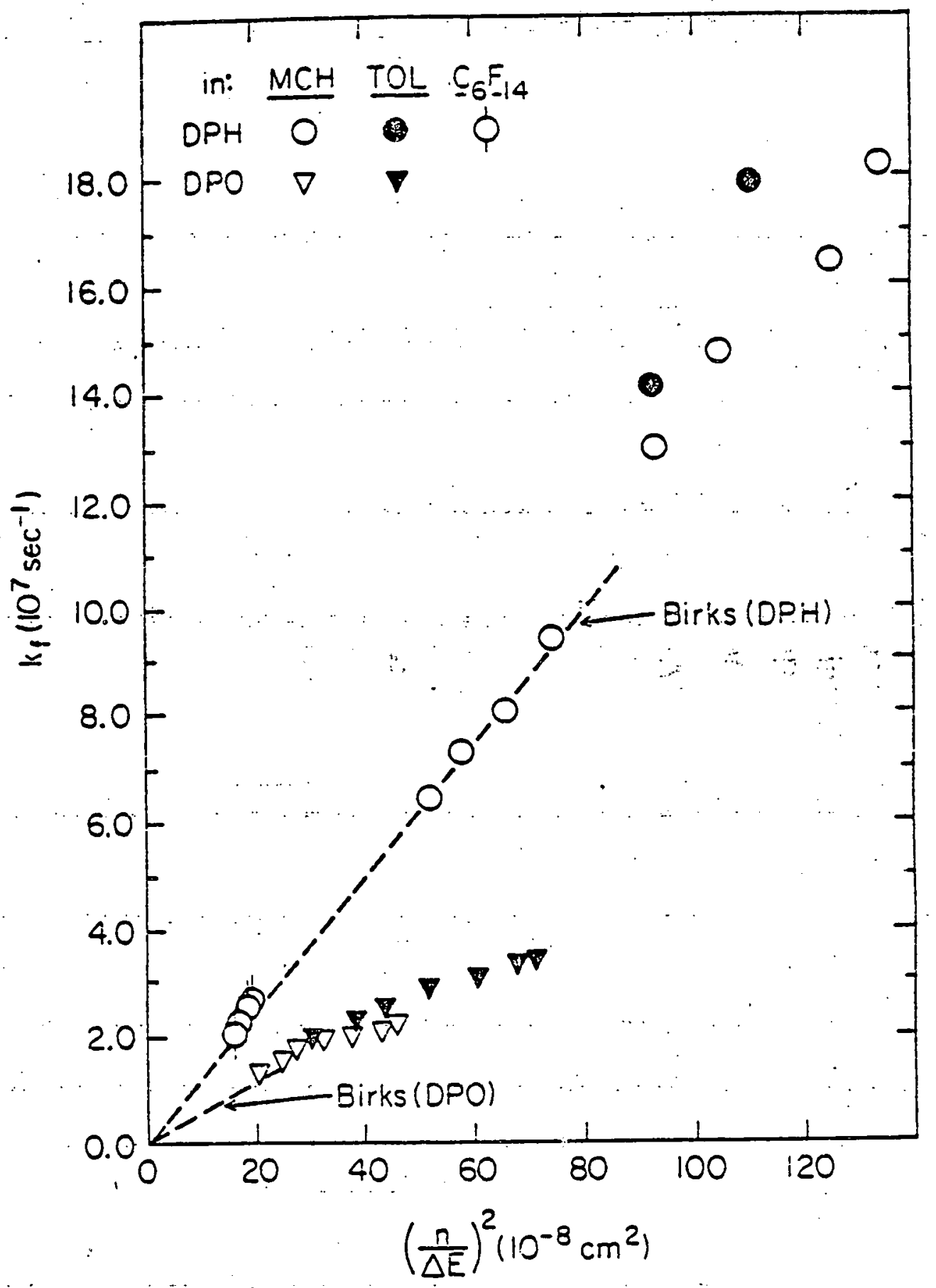

Figure 25. Polyene Radiative Rates in Fiuid Solution vs. $\left(\frac{n}{\Delta E_{0-0}}\right)^{2}$ 


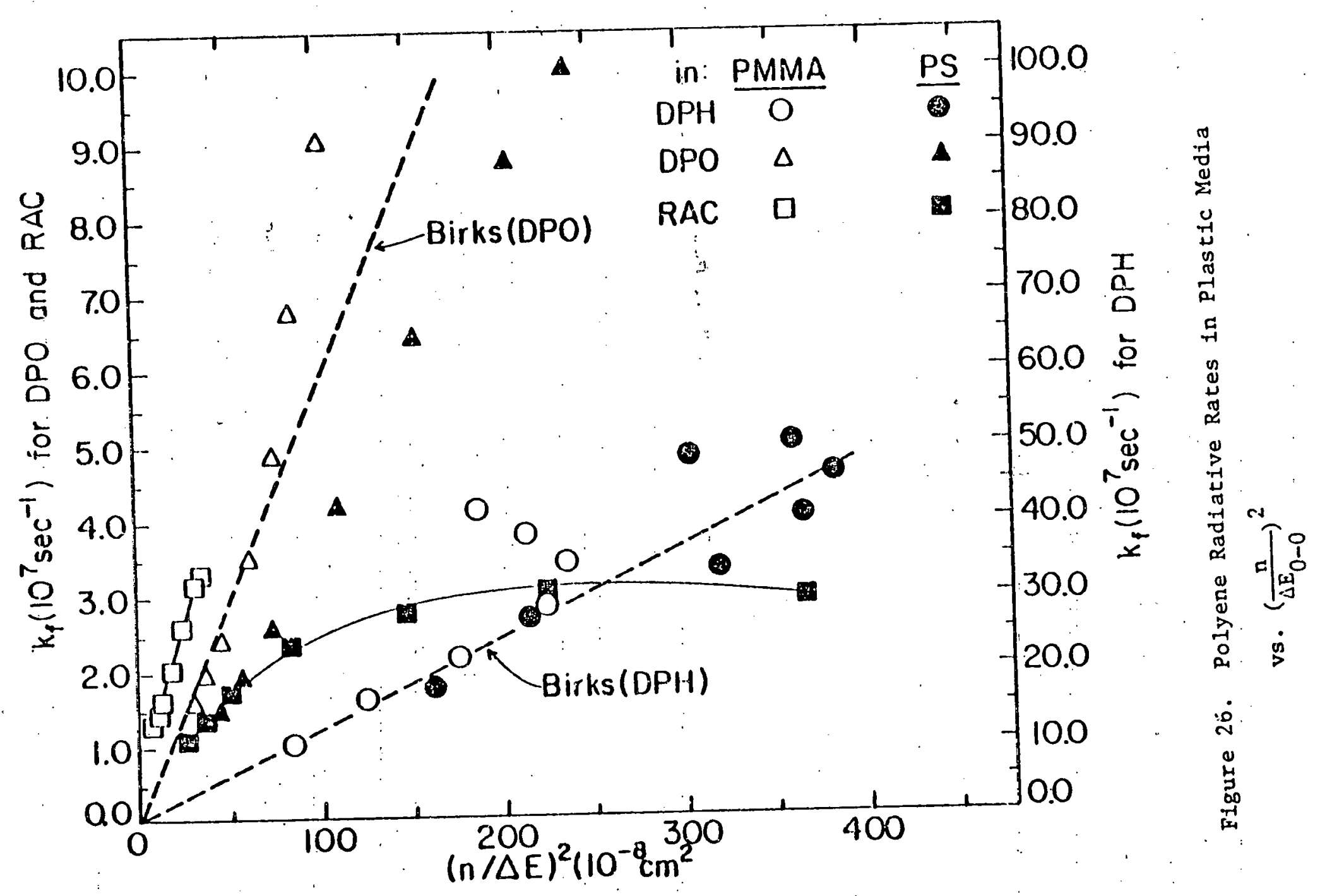


values are a factor of $1.25 \pm 0.04$ greater than those used by Birks which were taken from reference 99 (see experimental section). Our data for DPO closely follow. Birks' extrapolated data over much of the experimental range. The fairly small deviation at high 3 values is judged to be within the possible experimental error. Figure 26 presents the data for the three polyenes in polymertc media to $40 \mathrm{kbar}$.. The dashed lines are extrapolated from Birks. Note the larger range of $\beta$ attained in the plastics over that in fluid solution, except for $\mathrm{DPH}$ in toluene, for which $\Delta \mathrm{E}_{0-0}$ decreases to about $650 \mathrm{~cm}^{-1}$ at 9 kbar due to the much larger red shift of absorption relative to emission. Although the absorption red shift in the plastics is equal or greater to that in toluene, it is counterblanced by the large emission red shift resulting in smaller values of 3. For DPH our data and the extrapolation of Birks' data are in good agreement. The scatter at high values is due both to the increased uncertainty in determining $\Delta \mathrm{E}_{0-0}$ at nigh pressures as the result of pressure broadening of the emission and to the sensitivity of $\beta$ to the exact $\Delta E_{0-0}$ used for $\operatorname{sma11} \Delta E_{0-0}$

The pressure data for DPO fail to either side of the extrapolated 11ne. The differences in behavior between the PMMA and PS films appear to be larger than can be accounted for by any likely experimental error. Although small errors in $\Delta E_{0-0}$ can cause large changes in the calculated parameters at high pressures (i.e., $\Delta E_{0-0}$ small) their effect is much smaller at low pressures. The observation that even at low pressures the data points in PMMA and PS do not fall on the same line süggests that the ifscrepancy is a real one.

A similar situation arises for RAc. Althougin the crude procedure. used to obtain $\Delta_{0-0}$ Erom these structureless spectra (see experimental 
section) may result in large errors, the low pressure values of 3 should be falfly insensitive to.them. - Again, the data points fall on different curves as Eor DPO.

\section{Conelizions}

High pressure can be used to perturb signficantiy the Lonic ${ }^{*}{ }_{u}$ state In all linear polyenes studled, while leaving the covalent "A state. essentially unaffected in DPO and RAC. If the unexpectedly large presisureInduced shifts in ${ }^{*}{ }_{U}$ for RAc are a general feature of the retinyl polyenes, potentially interesting changes in their photochemical behavior could be produced by high pressure.

Eq 21 can be used to calculate the changes in radiative rate $k_{\text {f }}$ for DPH upon modulation of the energy gap between the lendiag $\left({ }^{*}{ }_{u}\right)$ and borrowing ( $\left.{ }^{*} A_{g}\right)$ states by high pressure just as it can for solvent and temperature induced gap changes. It appears to also holo to a slightly lesser degree for DPO, but to fail for RAc.

The DPH nori-radiative rate is affected by high prossure in a very. ifferent way than by lowering the temperature contrary to expectations based en simple solvent density arguments. The non-radiative rates for DPO and RAc are wuch less affected by pressure. 
FUMIARY

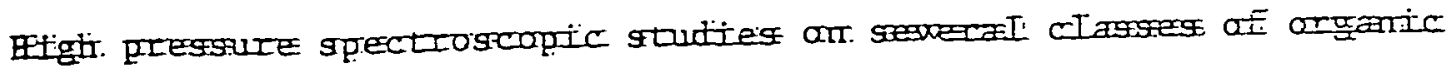

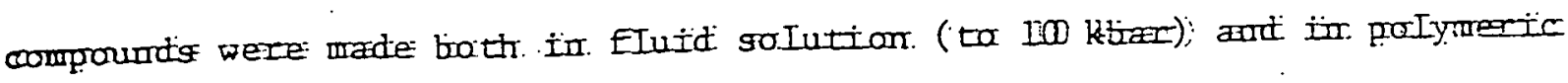
medif (to $40 \mathrm{kbar}$ ). The first three studies weme contucteat in: Elurif

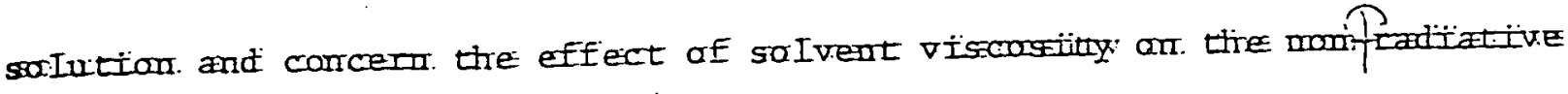

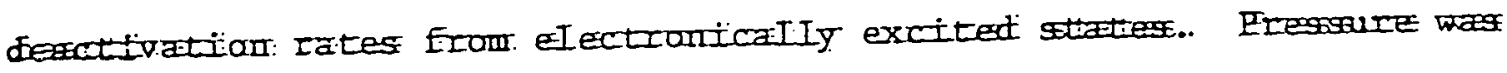

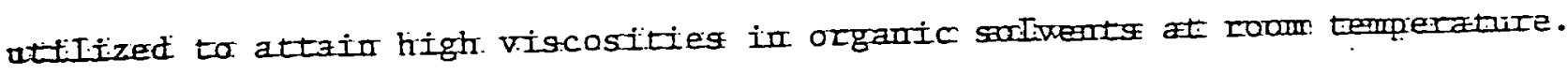

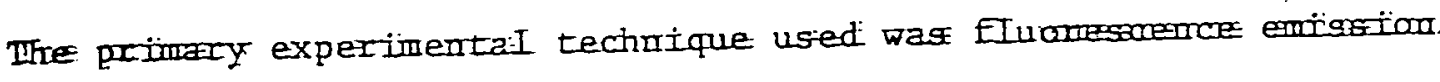
spectrascopy. In. the fourth and Iast study absenwions wexe madie bati

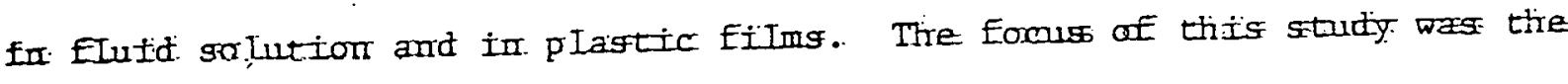
effect of pressure on. the soivent-chromophore dïspenstion: interaction ïr severaI poIyenes and the concomitant changes Im bouth the caditative and mon-radiative rates from the excrited states. Extrensive use was made of Elworescence Iifetime measurements and excitation spectra. of the dyes crystal violet and auramine 0 shows a Inoge timcrease as solvent

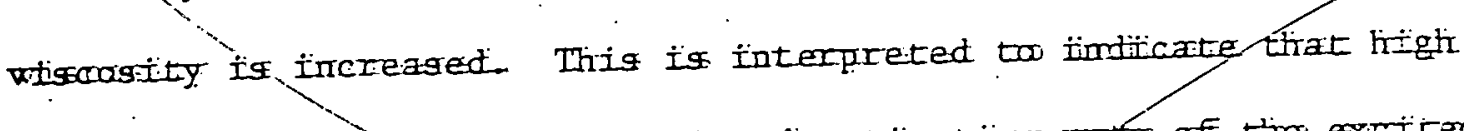

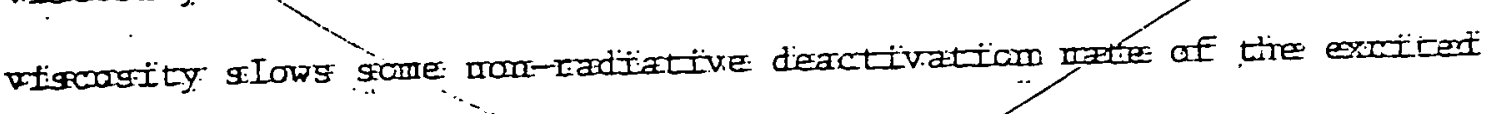

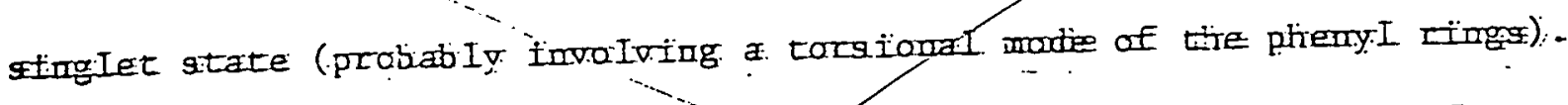

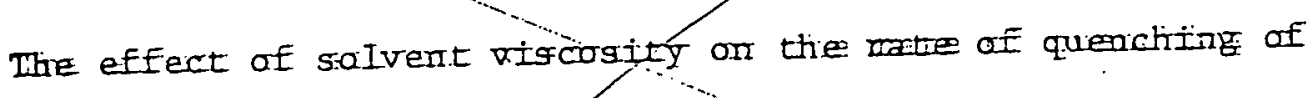

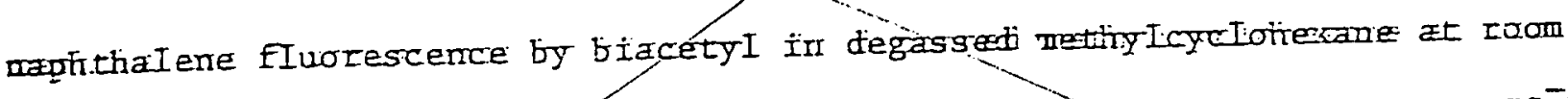

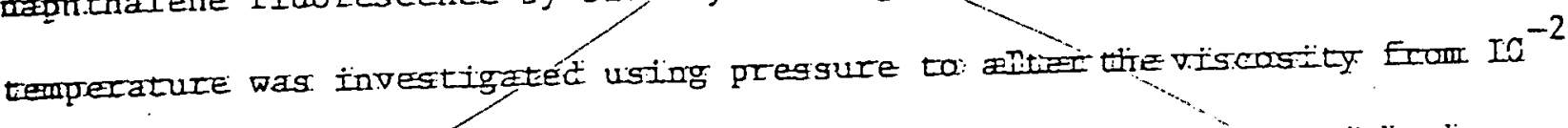

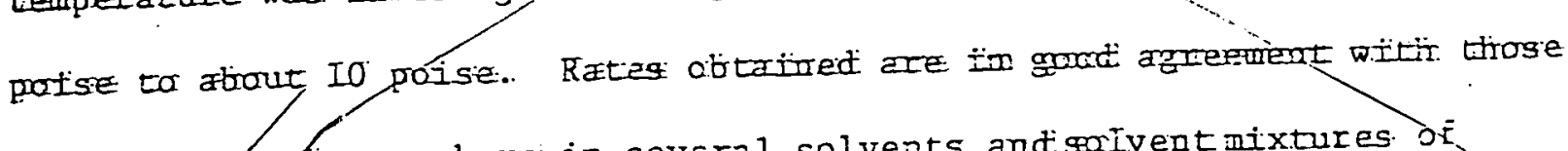
measured

in several solvents and gaiventmixtures of 
SUMAMARY

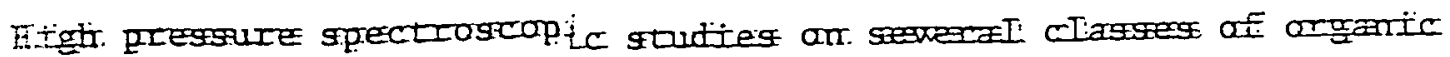

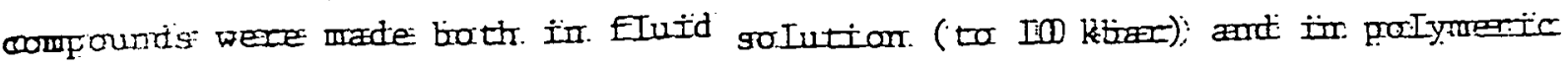

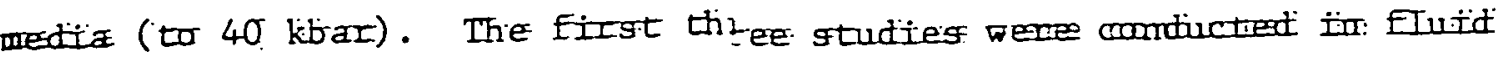

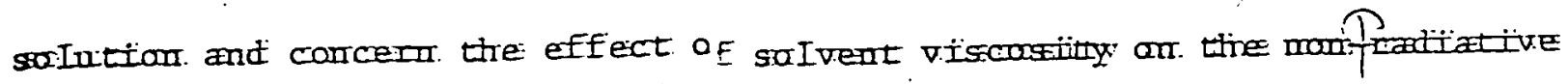

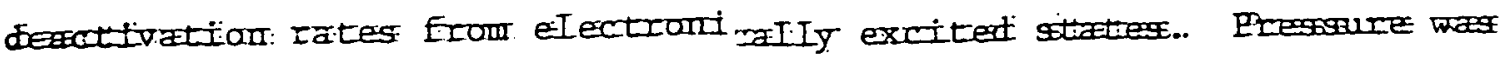

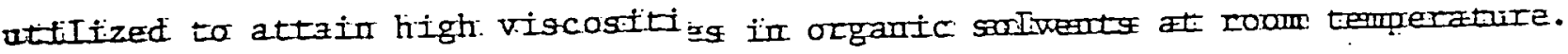

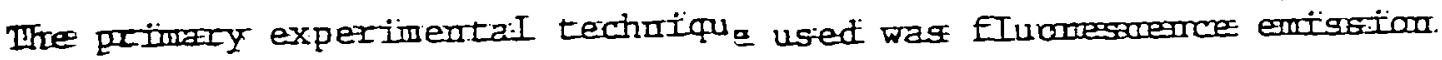
spectroscopy. In. the Eourth. and last gtudy: obserwatians were made bathi fin flutid solution and in plastic EiIms. The focuss of this study was the efect of pressure on. the soIvent-chromaphore dispenstion interaction Ïn

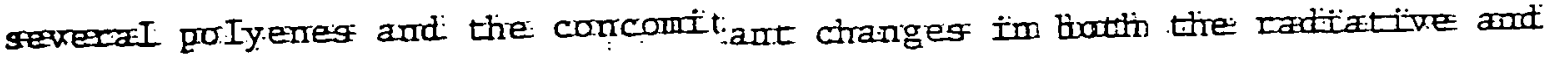
mon-cadiative rates from the exci.ted states. Extensive uge was made of Fivorescence Iiferime measurement.g and excitation spectra-

In the IIISt stridy It was abserved- that tine Eluncescence efficienty

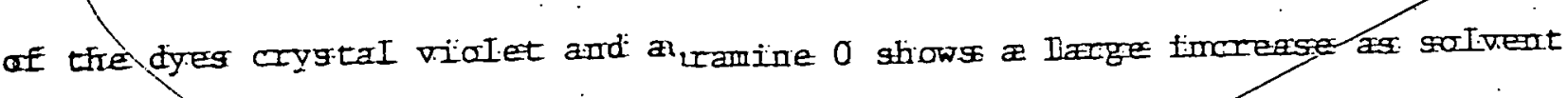

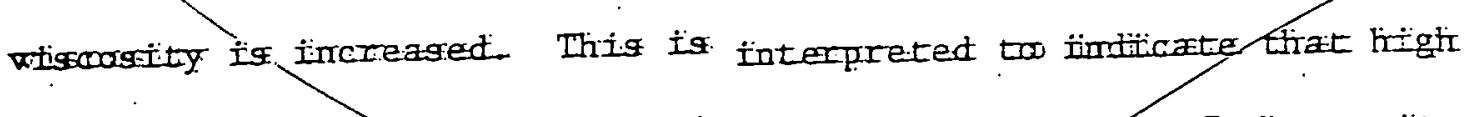

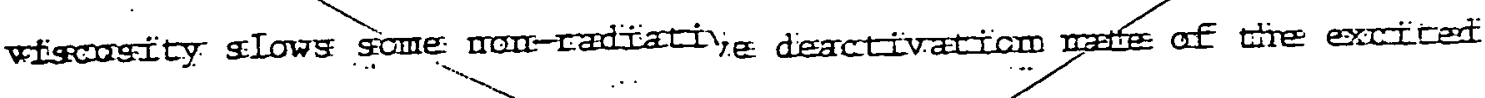

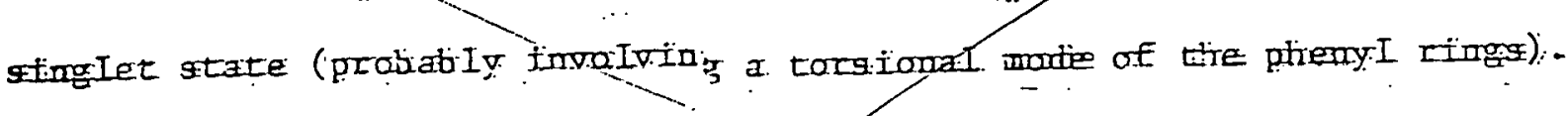

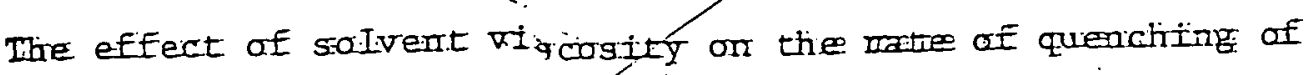

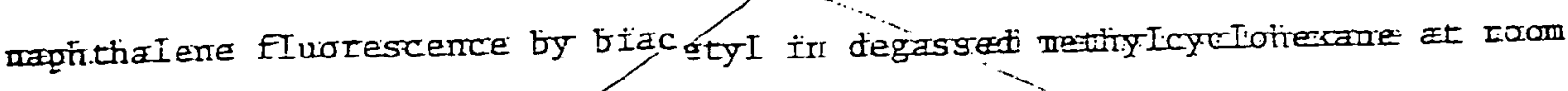

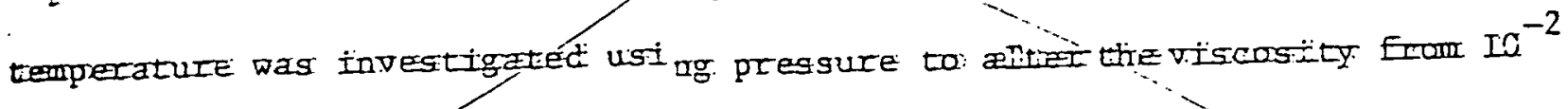

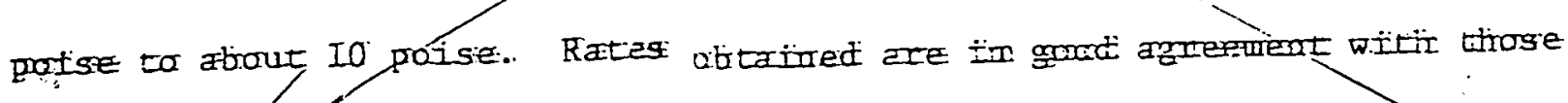
measured by otfier workers in several solvents and gaivent mixtures of Warying viscositieg atrogpherte pressure. 
The fluorescence quantum yields and the initial photoisomerization rates for trans-stilbene in several deoxygenated solvents wefe obtained as 2 function of solvent viscosity at room temperature by ysing pressures to $11 \mathrm{kbar}$ to aiter solvent viscosity.. At high viscosities in paraffin oil and glycerol, the fluorescence yieid approaches a limiting value associated with the compiete inhibition of molecular twist. Analysis of the data gives the rates of incersystem crossing and of viscosity dependent deactivation via twist ok the planar excited singlet.

In many polyenes, trańsitions to the lowest excited singiet stace are symetry forbidden while transitions to the next highest singlet are strongly allowed. Emisstion occurs from the lowest excited singlet. The radiative rate from this state is a strong function of the energy gap between the two states. Pressure is used to modulate the energy gap and the resultant changes in the radiative rate are compared to those predicted from a/simple intensity-borrowing expression. 


\section{IIST OF REFERENCES}

1. 7. 6. Drickamer, Solid State Phys., 17, 1 (1965).

2. H. Grickamer and C. W. Frank, Electronic Transitions and tine High
Pressure Chemistry and Physics of Solids, Chapman and Hall (London), 1973.

3. I. D. Bridgman, App1. Phys:, 12, 461 (1941).

4. P. 10. Bridgman, Proc. Am. Acad. Art. Sci., 83, 3 (1954).

5. . S. Balchan and H. 6. Drickamer, Rev. Sci. Instr., 32, 308 (1961).

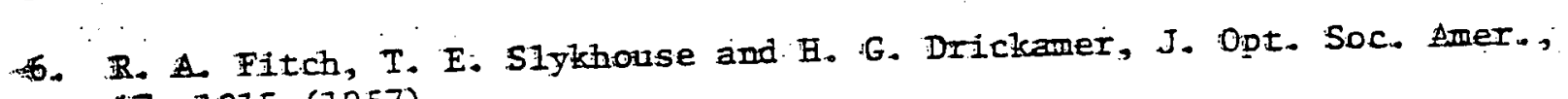
47. 1015 (1957).

7. C. E. Tyner and H. G. Drickamer, J. Chem. Phys., 67, 4103 (1977).

B. T. T. Mao and P. M. Beit, Science, 200, 1145 (1978).

9. C. C. Bradley, High Pressure Methods in Solid State Research, Plenum (2) York), 1966 .

10. I. S. Bradley (ed.), Advarces in High Pressure Research, Acadenic Press (New York), 1966.

11. W. Pawl and D. M. Warschauer (eds.), Solids Inder Pressure, McGraw-Hi11 (Hew York), 1963.

12. R. W. Wentorf (ed.), Modern Very High Pressure Techniques, Butterworth (1ondon), 1962.

13. 1. Kasha, Disc. Faraday Soc., 9, 14 (1950).

14. J. B. Birks (ed.), Organic Molecular Photophysics, Wiley (New York), Vo1. 1 1973; Vo1; 21975.

15. D. Bryce-Smith (Senior Reporter), Specialist Periodical Reports:
Photochemistry, Burlington House (London), Vol. 1 1970; Vol. 81978.

16. S. J. Strickler and R. A. Berg, J. Chem. Phys., 37814 (1962).

17. J. B. Birks and D. J. Dyson, Proc: Roy: Soc, A2.75, 135 (1963).

18. R. B. Cundail and I. C. Pereira, J. Chem. Soc. Faraday Trans. II, 68, $1152(1972)$.

19. I. B. Beriman and O. J. Steingraber, J. Chem. Phys., 43, 2140 (1965). 
20. W. R. Ware and B. A. Baldwin, J. Chem. Phys., 40, 1703 (1964).

21. B. Y. Okamoto, Ph.D. Thesis, University of Illinois, 1974 .

22. W. D. Drotning, Ph.D. Thesis, University of Illinois, 1975.

23. G. J. Piermarini, S. Block, J. D. Barnett, and F. A. Forman, J. Appl. Phys., 46, 2774 (1975).

24. C. E. Tyner, Ph.D. Thesis, University of Illinois, 1977.

25. C. A. Parker and W. T. Reese, Analyst, 85, 585 (1960).

26. R. D. B. Fraser and E. Suzuki, Spectral Analysis: Methods and Techniques, J. A. Blackman (ed.), Marcel Dekker (New York), 1970; ch. 5 .

27. C.E. Tyner, W. D. Drotning; and H. G. Drickamer;- J:App1: Phys , 47, 1044 (1976).

28. T. H. Förster and G. Hoffman, Z. Physik. Chem. NF75, 63 (1971).

29. C. J. Mastrangelo and H. W. Offen; Chem. Phys. Lett. 46; 588. (1977)=-

30. P. M: Bridgman, Proc. Am. Acad...51, 57 (1926)...

31. E. V. Zolotykh, Tr. Inst. Kom. Standartov Merilzmeritel'nykh Priborov SSSR 75, 123 (1964).

32. G. N. Lewis, T. T. Magel and D. Lipkin, J. Am. Chem. Soc. 64, 1774 (1942).

33. B. Y. Okamoto and H. G. Drickamer, J. Chem. Phys. 61, 2870 (1974).

34. W. D. Drotning and H. G. Drickamer, Phys. Rev, B 13;4568 (1976).

35. P. W. Bridgman, The Physics of High Pressure (Bell and Sons, London; 1931).

36. S. Sharafy and K. A. Muszkat, J. Am. Chem. Soc. 93, 4119 (1971).:

37. G. Oster and Y. Nishijima, J. Am. Chem. Soc. 78, 1581 (1956).

38. W. H. Melhuish, J. Phys: Chem. $65 ; 229$ (1961):

39. C. A. Parker, Photoluminescence of Solutions (Elsevier, Amsterdam, 1968).

40. J. T. Dubois and B. Stevens, Luminescence of Organic and Inorganic Materials (Wiley, New York, 1962).

41. J. T. Dubois and M. Cox, J. Chem. Phys. 38, 2536 (1963). 


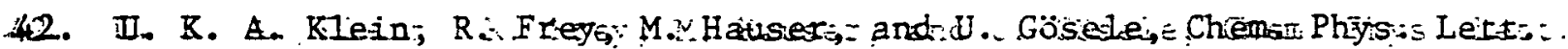
$41,139(19: 76)$.

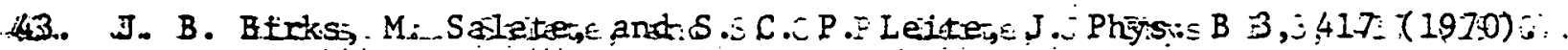

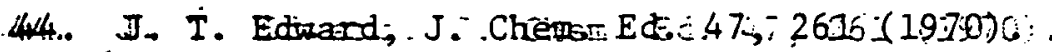

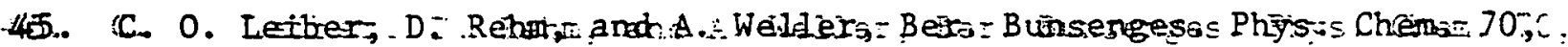
개 86 (IF6)..

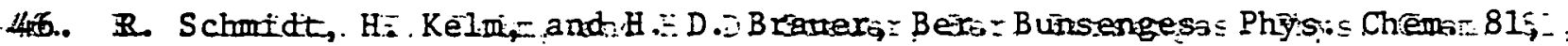
4402 (1977).

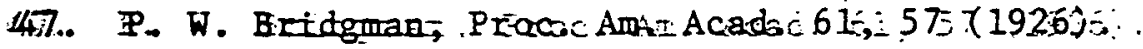

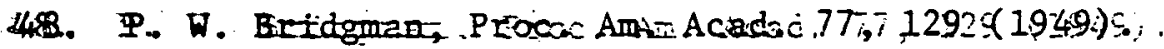

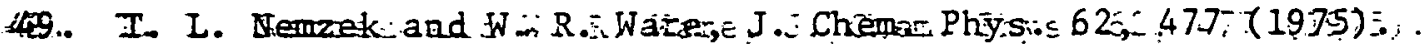

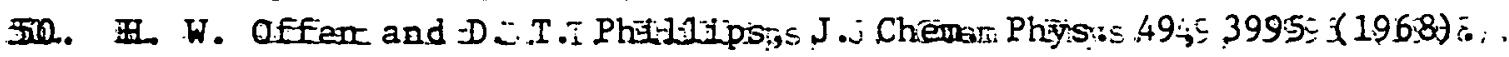

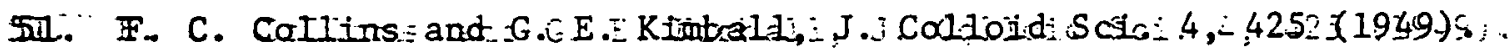

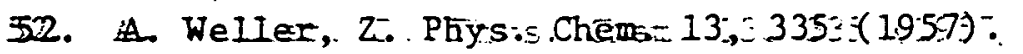

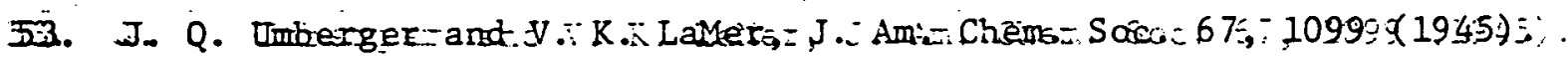

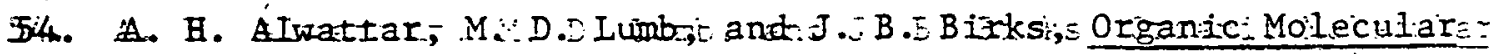

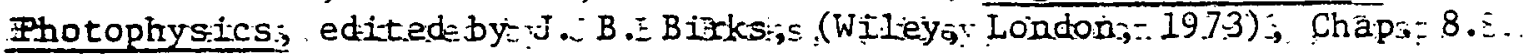

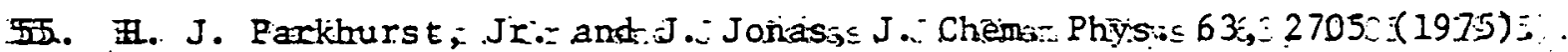

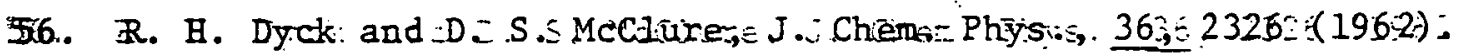

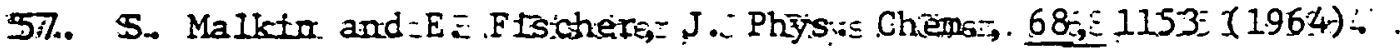

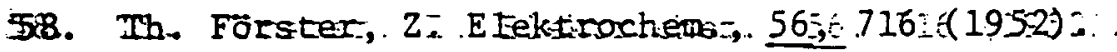

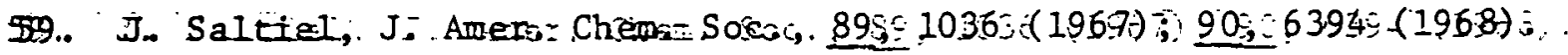

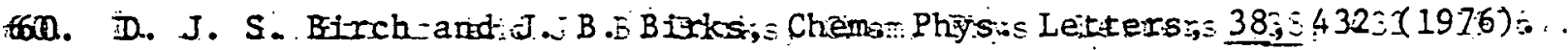

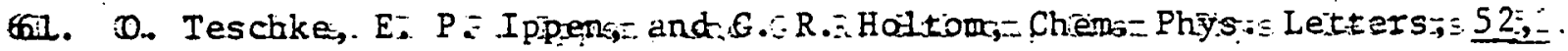
$233(1977)$.

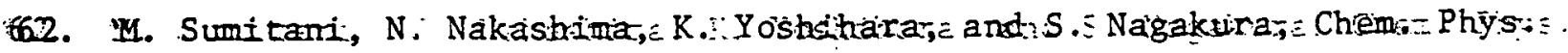
Inetters, 5:1, 183 -(1977) :.

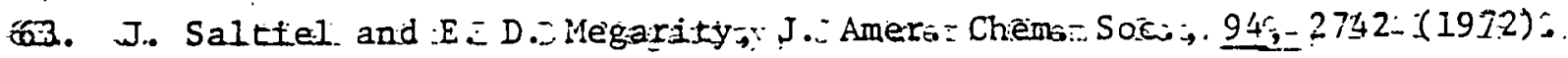

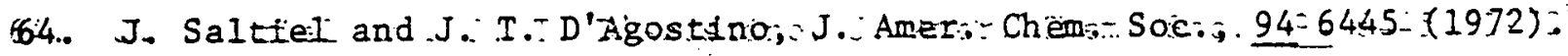


65. B. S. Hudson and B. E. Kohler, J. Chem. Phys., 59, 4984 (1973), and
references therein.

66. K. Schulten and M. Karplus, Chem. Phys. Letters, 14, 305 (19.72).

67. R. B. Birge, K. Schulten, and M. Karplus, Chem. Phys. Letters, 31 ,
451 (1975).

68. J. B. Birks and D. J. S. Birch, Chen. Phys. Letters, 31, 608 (1975).

69. J. B. Birks, G. N. R. Tripathi, and M. D. Lumb, Chem. Phys., 33, 185 (1978).

70. G. Oriandi and W. Siebrand, Chem. Phys. Letters, 30, 352 (1975).

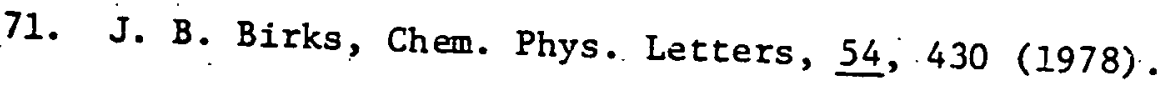

72. J. L. Char!ton and I. Saltiel,.. J. Phys. Chem, 81, -1940 (1977).

73. G. A. Von Salis and H. Labhart, J. Phys. Chem. 72, 752 (1968).

74. W. Yu, F. Pellegrino, N. Grant, and R. R. Alfano, J. Chem. Phys.,
67,1766 (1977) .

75. J. Kordas and M. A. El-Bayoumi, J. Amer. Chiem. Soc.; 96, 3043" (1974).

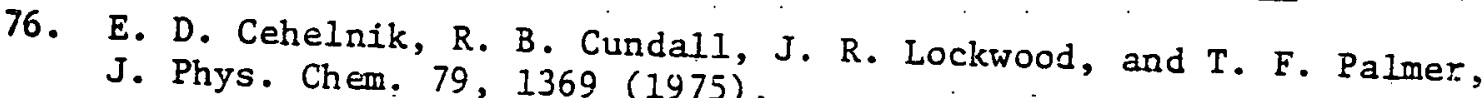

77. A. Marinari and J. Saltiel, Mol. Photochem., 7, 225 (1976).

78. J. B. Birks, Chem. Phys. Letters, 38, 437 (1976).

79. P. Bortolus and G. Galiazzo, J. Photochem., 2, 361 (1973-1974).

80. M. Sumitani, S. Nagakura, and K. Yoshihara, Chem. Phys. Letters, 2.9 ,

81. N. P. Kovalenko, Yu. D. Shek, L. Ya. Malkts and M. V. Alfimov, Izv. Akad. Nauk SSR, Ser..Khim., 298 (1975).

82. G. G. Aloisi, V. Mazzucato, J. B. Birks and.L. Minuti, J. Am. Chem.

83. J. Saltiel, J. T. D'Agostino, E. D. Megarity, L. Metts, K. R. Neuberger,

M. Wrighton, and O. C. Zafiriou; Org. Photochem., 3, 1 (1973).

84. D. Gegiou, K. A. Muszkat, and E. Fischer, J. Amer. Chem. Soc., 90 ,
12 (1968).

85. D. Mitchell, private communication. 

VITA

\begin{abstract}
Larry Alden Brey
attended elementary schools in Oskaloosa, Kansas; he graduated from Oskaloosa High School in June, 1968. He subsequently attended the University of Kansas and received a Bachelor of Science degree in Chemistry with honors in June, 1972. After graduation he served two years in the U.S. Army. In May, 1976, he received the Master of Science degree in Chemistry from the University of-Illinois at Urbana-Champaign. In the course of his research at the University of Illinois, he has co-authored several technical publications with Professors H. G. Drickamer and G. B. Schuster.
\end{abstract}




\section{APPENDIX A \\ TABULATED POLYENE SPECTRAL DATA}

In this appendix are presented the smoothed experimental fluorescence

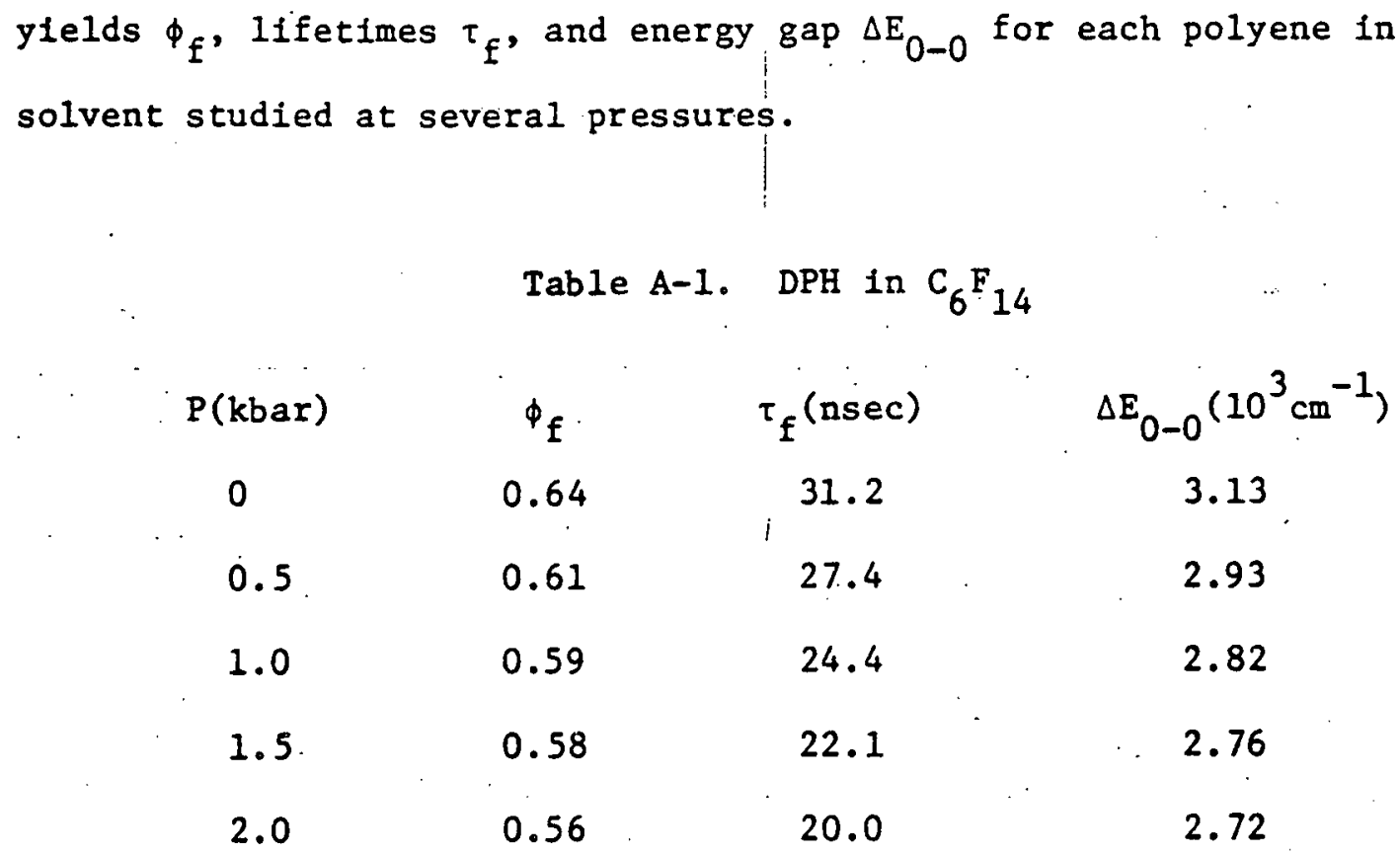


Table A.2. DPH in toluene

$\begin{array}{lccc}P & \phi_{E} & { }^{\top}{ }_{E} & \Delta E_{0-0} \\ 0 & 0.87 & 6.1 & 1.55 \\ 0.5 & 0.83 & 4.7 & 1.44 \\ 2 & 0.76 & 3.6 & 1.22 \\ 4 & 0.70 & 2.9 & 1.02 \\ 6 & 0.66 & 2.5 & 0.89 \\ 8 & 0.62 & 2.2 & 0.74 \\ 9 & 0.61 & 1.9 & 0.63\end{array}$

Table A-3. DPH in $\mathrm{MCH}$

\begin{tabular}{|c|c|c|c|c|}
\hline 0 & 0.83 & 13.2 & & 1.97 \\
\hline 0.5 & $0.80^{\circ}$ & 10.9 & & 1.90 \\
\hline 1 & 0.78 & 9.8 & & 1.80 \\
\hline 2 & 0.74 & 8.0 & & 1.72 \\
\hline$\because$ & & $\cdots \cdots$ & 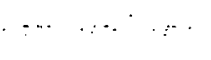 & \\
\hline 4 & 0.68 & 5.4 & & 1.57 \\
\hline 6 & 0.66 & 4.7 & & 1.50 \\
\hline $8^{\circ}$ & 0.63 & 4.1 & · & 1.39 \\
\hline & 0.59 & 3.3 & & \\
\hline
\end{tabular}


Table A-8. DPO in PS

$\begin{array}{cccc}P & \phi_{f} & \tau_{f} & \Delta E_{0-0} \\ 0 & 0.10 & 7.0 & 2.40 \\ 4 & 0.13 & 6.5 & 2.20 \\ 8 & 0.15 & 5.9 & 1.97 \\ 16 & 0.19 & 4.7 & 1.66 \\ 24 & 0.24 & 3.6 & 1.44 \\ 32 & 0.26 & 2.9 & 1.26 \\ 40 & 0.26 & 2.6 & 1.19\end{array}$

Table A-9. DPO in PMMA

$\begin{array}{llll}0 & 0.11 & 7.1 & 2.78 \\ 4 & 0.13 & 6.9 & 2.57 \\ 8 & 0.16 & 6.6 & 2.30 \\ 16 & 0.21 & 5.8 & 2.04 \\ 24 & 0.25 & 5.1 & 1.88 \\ 32 & 0.29 & 4.4 & 1.79 \\ 40 & 0.33 & 3.7 & 1.64\end{array}$




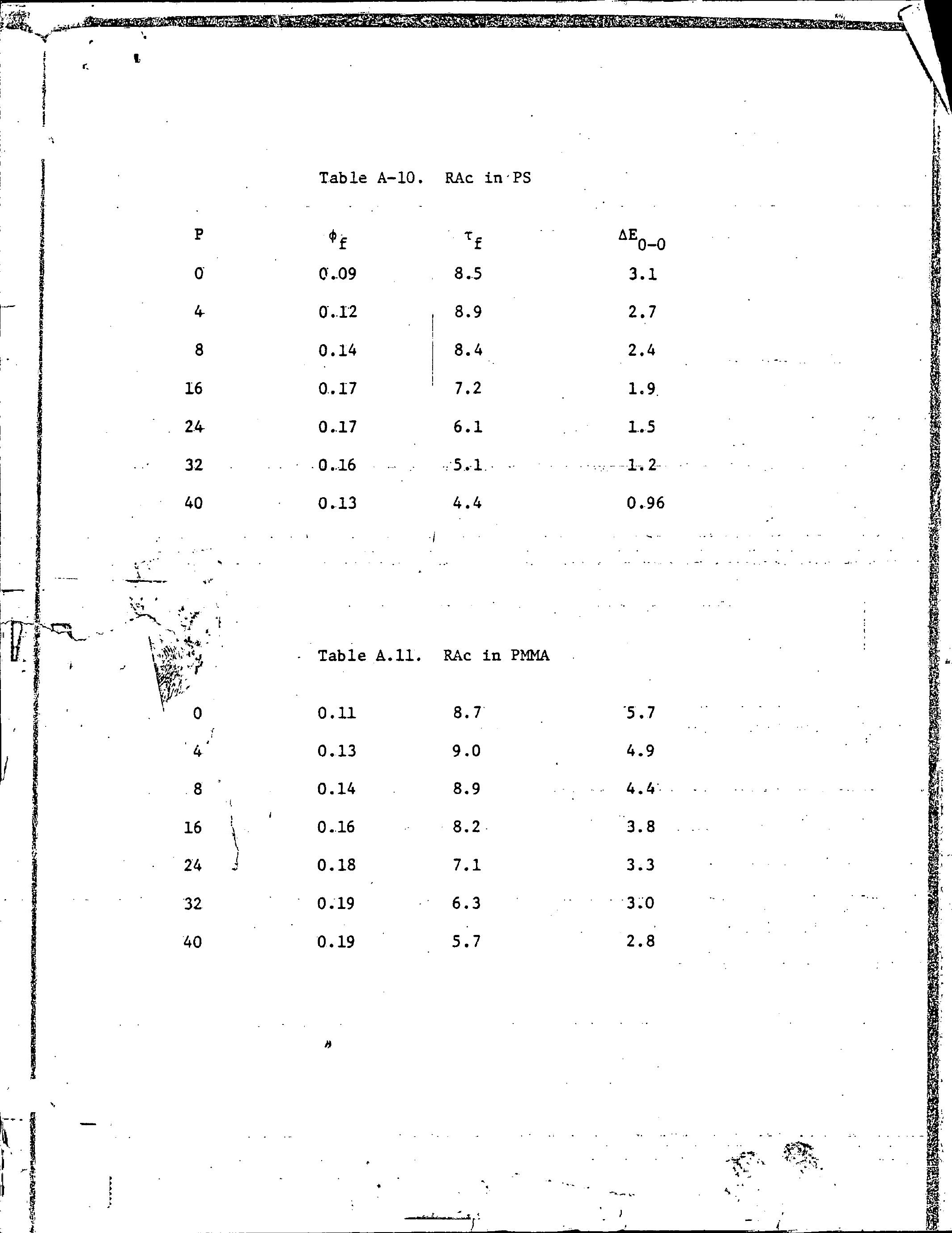

